\title{
The principal's role in creating a school culture that fosters achievement of students with high incidence disabilities: A study of one school
}

Shelby B. Haines

West Virginia University

Follow this and additional works at: https://researchrepository.wvu.edu/etd

\section{Recommended Citation}

Haines, Shelby B., "The principal's role in creating a school culture that fosters achievement of students with high incidence disabilities: A study of one school" (2009). Graduate Theses, Dissertations, and Problem Reports. 3505.

https://researchrepository.wvu.edu/etd/3505

This Dissertation is protected by copyright and/or related rights. It has been brought to you by the The Research Repository @ WVU with permission from the rights-holder(s). You are free to use this Dissertation in any way that is permitted by the copyright and related rights legislation that applies to your use. For other uses you must obtain permission from the rights-holder(s) directly, unless additional rights are indicated by a Creative Commons license in the record and/ or on the work itself. This Dissertation has been accepted for inclusion in WVU Graduate Theses, Dissertations, and Problem Reports collection by an authorized administrator of The Research Repository @ WVU.

For more information, please contact researchrepository@mail.wvu.edu. 
The Principal's Role in Creating a School Culture that Fosters Achievement of Students with High Incidence Disabilities: A Study of One School

Shelby B. Haines

\author{
Dissertation submitted to the \\ College of Human Resources and Education \\ at West Virginia University \\ in partial fulfillment of the requirements \\ for the degree of
}

\author{
Doctor of Education \\ in \\ Special Education
}

\author{
Barbara Ludlow, Ed.D., Chair \\ Katherine Calabria, Ph.D. \\ Paul Chapman, Ph.D. \\ Elizabeth Dooley, Ed.D \\ David Hoppey, Ph.D. \\ Department of Human Resources and Education
}

Morgantown, West Virginia

2009

Keywords: School Culture; Principal’s Role; Response to Intervention 


\begin{abstract}
The Principal's Role in Creating a School Culture that Fosters Achievement of Students with High Incidence Disabilities: A Study of One School
\end{abstract}

\title{
Shelby B. Haines
}

The purpose of this study was to examine the role of the principal in shaping a school culture that fostered academic achievement of students with high incidence disabilities. Research was conducted by means of a qualitative case study approach with data courses of informant interviews, parent focus group, observations of the daily workings of the school, and artifact reviews. Data unveiled five prominent areas of school culture: rituals, collaboration, an individualized instructional focus, community, and social emotional support. Each of these findings are defined and discussed based on data collected throughout the study. Data also support four additional findings in regard to the roles the principal played to impact each component of school culture including: serving as an administrator, instructional leader, community liaison, and child advocate. Matrix analysis compared the interactions of the school culture and the impact the principal played in each to determine what roles the school principal filled that directly affected the culture including the academic performance of students with high incidence disabilities. 


\section{Acknowledgments}

I would like to express my deepest gratitude to my doctoral committee beginning with chairperson, Dr. Barbara Ludlow whose encouragement and support served as continual motivation through this project. Also, I would like to recognize Dr. David Hoppey whose experience in completing qualitative research provided advice and support throughout the study as well as Dr. Paul Chapman who sparked my interest in the importance of school culture. Also, Dr. Elizabeth Dooley's passion for choosing a topic of interest and researching it in depth was an inspiration for seeing this project through. Finally, Dr. Katherine Calabria, without you I would have never had the faith in myself to enter the program, let alone complete the degree. You provided two of the most important roles, emotional support and professional mentorship. 


\section{TABLE OF CONTENTS}

TABLE OF CONTENTS iv

LIST OF TABLES vii

LIST OF FIGURES viii CHAPTER

I. Introduction 1

Educational Accountability ............................................. 1

Current Changes to Policy and Practices .............................. 3

Statement of the Problem .................................................. 11

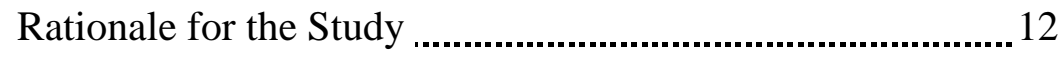

Research Questions and Design ..................................... 13

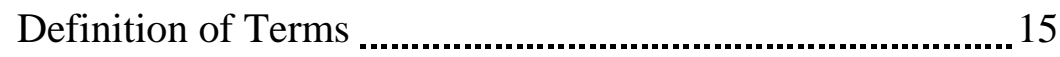

II. Literature Review .................................................................. 17

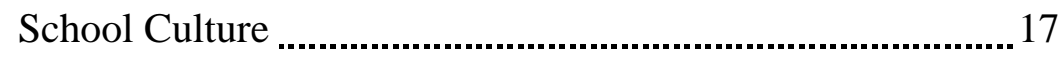

Inclusive Practices ........................................................ 21

The Principal's Role in Creating an Inclusive Culture ........ 28

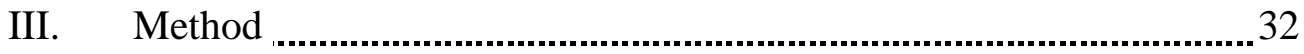

Introduction _........................................................ 32

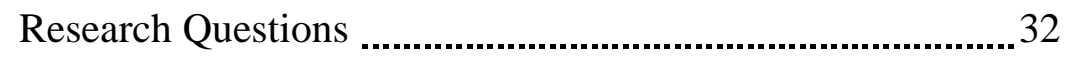

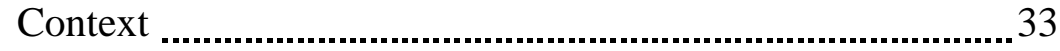

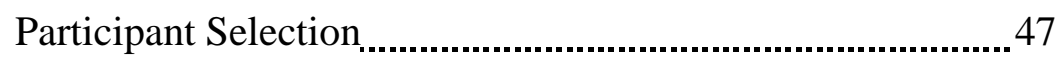

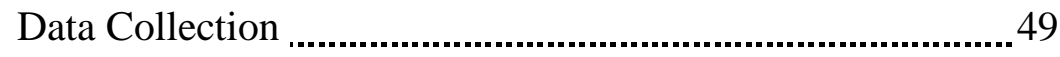

Methods of Data Analysis ................................................5 56 
Trustworthiness 59

Ethical Issues 61

Assumptions and Limitations 65

Conclusion 66

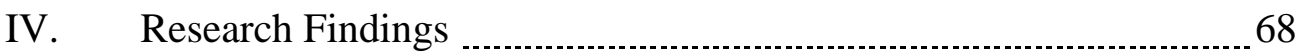

Purpose of the Study

Findings of School Culture

Findings of the Principal's Role $\ldots \ldots \ldots$

Key Interactions of Findings

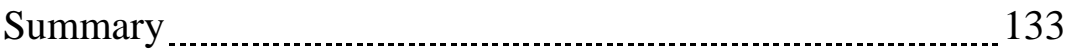

V. Conclusions and Discussion

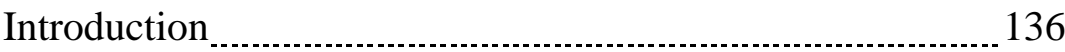

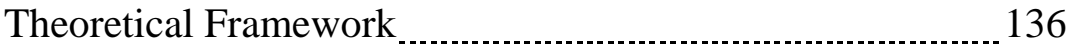

Extension of Current Literature

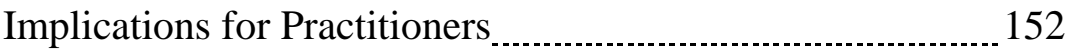

Limitations of the Study ............................................... 154

Recommendations

REFERENCES $\ldots$

APPENDICES

A. Letter from School System Superintendent …......................... 167

B. Institutional Review Board Exception Letter ........................ 169

C. Cover Letter for Research Participants _................................... 171

D. Interview Protocol

E. Data Collection Summary Sheet _.......................................... 177 
Principal's Role in Shaping School Culture vi

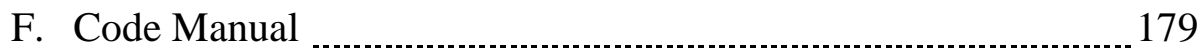

G. Research Question Matrix ………………………………...... 181

CURRICULUM VITAE 


\section{List of Tables}

1. Student Subgroups of Valley Elementary School

2. WESTEST Reading Performance Data for Students with Disabilities at Valley

Elementary 36

3. WESTEST Mathematics Performance Data for Students with Disabilities at Valley Elementary....... 38

4. WESTEST Reading Proficiency Data for Students in the "Black” Subgroup 40

5. WESTEST Mathematics Performance Data for Students in the "Black” Subgroup ........ 42

6. WESTEST Reading Performance Data for Students in the "Low SES” Subgroup.......... 44

7. WESTEST Mathematics Performance Data for Students in the "Low SES"

Subgroup 46

8. Structured Interview Participants Current Placement and Experience 


\section{List of Figures}

1. Student A tier I performance data documenting adequate progress in tier I .................. 7

2. Student B tier I and tier II performance data documenting progress in tier II ................8

3. Student C tier I and tier II performance data documenting the need for tier III ............. 9 


\section{Chapter I}

Introduction

The field of special education has been in a state of evolution since the 1970s fostered by a cycle of Supreme Court decisions and legislative actions interpreted through state policy. As the field developed, the accountability for the education of students with disabilities increased and prompted states, including West Virginia, to initiate inclusionary practices; such as, tiered instructional models that afford all students access to and progress from a free and appropriate public education. Increased inclusionary practices and accountability changed the culture of many schools and the role that principals play in developing and maintaining school cultures that embrace inclusion and produce academic achievement for all students, including students with disabilities.

This chapter will first present the legal aspects of educational accountability leading to the section of current changes in special education policy and practice. This will lay the groundwork for the third section; the problem that is developed through the implementation of these policies and practices, followed by the rationale for the current study. The final two sections will introduce the reader to the research question and design study as well as a definition of terms.

\section{Educational Accountability}

The signing of PL 94-142, the Education for All Handicapped Children Act, by President Gerald Ford in 1975 began an evolution of special education law establishing access to a free and appropriate public education for all students with disabilities. This law required school systems to identify and serve students with disabilities, ensuring access to the public education system 
(Turnbull, Turnbull \& Wehmeyer, 2007). However, the law focused only on access to, not progress in, the educational system.

In 1997, the Education for All Handicapped Children Act was amended and titled the Individuals with Disabilities Education Act (IDEA); the amended act clarified the intent of special education as a set of services, not a place (NASDSE, 2005). IDEA 1997 clearly encouraged more effective instruction and placement of students in special education as the act advocated high expectations for students receiving special education services and provided incentives for schools implementing school wide initiatives (Turnbull, Huerta \& Stowe, 2006). Student achievement, however, remained a loosely monitored requirement of IDEA 1997. In fact, the National Longitudinal Transition Study found, as recently as 2002, students in special education received "a basic level of access to the general curriculum" as they attended classes, but were not held accountable for the subject matter (as referenced in Danielson, Doolittle \& Bradley, 2005, p.138). Not until the most recent reauthorization of IDEA in 2004 was the monitoring of student progress in special education clearly mandated (Prasse, 2006).

Changes put in motion by IDEA 2004 ensured that special education was a gateway to more effective instruction and intervention and not an "endpoint" driven by a mound of paperwork (President's Commission on Excellence in Special Education, 2002). The 2004 reauthorization of IDEA coupled with the 2001 No Child Left Behind (NCLB) Act, the most recent reauthorization of the Elementary and Secondary Education Act, began the shift that changed the primary focus of special education from access to general education to that of student achievement. School districts became accountable for the progress of students, including students receiving special education services (Yell, Katsiyannas \& Shiner, 2006). 
Requirements established by NCLB and IDEA 2004 focused attention on accountability for the achievement of all students served in both general and special education classrooms (Turnbull, Turnbull, \& Wehmeyer, 2007). NCLB mandated that states assess all students’ progress, including students with disabilities, yearly in grades 3 through 8 and once between grades 10 through 12 . These results must then be disaggregated into subgroups such as students with disabilities, limited English proficiency, and low socioeconomic status and reported as a means of improving the achievement of all students (U.S. Department of Education, 2002).

Considering the accountability practices established by NCLB, IDEA 2004 took student achievement one step further by stating that students receiving special education services should be served with their nondisabled peers to the greatest extent possible and be considered general education students first and foremost (Turnbull, Turnbull \& Wehmeyer, 2007). As a means of documentation of the aforementioned inclusive efforts, IEP teams must specifically document a rationale for the removal of a student with disabilities from the general education classroom for services. The student's individualized education plan (IEP) is required to contain a statement explaining why a placement outside of the general education environment is warranted (Wright, 2004). In light of these legislative mandates, school systems began providing special education services in inclusive settings in which general and special education teachers are accountable for the performance of students with disabilities. One instructional model of increased monitoring and accountability for student achievement is that of a tiered instructional model.

\section{Current Changes to Policy and Practices}

IDEA 2004 expanded methods of high quality instructional and assessment practices for students with disabilities through the addition of response to intervention (RtI) as an eligibility determinant based on researched based instructional practices and data based decision making. 
This law gave states the option to disband the use of the discrepancy model as part of a multidisciplinary assessment, to begin using documentation of interventions in a tiered instructional model, and to use the student's response to evidence based instruction and intervention as criteria for special education service (US Department of Education, n.d.).

Response to intervention (RtI) is an instructional model based on tiers of instruction that school systems can use to educate all students. The RtI framework allows for all children to receive research based interventions before they are formally referred for special education services. The RtI framework also produces documentation of a child's response, or lack thereof, to interventions that can aid in the determination of eligibility for special education services in high incidence categories (National Center for Response to Intervention, n.d.). Although many models of tiered instruction have been proposed, core components of all models include a multitiered instructional approach focusing on high quality classroom instruction, research based instruction and intervention, data based decision making with frequent progress monitoring, and early intervention (Council for Exceptional Children, 2007; Mellard, 2004; NASDSE; 2005 \& NJCLD, 2005).

In a solid tiered instructional model, all students receive core curriculum instruction in the general education environment of tier I. This instruction is derived from research based instructional strategies, including but not limited to, differentiated instruction, coteaching, and fidelity to the core program (West Virginia Department of Education, 2008). Evidence by the tier I instructor must show that students have received adequate and appropriate education in tier I before interventions in tiers II or III occur (Graner, Faggella-Luby \& Fritschmann, 2005). Students who display inadequate performance in tier I receive additional services in a tier II setting which is supplemental to the core instruction of tier I. Tier II interventions are chosen in 
response to the student's specific deficit areas as proven by data collected in tier I. Student progress in tier II is monitored at a frequency of approximately two week intervals. According to WV Policy 2419, tier II instruction should consist of a minimum of 2, 8 to 12 week intervention cycles (West Virginia Department of Education, 2007). Based on progress monitoring, tier II instruction can be modified, continued, terminated or tier III instruction can be considered (National Association of State Directors of Special Education, 2005). If a student does not respond to interventions presented in tier II, they could be considered for tier III interventions that are more frequent, long term interventions. Upon entering tier III, a student is not considered special education. Tier III is comprised of both general and special education students; as are all of the tiers. Students who do not present adequate response to tier III intervention may be considered for special education eligibility (West Virginia Department of Education, 2007; West Virginia Department of Education, 2008, West Virginia Department of Education, 2008c).

Fuchs and Fuchs (2005) clarify the components of response to intervention with the use of student data sets. Presented below are examples of the data illustrating the progress of three students similar to that presented by Fuchs and Fuchs (2005). As shown in Figure 1, the performance data of Student A clearly displays that this student's academic performance is on target based on consistent, acceptable performance on word recognition probes, therefore, the student will remain in tier I. Figure 2 provides a brief glimpse at data collected on Student B whose performance in tier I was significantly discrepant from peer performance, but showed significant response to intervention in tier II. The student's response was above baseline and a return to tier I could be anticipated. The Student C data, see Figure 3, represents a student whose 
performance may warrant placement into tier III as a result of limited response to intervention, as displayed by the flat slope of the tier I and tier II lines. 
Figure 1.

Student A tier I performance data documenting adequate progress in tier I.

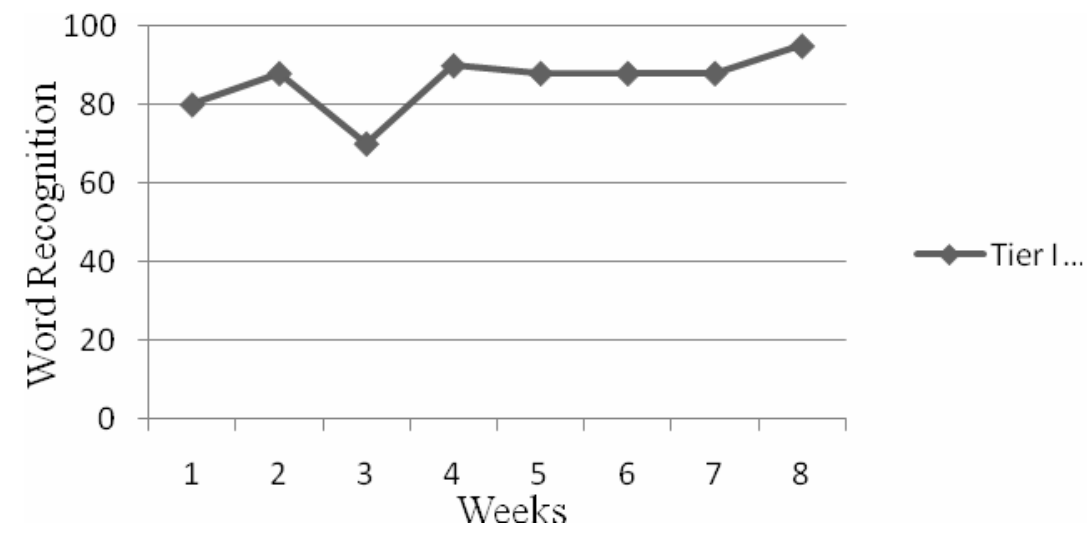


Figure 2.

Student B tier I and tier II performance data documenting progress in tier II.

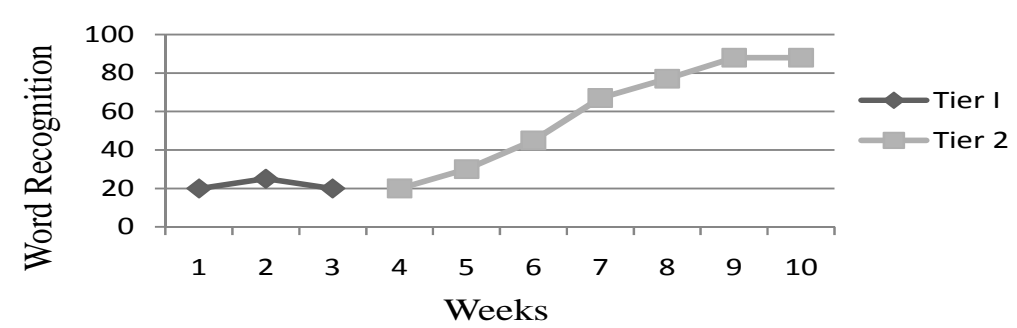


Figure 3.

Student C tier I and tier II performance data documenting the need for tier III.

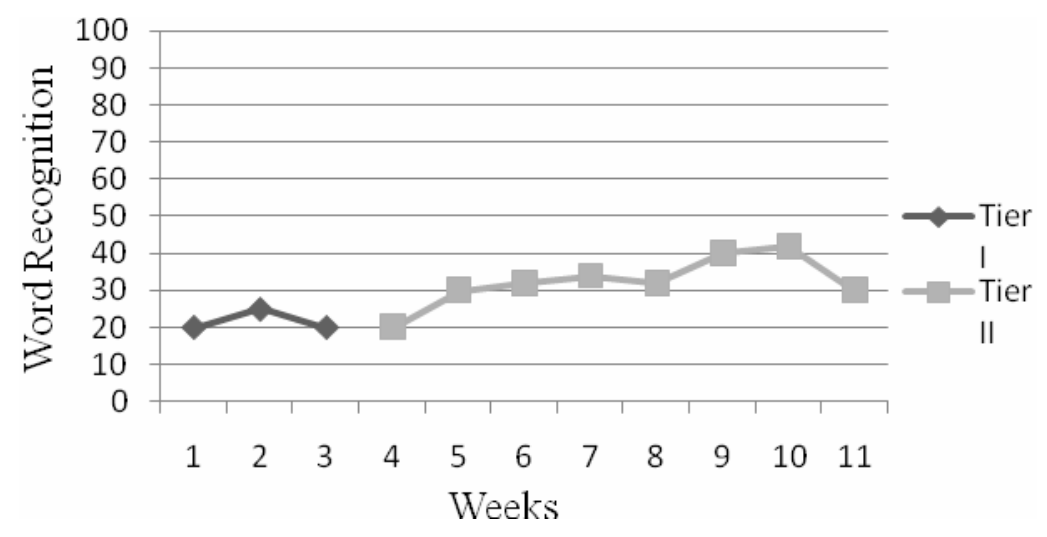


Successful implementation of a tiered instruction model requires extensive collaboration among teachers. Tiered instruction relies on both general and special education teachers to collaborate in making instructional decisions for all students (Council for Exceptional Children, 2007). Collaborative teams, student assistance teams, prereferral intervention teams, child study teams, and intervention teams are some of the terms coined to describe the collaboration of teachers in which student performance is reviewed and interventions are suggested and monitored (Somson, 2007; Burns, et al., 2005; McNamara \&Hollinger, 2003). Increasing student achievement requires "more than just choosing the right intervention and implementing it with fidelity” (Levine \& Marcus, 2007, p. 117). If teaching professionals are given time to collaborate to support student achievement beginning with a student assistance team and ending with a plan for intervention, student achievement and instructional methodologies can be reflected upon and improved. Such collaborative learning communities arranged horizontally allow for the collaboration of grade or content similar professional in which student achievement and instructional methodologies can be reflected upon and improved. This collaboration time also supports the analysis of student specific data based decision making to ensure appropriate interventions and to analyze the effectiveness of the interventions (Levine \& Marcus, 2007; Reeves, 2007).

The National Center on Progress Monitoring, in conjunction with Lynn and Douglas Fuchs (2006) referenced a study in which teams of teachers were trained in data collection and implementation associated with curriculum based measures. Discussions during prereferral meetings of trained teams were compared to discussions of an untrained control group. Teachers in the experimental group more frequently discussed specific student performance data and instructional techniques in comparison to the control group who were more likely to present 
problems that were less performance oriented; such as, student motivation and parent involvement (Fuchs \& Fuchs, 2006).

IDEA 2004 presented state and local education agencies opportunities to use funds to serve overlapping populations of students, and thus the ability to provide early intervention services to all students regardless of disability based on the implementation of tiered instructional practices (National Association of State Directors of Special Education, 2005). The West Virginia Department of Education interpreted this federal law through state policy and published an implementation timeline for RtI through Policy 2419. The policy stated that RtI must be fully implemented in all elementary schools by July 1, 2009, in all middle schools by July 1, 2010, and in all high schools by July 1, 2011 (West Virginia Department of Education, 2007).

Statement of the Problem

Implementation of effective and efficient tiered instructional programs requires school systems to change the many roles and responsibilities of stakeholders (Council for Exceptional Children, 2007; West Virginia Department of Education, 2008). The roles of teachers and administrators may change due to the need for achievement probes, data collection, and the monitoring of fidelity of implementation procedures. Federal law and state policy are forcing significant change in educational institutions. As instructional leaders, principals are charged with assuring that all students receive a free and appropriate public education monitored by accountability practices based on student achievement. In response to the implementation timeline of West Virginia Policy 2419, principals must also implement specific strategies to support the inclusion and achievement of all students through the RtI framework. It is the belief of this researcher that abiding by federal law and implementing instructional strategies as 
mandated by state policy while concurrently maintaining a positive school culture cannot be a simple task for many principals.

Rationale for the Study

Due to insufficient research linking positive school culture to the academic achievement of students with disabilities, I believe that a study investigating the culture of one school and how the principal is creating a culture that fosters achievement of students with high incidence disabilities in light of such educational reforms is warranted. In addition, from my vantage point, to offer insight applicable to other schools, specifically those governed by West Virginia state policy, the study must focus on a school community that is implementing successful instructional practices as reflected through measured student performance at or above local and state norms.

The purpose of this study is to investigate the principal's role in creating a school culture that fosters achievement of students with high incidence disabilities. In response to West Virginia policy the school has also begun to integrate research based initiatives including RtI, and has built a school culture in which students are included and achieving. Administrator support is pivotal in the successful implementation of school wide inclusive practices such as response to intervention. Principals control the major components of organizational structure; for example, class schedules, planning times, and collaboration times (Graham, 2007). These resources can foster collegial learning communities in schools, enhancing the effectiveness of inclusion (Graham, 2007; McGregor \& Vogelsberg, 1998). The principal’s energies also extend into building a positive school culture where collaboration and student achievement are at the core of all programs (Deal and Peterson, 1999). "School culture encompasses the norms, values, beliefs, traditions, and rituals molded over time as people work together, solve problems, and confront challenges” (Peterson and Deal, 1998, p.28). The culture of the school influences the 
feelings and actions of the people within the culture (Deal and Peterson, 1999). Without a positive school culture guided by strong leadership, even the best laid plans of inclusion will fail (Mamlin, 1999).

The literature is clear; a positive school culture enhances student achievement within the framework of general education (Lezotte \& Bancroft, 1985; Pritchard, Morrow \& Marshall, 2005; Goddard, Goddard \& Tschannen-Moran, 2007); however, the link between school culture and the achievement of students with disabilities has not been addressed extensively in the literature. A study of a school culture that fosters high achievement of students with high incidence disabilities and the role the principal plays in that culture could address the lack of research in the literature. This study may also provide information on fostering a culture of high achievement for other schools and principals in light of the state and federal mandates of instructional reform.

Schein (2004, p. 25-26) states that organizational cultures are comprised of three levels: "artifacts, espoused beliefs and values, and underlying assumptions." For a researcher to truly understand a school's culture, the following factors must be observed: a) "visible structure and processes," i.e., artifacts; b) the "strategies, goals, and philosophies," i.e., espoused values; and c) “unconscious, taken for granted beliefs, perceptions, thoughts and feelings,” i.e., the underlying assumptions. Considering that the current study researched the culture of the school and how it supports inclusive practices, the study was completed using qualitative structures.

\section{Research Question and Design}

The case study was conducted in one school in West Virginia. This school was selected based on the diversity of its total student population, the profile of its special education population, and the achievement of students with and without disabilities based on standardized 
state testing. Data were collected and analyzed to investigate the research question of: What role does the principal of one elementary school play in shaping a school culture that fosters academic achievement of students with high incidence disabilities?

Numerous studies (Lindsay, 2007; Nind, et al., 2004; Strahan, 2003) have ascertained the components of effective school cultures through both qualitative and quantitative research, however, each school culture is unique and is represented by the artifacts and actions of each member as they participate in daily operations, rituals, celebrations, and general interactions. The unique aspects of the artifacts and actions of each member of the school community suggest to effectively investigate the components of an inclusive school culture one must employ qualitative investigation strategies.

The parameters of the study included sampling people, settings, events, and processes aligned with the specific research question. The selection of the school was completed through purposeful sampling, (Patton, 2002) in that the school was selected based on the performance of students with high incident disabilities. Specific interview participants were selected through the implementation of naturalistic inquiry (Patton, 2002) allowing for the selection of interview and observation participants to unfold naturally. Data were collected through various means: structured interviews, informal interviews, observations, artifact reviews, and a parent focus group.

Following approval by the Institutional Review Board, the study occurred during the second semester of the 2008-2009 school year over a 10 week period. First, I was introduced at a faculty meeting to give an overview of the study, allow teachers and staff the opportunity to ask questions, and give persons a copy of the research cover letter. I made a minimum of two visits 
per week to the school and one evening visit monthly to attend parent groups, meetings, or extracurricular activities for the events entirety.

Definition of Terms

1. General curriculum / core curriculum - "The curriculum adopted by a district, schools within the district, or where applicable, the state education agency for all students from preschool through secondary school. In these regulations, the term means the 21st Century Content Standards and Objectives for West Virginia Schools” (West Virginia Department of Education, 2007, p.147).

2. High incidence disabilities - for the purpose of this research, the term encompassed learning disabilities, behavior disorders and mild mental impairments as defined by WV Policy 2419 (West Virginia Department of Education, 2007).

3. Horizontal teaming - planning, collaboration, and consultation with colleagues within similar content areas or grade levels (Kowal, 2002).

4. Inclusive classroom - all students are welcome into inclusive classrooms no matter what their academic functioning level, ethnicity, socioeconomic status, and given goals respective of high standards based on their personal strengths and weaknesses (Stainbeck and Stainbeck, 1997).

5. School culture - "culture is the underground stream of norms, values, beliefs, traditions, and rituals that builds up over time as people work together, solve problems, and confront challenges. This set of information, expectations, and values shapes how people thinking, feel, and act in schools” (Peterson \& Deal, 1998, p. 28). 
6. Student assistance team - "a trained school based team that provides a formalized process for the review of student needs and complements the work of instruction and intervention teams" (West Virginia Department of Education, 2007, p.161).

7. Vertical teaming - planning, collaboration, and consultation with colleagues over a variety of grade levels and content areas (Kowal, 2002). 


\section{Chapter II}

Literature Review

This review of literature contains three sections covering the premises of school culture, inclusive practices, and the principal's role in creating an inclusive culture. Section one reviews current research of school cultures; section two describes effective inclusive practices; and section three presents theory related to the principal's role in molding a particular culture.

\section{School Culture}

All schools have a culture guiding programs, decisions, and interactions. The school culture is a set of unwritten guidelines influencing the way "people think, feel, and act" (Peterson, 1999, p. 1). A school's culture encompasses not only its norms and values, but also the rituals and ceremonies to celebrate success, to provide closure, and to recognize achievement and contributions of those in the learning community. Parents, faculty, staff, and community members interact to build the school culture (Stine, 2000). Positive school cultures reflect a common mission, and the collective members work hard to achieve the goal of increased student achievement (Anfara, Roney, \& Mahar, 2003). Schools with positive cultures have students who are motivated to learn as well as faculty and staff who are motivated to teach (Barnett \& McCormick, 2004). Schools with a positive culture create a community where colleagues discuss instructional practices to focus on attaining success for every student (Carrington \& Elkins, 2002).

The culture of a school is also influenced by parents and the outside community. Schools with a positive culture facilitate learning communities that engage parents in the educational advancement of their child and conduct family outreach programs; such as parent meetings and family fun nights. As a result, a sense of trust and mutual support is built (Peterson, et al., 2001). 
The sense of community gained from positive cultures does not end with parents and teachers, it also impacts student achievement.

Researchers have studied schools with positive school cultures that effectively promote student achievement. Schools with high minority and poverty rates were part of the effective schools research of the 1980s that presented broad "attributes" of high performing schools. The schools were studied because of their high minority and poverty rates, as well as, their level of adequate or above student achievement. It was found that these effective schools expected quality and equity, provided research based professional development programs, and used data based decision making when planning instruction (Lezotte \& Bancroft, 1985). This research became the springboard for many school reforms in the late 1980s and 1990s under the premise that effective schools are lead by an instructional leader, have a clear mission, and high expectations. This research, however, had limited association with the performance of students with disabilities.

Research investigating the connection between school culture and achievement of students with disabilities is limited. Peterson, et al. (2001) in their "Whole Schooling” research project, conducted a study of the inclusion practices of 14 Wisconsin and Michigan schools. The study used purposeful sampling to investigate inclusive schools in which research based instructional strategies were employed. Schools were nominated for the study by building or county administration and were sent a self assessment tool to complete and return. This self assessment tool coupled with phone interviews aided the research team in building an understanding of the personnel's perception in the five areas of empowering members of the culture, inclusion, differentiated instruction, supporting learning, and parent and community involvement. The self assessments and phone interviews narrowed down the selection of the 
schools to the ones presented in the article. The inclusive instructional practices in all schools were reviewed through interviews and observations for impact on students with and without disabilities and some of the schools participated in focus groups. The researchers concluded that effective inclusion was promoted by strong leadership, differentiated instruction, and a sense of community. They reported variation in the levels of inclusion and the specific structures that made inclusion possible. The study extensively reviewed specific curricular and instructional practices in each of the schools but did not report impact in overall student achievement.

Another study conducted by Quiambao (2004) examined the relationship between three dimensions of school culture to the least restrictive environment placement and achievement of students with disabilities in four middle schools. School personnel completed a survey in which they rated three domains: teacher collaboration, teacher collegiality, and teacher efficacy. The scores on these surveys were compared to least restrictive environment placement decisions made for their students; no correlation was found. The researcher also investigated if a relationship existed between the teacher scores on the survey and the performance of their students with learning disabilities; no correlation was found.

One Texas study reviewed the workings of five high schools that displayed adequate or above achievement as measured by state standards. The schools were chosen based on demographics including poverty and minority status, as well as, performance on state assessments, end of course evaluations, and advanced placement class enrollment. While the study found common practices similar to those presented within this review including: data based decision making, collaboration, and a student centered mindset, there was little to no reference of students with disabilities or their performance (Clubine, Knight, Schneider, \& Smith, 2001). 
Strahan and colleagues completed a case study on one successful school as measured by student achievement on statewide standardized assessment and its demographic composition of minority and poverty rates over 50\%. Based on qualitative data collection, researchers reported overarching strategies of horizontal teaming focused on student achievement and data based decision making as salient points of teacher engagement. They also noted a consistent focus on student achievement and effective instruction (Strahan, Carlone, Horn, Dallas, \& Ware, 2003). The findings in this research are comparable in that many key attributes from other research based practices are also evident within this effective school, however, the research does not specifically investigate the impact of these key attributes on the achievement of students with disabilities within the school.

Not all schools have a positive school culture. Peterson (2002) examined what he termed toxic cultures where faculty, staff, and students do not value learning. In these cultures, often the faculty and staff do not value professional development, do not collaborate effectively, and blame students for lack of academic progress. Faculty and staff with a positive outlook may transfer to another school or simply become outcasts (Peterson, 2002). Principals in toxic cultures are often ineffective because they make decisions that will impact the school without input from stakeholders including faculty and parents, are afraid of change, or try too many educational fads. Principals in toxic cultures need to address the negativity in an aggressive manner to begin reforming the culture to produce an environment conducive to learning (McGregor \& Vogelsberg, 1998; Peterson, 2002).

To develop positive cultures, principals must become more than instructional leaders in the school, they must be moral leaders who can build positive cultures that support learning communities. A positive culture nourishing student achievement for all students is important in 
light of legislative initiatives focusing on student achievement based on higher curriculum standards (Fullan, 2002, Peterson, 2002, Sergiovanni, 1984).

Inclusive Practices

In the $21^{\text {st }}$ century classroom, inclusion reflects the practices of instructing students in heterogeneous groups, in a variety of placement options including general education environment, coteaching, or pull out instruction in small groups to best meet individual student needs through appropriate accommodations, modifications, and interventions (Hoover \& Patton, 2008). Varied service delivery options that support inclusive instruction were not the norm when students with disabilities were first introduced to the public school system. At that time mainstreaming students into the school system was more about access to public schools and general education classrooms than documented progress from the education. The 1972 courts' ruling in Mills versus DC Board of Education gave the right of a public education to students with disabilities based on student need not resources available to the district (Turnbull, Turnbull \& Wehmeyer, 2007). With the passage of PL 94-142 in 1975, students with disabilities were granted access to a free and appropriate education in the least restrictive environment. The 1997 amendments to this law, now referred to as the Individuals with Disabilities Education Act (IDEA), introduced accountability for the progress of students with disabilities on annual state and assessments (Skrtic, Harris, \& Shriner, 2005).

The No Child Left Behind Act of 2001 also addressed the need for students with disabilities to be educated with and held to the same high standards of accountability as their non disabled peers (Sailor \& Roger, 2005).The practice of inclusion was most recently addressed in the 2004 reauthorization of IDEA. This act calls for not only access to, but progress from 
education within the general education curricula with placement in the regular classroom setting to the maximum extent possible (Turnbull, Turnbull, \& Wehmeyer; Wright, 2004).

The current legislative mandate of increased access to more inclusive classrooms and adequate yearly progress on measures of student achievement within the context of a free and appropriate public education for students with disabilities has led to debates about effective practices. Teachers and researchers have debated the expertise of general education teachers for educating students with disabilities, the continuum of services for students with disabilities, and the effect inclusion may have on the general education population (Zigmond \& Baker, 1996). McGregor and Vogelsberg (1998) reported that two thirds of teachers agreed with the concept of inclusion, but this supportive stance decreased when inclusion was personalized to having “them” in "your” classroom. As students with disabilities were more often included in general education classrooms, teachers expressed reservations about knowing the strategies necessary to educate students with disabilities and have feared that including students with disabilities in their heterogeneous classrooms would negatively impact the educational performance of the students without disabilities (Ferri \& Connor, 2005).

During the evolution of inclusion, classes were and possibly still are in some schools, homogeneously grouped into classrooms containing high percentages of students with disabilities. Some teachers may also include students with disabilities in the general education classroom, only to give them a lower level curriculum instead of modifying the curriculum to meet the needs of diverse learners (Carrington \& Elkins, 2002). Students with disabilities may also be excluded when the special education teacher delivers remedial services in the back of the general education classroom or in the hallway outside of the classroom (Mamlin, 1999). Many general education teachers who participate in this type of "inclusion” often report having 
students with disabilities in their classrooms hinders overall class progress (McGregor \& Vogelsberg, 1998).

Educators who have used methods such as instructional grouping or remedial services in the back of the classroom have not experienced effective inclusion practices that support the achievement of all students in heterogeneous instructional settings (Sailor \& Roger, 2005). Inclusive schools "enable diverse individuals to participate in common educational experiences” (Carrington \& Elkins, 2002, p.5). This philosophical restructuring can lead to the acceptance of all students in a learning community. Students are placed in general education classrooms to meet the individual educational needs of all students by using best practices in education, supplemental aids and services, and collaboration between educators (Moore, Gilbreath, \& Maiuri, 1998; Hoover \& Patton, 2008). McGregor \& Vogelsberg (1998) define an inclusive school as,

“An inclusive school is a place where everyone belongs, is accepted, and is supported by his or her peers and other members of the school community in the course of having his or her educational needs met. Inclusive school practices are those that lead to the creation of supportive educational communities in which services necessary to meet the individual needs of all students are available” (p. 12).

Inclusion is more than integration of diverse students; inclusion is collaboration between staff, and implementation of effective instructional practices to meet the needs of all students, not just students with disabilities. In a truly inclusive school, all students are considered inclusion students, not just students with disabilities (Peterson, et al., 2001). Inclusion affords every student the opportunity to work with peers on projects, to learn in fluid grouping of students and to experience a variety of teaching approaches. Teachers in inclusive schools teach all students 
regardless of disability (Ferguson, et al., 1998). Students learn in heterogeneous classrooms that actively engage all students on their instructional level, instead of teaching to the perceived “middle” of student achievement. Students with high incidence disabilities who have been included in heterogeneous general education classrooms using effective instructional practices make increased gains in core academic areas when compared to students in pull out programs such as resource rooms, separate classrooms, or special schools (Moore, Gilbreath, \& Maiuri, 1998).

Legislative mandates requiring access to and documented progress within the general education curriculum for students with disabilities have generated academically diverse classrooms (Riehl, 2000). One method of delivering instruction to meet the individual needs of all students in diverse classrooms is through differentiated instruction (Hoover \& Patton, 2004). Instruction in inclusive classrooms should be active, with hands on learning, and assessments going beyond reciting basic facts and extending into application of knowledge within projects, presentations, and portfolios (Ferguson, et al., 1998). Teachers who lead differentiated classrooms create learning environments that require the use of a variety of skills and appreciate student contributions, discussions, and engagement (McGregor \& Vogelsberg, 1998; Heacox, 2002). Many classroom teachers who have adopted differentiated instruction to meet the needs of heterogeneous classrooms have replaced traditional school desks with tables for group work. These teachers present multi leveled assignments; such as, tiered lessons, assignments menus, and student directed learning activities that encourage students to work to the best of their ability (Peterson, et al., 2001; Heacox, 2002).

Another method of delivering instruction to meet the individual needs of all students is through coteaching. Coteaching supports differentiated instruction and can increase student 
engagement by making the curriculum more interesting with debates, discussions, and teaming (Welding, 1996; Friend \& Bursuck, 2002). Coplanning supports the implementation of effective teaching techniques; for example, problem based learning, literature circles, study teams, and cooperative learning strategies (Friend \& Bursuck, 2002).

A third inclusive practice that incorporates both differentiated instruction and coteaching is response to intervention (RtI). Response to intervention applies a tiered instructional model to make data based decisions to inform instruction for students as a means of preventing academic failure (Hall, 2008). West Virginia has adopted a three tiered model (West Virginia Department of Education, 2008). In tier I, a heterogeneous group of students receives research based core content instruction in which differentiated instructional strategies are employed to ensure effective instruction for all students. In this environment, general education teachers are highly qualified to teach content using a variety of research based techniques while differentiating instruction to meet the individual student needs. Teachers of students with disabilities may also coteach this core curriculum (West Virginia Department of Education, 2008). Every student in tier I receives a screening as a means of collecting baseline data on student performance (Hall, 2008). Because these steps are taken with all students as a means of preventing academic problems, tier I is considered a primary prevention strategy. If this primary prevention is effective, approximately $80 \%$ of the entire student population achieves without supplemental instruction (Bradley, Danielson, \& Doolittle, 2005; NASDSE, 2005; NJCD, 2005; University of Texas System, 2004).

Ongoing progress monitoring and fluid grouping in tier I increase the likelihood of academic and behavioral success for students with and without disabilities. West Virginia has adopted the procedure of monitoring student progress four times a year in tier I using benchmark 
assessments; assessments based on the core curriculum. (West Virginia Department of Education, 2008). This progress monitoring data along with any additional data collected by teachers such as student work samples, unit or chapter assessments are used to make instructional decisions to guide instruction, as well as, determine the need for additional instructional support beyond tier I instruction (Hall, 2008).

Tier II instruction is provided in addition to tier I instruction and is designed to supplement instruction in tier I or remediate targeted weaknesses as determined by tier I universal screening and progress monitoring. Even with effective tier I instruction, approximately 15 to $20 \%$ of the student population will require the supplemental services offered in tier II (Hoover \& Patton, 2008). Tier II instruction can be provided by Title I, special education, or general education teachers depending upon available resources and scheduling. Tier II instruction should occur for a minimum of 2 intervals of 6 to 12 weeks of intervention (West Virginia Department of Education, 2008). Student progress continues to be monitored frequently with open communication between parents, teachers, and any additional resource personal (Bradley, Danielson \& Doolittle, 2005; NASDSE, 2005; NJCD, 2005; University of Texas System, 2004).

Students who display a positive response to intervention can be removed from tier II interventions. A positive response to intervention would be evident based on increasing student performance based on biweekly progress monitoring assessments specific to the intervention program (Hall, 2008, West Virginia Department of Education, 2008). Students who continue to show little or no increase in academic performance based on progress monitoring specific to the intervention may be moved into tier III. Tier III instruction is also offered in addition to tier I instruction and is an intensive systematic instructional program (Hall, 2008). Even with 
effective tier I instruction and tier II intervention, approximately five percent of students will require the intensive service of tier III. Tier III is often instructed by special education or Title I teachers, but does not require a student to have a special education label to receive services in a special education environment. These students receive more intensive services customized to meet individual student learning needs via small group or individual instruction (Bradley, Danielson \& Doolittle, 2005; NASDSE, 2005; NJCD, 2005; University of Texas System, 2004). Students are only referred for special education for a possible learning disability once they have received services in tier II and III; and in addition, the students have displayed little or no response to the interventions based on progress monitoring assessments from the intervention programs or evidence found in student work samples and portfolios (West Virginia Department of Education, 2008; West Virginia Department of Education, 2008c). Although student placement is flexible within the tiers, students continue to be participants in the differentiated, research based instruction of tier I due to the inclusive nature of this model.

For effective inclusion, such as a tiered instructional program, special education teachers and general education teachers must come together in a learning community to meet the needs of all students (Ferguson et al., 1998). Positive school climates fostering inclusion and learning communities have been linked to increased achievement for nondisabled students as well (Anfara, Roney, \& Mahar, 2003). In a study by McGregor \& Vogelsberg (1998), one principal from a positive learning community stated,

“Our school district does not view inclusion as a program. It is part of our total belief and practice. It goes part and parcel with the idea that our responsibility is to all children. If inclusion is only used as a way to deal with special education students, it will never accomplish anything” (p. 7). 
This belief of principals is crucial to building inclusive learning communities. Principals who recognize and encourage collegial support are building the framework for inclusive cultures (McGregor \& Vogelsberg, 1998).

\section{The Principal's Role in Creating an Inclusive Culture}

Principals are regarded as the instructional leaders of the school (Liethwood et al., 2004; Rammer, 2007). This definition is too narrow for the roles a principal must play in shaping school culture as they improve teaching, learning, and morale. While researching inclusive practices in schools, Mamlin (1999), found leadership to be the predominant element of successful schools. Principals who believed in inclusion and supported a learning community were able to shape the culture. Schools led by principals who did not make inclusion central to the mission of the school, did not whole heartedly believe in inclusion, and did not communicate an inclusive philosophy were unable to generate an inclusive community.

The role of the school principal is pivotal to school culture and reform. Incompetent leaders build incompetent schools leading to diminished student achievement and parental detachment (Sergiovanni, 1984). The power a leader has over school culture was evident in schools studied by Peterson et al. (2001). In one particular school, the school principal encouraged and supported differentiated instruction, community involvement, and full inclusion. Each element was reflected in the mission of the school and in the daily actions and communications of the principal. When this principal retired, the new principal verbally supported the existing mission, but he did not communicate, model or monitor the stated mission of the school. As the inclusive practices began to falter, student misbehavior began to increase, and the inclusive culture severely eroded. A second school in the study also experienced a 
change in leadership, however, both principals communicated, modeled and offered support to the inclusive mission of the school. As a result the culture remained positive and inclusive.

Barbara Sizemore studied three high achieving schools in Pittsburgh, Pennsylvania whose enrollment was predominantly African American and concluded the principal was the main support for student achievement (Sizemore, 1985). She cited 12 strategies employed by the school principal that foster a culture based on student achievement:

1. increased student responsibility for attendance and discipline

2. daily visits by the principal to monitor teacher and staff performance

3. professional development based on evaluation of teachers and staff

4. frequent benchmarking of student achievement in reading and mathematics

5. staff involvement in decision making

6. parent involvement

7. the office was "central business command post"

8. multileveled instruction in reading and mathematics

9. extended school day that included tutoring opportunities

10. use of materials or programs in addition to county issued textbooks

11. inclusion of students with mental impairments (the only disability category included in the study) to the greatest extent possible

12. selectivity in the types of programs instituted within the school

Principals improve schools by building a culture that encourages effective instructional practices and offers avenues for communication and support for faculty. Effective principals facilitate discussions of instructional strategies and student performance and provide supports such as student assistance teams, professional development and data tracking (Anfara, Roney, \& 
Mahar, 2003). Student assistance teams are one example of bringing teachers together to address student related problems. These teams involve regular education teachers, special education teachers, school counselors, principals, and parents who collaborate to identify, implement, and evaluate the effectiveness of strategies for behavior intervention, academics performance, health concerns, and instructional interventions for individual students at risk for school failure (Peterson et al, 2001, West Virginia Department of Education, 2007).

In addition to scheduling time for student assistance team meetings, principals can shape the school culture by developing a schedule for common planning times that facilitate meetings of horizontal and vertical team members. Horizontal teams are comprised of general education and special education teachers who work at the same grade level. This team collaboration allows teachers time to discuss a student's strengths and weaknesses by examining instructional strategies and assessment practices based on a review of student data (Kowal, 2002). Principals may also schedule time for vertical team meetings in which teachers collaborate with colleagues teaching prior and subsequent grade levels to clarify issues concerning the appropriate scope and sequence of the curriculum (Ferguson et al., 1998).

Principals of effective schools ensure professional development and collaborative meeting time with teachers is spent evaluating student assessment data. The data are then used to monitor student progress, share instructional achievement with team members, and guide school teams in making decisions regarding student learning (Anfara, Roney, \& Mahar, 2003). Peterson et al.(2001) observed one principal who met with teachers and guided them through the alignment of the curriculum with the state standards, the development of ongoing assessments to meet students' needs, and monitored differentiated teaching strategies. This school used data to drive instruction, and made significant gains in state assessment scores. 
Positive cultures are productive cultures where the principal puts student learning first and involves teachers in monitoring student learning. Without a child centered culture, reform will not be attained; staff morale will diminish; and student achievement will decline (Fullan, 2002). When principals recognize accomplishments of teachers and students, teachers and students feel more motivated to work and as a consequence, higher achievement occurs (Peterson \& Deal, 2002). In their recent study of 16 schools, Peterson et al. (2001) researched "the relationship among effective and successful inclusion, effective curriculum and instructional practice, building of community and support, school improvement and restructuring efforts and increased learning of children with and without disabilities” (p. 8). The findings of this five year study substantiate the leadership of the principal as a critical factor in school reform initiatives. Schools led by principals who developed effective school cultures fostering collegial relationships and celebrating success of teachers and students increased the learning of children with and without disabilities.

The aforementioned research strengthens the foundation for the study of a school in which the principal creates and maintains a positive school culture that embraces inclusion. The theories of the principal's role in creating culture have not been reviewed in a school in which the inclusive practice of response to intervention is being employed for students with high incidence disabilities. A study of one such school and the role the principal plays in a school that has proven to generate achievement for students with high incidence disabilities is therefore warranted. 


\section{Chapter III}

\section{Method}

\section{Introduction}

The field of special education has evolved from allowing students with disabilities mere access to a free and appropriate public education to increased expectations that students with disabilities should benefit from a free and appropriate education. These changes, brought about by Supreme Court rulings and federal laws, must be implemented at the local level in accordance with state policy. The principal is responsible for carrying out mandated changes at the local level and consequently, the principal exerts a direct influence on the school culture and the inclusive practices of the school. The current climate of school reform and inclusive practices demands a principal to maintain a positive school culture, to institute the inclusive practices of response to intervention, and to utilize data based decision making. In addition to fulfilling the of role of an instructional leader, a school principal is required to maintain the daily operations of the school; for example, overseeing the maintenance of the building, creating schedules, filing reports, and attending meetings. The dynamic between the multiple roles and responsibilities of a principal and a positive school culture advancing the achievement of students with high incidence disabilities is the focus of this study.

\section{Research Question}

Data were collected and analyzed to investigate a single research question of: What role does the principal of one elementary school play in shaping a school culture that fosters academic achievement of students with high incidence disabilities? In order to do this, I examined one school culture that fosters achievement of students with high incidence disabilities. 


\section{Context}

The study was conducted in one elementary school that served students from preschool through fifth grade. Valley Elementary school is located in Union, a small city in West Virginia. This school was chosen for this study based on the outstanding academic achievement of its diverse population, including students with disabilities. In 2008-2009 Valley’s population was comprised of 268 students with 45 students in preschool, 48 in kindergarten, 40 in first grade, 40 in second grade, 33 in third grade, 28 in fourth grade, and 34 in fifth grade (West Virginia Department of Education, 2008b). A breakdown of the school by various student demographic factors, including students receiving free or reduced lunch, students enrolled in special education and students from minority groups, during the school years from 2004 to 2008 is shared in Table 1. an average $78 \%$ of the student population received free or reduced lunch, $29 \%$ received special education services, and 30\% were members of minority groups. 
Table 1

Student Subgroups of Valley Elementary School

\begin{tabular}{lccccc}
\hline Subgroup & 2004 & 2005 & 2006 & 2007 & 2008 \\
\hline Free/Reduced Lunch & 204 & 193 & 223 & 212 & 206 \\
Special Education & 64 & 75 & 74 & 84 & 83 \\
Minority & 74 & 70 & 76 & 84 & 91 \\
Total Population & 255 & 250 & 272 & 279 & 268 \\
\hline
\end{tabular}


The selection of the school was completed through purposeful sampling, (Patton, 2002) in that the school was selected based on not only its cultural make up but also, the success of students with disabilities. Valley Elementary school was selected as the research site because it has also shown success in serving students from low socioeconomic groups from both Caucasian and minority groups while being designated as a "high poverty school" by the West Virginia Department of Education (West Virginia Department of Education, 2008b). Valley Elementary was also recognized as a National School of Excellence, and a West Virginia Blue Ribbon School. State performance indicators as determined by the West Virginia student assessment (WESTEST) data showed their performance was at or above comparable state and school system subgroup performance.

Performance data for students with disabilities. Reading proficiency at the state, school system and school levels from 2004 through 2008 are presented in Table 2. The percentage of students with disabilities (SWD) reading at the proficient level in the state of West Virginia as measured by WESTEST performance increased by $9.89 \%$ (from $37.33 \%$ to $47.22 \%$ ), while in the school system reading proficiency level of students with disabilities increased by $11.89 \%$ (from $48.47 \%$ to $60.46 \%$ ). Over this same time period, Valley Elementary students with disabilities increased their reading proficiency by $18.98 \%$ (from $41.02 \%$ to $60.0 \%$ ). 
Table 2

WESTEST Reading Performance Data for Students with Disabilities Subgroup

Assessment Year

\begin{tabular}{lrrrrr}
\hline & & & & \\
& 2004 & 2005 & 2006 & 2007 & 2008 \\
WV - SWD & 37.33 & 42.08 & 45.4 & 46.94 & 47.22 \\
School system - SWD & 48.47 & 48.32 & 55.51 & 65.58 & 60.46 \\
School - SWD & 41.02 & 45.06 & 67.85 & 70 & 60 \\
\end{tabular}


As presented in Table 3, Valley Elementary students with disabilities showed a similar improvement in mathematics proficiency. Statewide, students with disabilities performing at the proficient level increased by $13.13 \%$ (from $39.28 \%$ to $52.41 \%$ ) while in the school system, the mathematics proficiency of students with disabilities increased by $9.12 \%$ (from $58.34 \%$ to 67.46\%). Valley Elementary students with disabilities showed a 51.54\% increase (from 38.46\% for $90.0 \%)$ in mathematics proficiency. 
Table 3

WESTEST Mathematics Performance Data for Students with Disabilities Subgroup

Assessment Year

\begin{tabular}{lrrrrr}
\hline & & & & & \\
& 2004 & 2005 & 2006 & 2007 & 2008 \\
WV - SWD & 39.28 & 46.71 & 52.19 & 53.93 & 52.41 \\
School System - SWD & 58.34 & 60.32 & 70.39 & 70.5 & 67.46 \\
School - SWD & 38.46 & 54.83 & 78.57 & 75.0 & 90.0 \\
\hline
\end{tabular}


Performance data for students in the black subgroup. Examining trend data further revealed an increase in academic proficiency of Valley Elementary students in the black subgroup for reading performance as measured by the WESTEST (Table 4). In reporting the results of the WESTEST, the West Virginia Department of Education uses the term "black" to identify African American students. To avoid confusion, black will be used whenever data for this subgroup is discussed in this study. Statewide, students in the black subgroup performing at the proficient level increased by $7.98 \%$ (from $67.0 \%$ to $74.98 \%$ ) while in the school system the reading proficiency of students in the black subgroup increased by $10.14 \%$ (from $71.26 \%$ to 81.4\%). Valley Elementary students in the black subgroup showed an $11.23 \%$ increase (from $70.58 \%$ to $81.81 \%$ ) in reading proficiency. While all students represented in the black subgroup in the school system were consistently more proficient than the total West Virginia black subgroup, Valley Elementary scores were on average 2.1\% higher than the school system scores and an average of $9.26 \%$ higher than the state scores. 
Table 4

WESTEST Reading Proficiency Data for Students in the “Black” Subgroup

Assessment Year

\begin{tabular}{lrcccc}
\hline & & & & & \\
& 2004 & 2005 & 2006 & 2007 & 2008 \\
WV - Black & 67.0 & 68.29 & 73.48 & 73.43 & 74.98 \\
School System - Black & 71.26 & 72.82 & 86.09 & 81.45 & 81.4 \\
School - Black & 70.58 & 74.28 & 88.23 & 88.57 & 81.81 \\
\hline
\end{tabular}


Comparing Valley's WESTEST data in the area of mathematics the school system and state data revealed trends similar to that of the reading achievement scores (Table 5). Over the five year time period, Valley Elementary consistently had a higher percentage of black students proficient in mathematics found at both the state and school system levels. For example, in 2004 $76.47 \%$ of Valley Elementary's black students were proficient, while $67.85 \%$ of the school system black population and $58.0 \%$ of the state's black population was proficient. Again in $2008,87.87 \%$ of the school's black subgroup was proficient while $82.3 \%$ of the school system's black subgroup and $68.93 \%$ of the state's black subgroup was proficient. Statewide, students in the black subgroup performing at the proficient level in mathematics increased by $10.93 \%$ (from $58.0 \%$ to $68.93 \%$ ) while students in the black subgroup at the school system level increased by $14.45 \%$ (from $67.85 \%$ to $82.3 \%$ ). Valley Elementary students in the black subgroup showed an $11.4 \%$ increase (from $76.47 \%$ to $87.87 \%$ ) in mathematics proficiency. 
Table 5

WESTEST Mathematics Performance Data for Students in the “Black” Subgroup

Assessment Year

\begin{tabular}{lrrrrr}
\hline & & & & & \\
& 2004 & 2005 & 2006 & 2007 & 2008 \\
WV - Black & 58.0 & 63.52 & 68.7 & 69.53 & 68.93 \\
School system - Black & 67.85 & 70.83 & 88.67 & 87.11 & 82.3 \\
School - Black & 76.47 & 68.57 & 94.11 & 94.28 & 87.87 \\
\hline
\end{tabular}


Performance data for students in the low socioeconomic status subgroup. Low socioeconomic status (SES) is a third subgroup for comparing data on the state, school system and school levels. The reading performance of the SES subgroup is presented in Table 6. Over the five year period, the percentage of proficient students in the low SES subgroup in West Virginia the area of reading increased by $6.52 \%$ (from $67.0 \%$ to $73.52 \%$ ). The subgroup at the school system level increased by $6.83 \%$ (from $72.57 \%$ to $79.4 \%$ ). The percentage of Valley Elementary students in the same subgroup increased by $10.89 \%$ (68.85\% to $79.74 \%$ ) over the same time period. 
Table 6

WESTEST Reading Performance Data for Students in the “Low SES” Subgroup

Assessment Year

\begin{tabular}{lccccc}
\hline & & & & & \\
& 2004 & 2005 & 2006 & 2007 & 2008 \\
WV - Low SES & 67.0 & 71.42 & 73.36 & 73.47 & 73.52 \\
School system - Low SES & 72.57 & 76.38 & 78.82 & 80.11 & 79.4 \\
School - Low SES & 68.85 & 73.68 & 84.84 & 85.39 & 79.74 \\
\hline
\end{tabular}


Table 7 presents the state, school system, and school mathematics proficiency levels of students in the low socioeconomic status subgroup over a five year period. Statewide, students in the low SES subgroup performing at the proficient level in mathematics increased by $7.81 \%$ (from $62.67 \%$ to $70.48 \%$ ) while students in the low SES subgroup at the school system level increased by $6.38 \%$ (from $75.08 \%$ to $81.46 \%$ ). Valley Elementary students in the low SES subgroup showed a $15.21 \%$ increase (from $72.13 \%$ to $87.34 \%$ ) in mathematics proficiency. While performance at the state and school system levels also displayed an increasing trend, the slope at which that trend was occurring is minimal compared to the increase in mathematics proficiency of students at Valley Elementary. 
Table 7

WESTEST Mathematics Performance Data for Students in the “Low SES” Subgroup

Assessment Year

\begin{tabular}{lrrrrr}
\hline & & & & & \\
& 2004 & 2005 & 2006 & 2007 & 2008 \\
WV - Low SES & 62.67 & 67.92 & 72.12 & 72.06 & 70.48 \\
School system - Low SES & 75.08 & 79.97 & 84.66 & 83.94 & 81.46 \\
School - Low SES & 72.13 & 75.43 & 88.88 & 91.01 & 87.34 \\
\hline
\end{tabular}


Subgroup performance trends in reading showed overall gains across all four subgroups. Disaggregating Valley Elementary School's WESTEST data by subgroups revealed a 1.86\% difference between proficiency of all students (83.67\%) and the black subgroup (81.81\%) while at the state level there was a $5.35 \%$ gap ( $80.33 \%$ for all students compared to $74.98 \%$ for the black subgroup) and at the school system level there was a $4.6 \%$ gap (86.0\% for all students compared to $81.4 \%$ for the black subgroup). Valley Elementary School also showed a 3.93\% difference between all students (83.67\%) and the low socioeconomic status subgroup (79.74\%) for the 2008 assessment year. The same comparison at the state and school system level showed a $6.81 \%$ gap and a $6.6 \%$ gap respectively. The state scores for all students indicated $80.33 \%$ proficient while state scores for the low socioeconomic status group indicated 73.52\% proficient. The school system scores for all students indicated $86.0 \%$ proficient while scores for the low socioeconomic status group indicated $79.4 \%$ proficient. At Valley Elementary, scores for all students indicated $83.67 \%$ proficient and the subgroup of students with disabilities was $60.0 \%$ proficient; a 23.67\% difference. At the state level the scores for all students indicated $80.33 \%$ proficient and the subgroup students with disabilities indicated $47.22 \%$ proficient; a 33.11\% difference. The all group at the school system level earned 86.0\% proficiency and the subgroup for students with disabilities at the school system level earned $67.46 \%$ proficiency; a $6.6 \%$ difference in proficiency rate.

\section{Participant Selection}

To develop a comprehensive picture of how the principal of Valley Elementary School influenced and shaped a school culture in which students with high incidence disabilities are successful, the principal was interviewed and observed. Methods of naturalistic inquiry support investigation as they occur in real time without manipulation from the researcher. Therefore, I 
observed occurrences and interactions among persons within the school as they unfolded naturally (Patton, 2002). Researchers use purposeful sampling to gain a deeper understanding of a situation or phenomenon in which an "information-rich case" is studied in depth (Patton, 2002, p. 230).

I approached the school system superintendent with the intent of studying this culture. The superintendent's letter of support is included in Appendix A. Next, I submitted an application to the West Virginia University Institutional Review Board (IRB) to conduct research. An expedited review was completed on this study because interviews and focus groups were limited to adults (parents, teachers, and administrators) and general observations (not specific to one child). The IRB granted approval in on March 27, 2009. Documentation of exempt status is presented in Appendix B. To introduce the study, I presented an overview of the research study at a faculty meeting. At this meeting, I discussed the purpose of the case study and answered any questions from the faculty. Although all faculty members were not to be directly observed or interviewed, I felt it was important that they be informed of the purpose of the case study and given the opportunity to participate.

In addition, at a monthly parent teacher association meeting, I presented the rationale for the study, answered questions from parents about the study, and invited parents to participate in a focus group. A copy of the cover letter that was given to all research participants is included in Appendix C.

Assumptions founded on my theoretical framework, formed my desire to study not only the culture that is producing such results, but also the role of the principal in this culture. I observed the daily workings of the school for 10 weeks, and on 22 separate days. I debriefed each week with the school principal to enhance trustworthiness of the study and to direct me to 
other observations and interviews. Such implementation of naturalistic inquiry allowed for the selection of interview and observation participants to unfold naturally (Patton, 2002). For example, during the first meeting with the principal, Mrs. Riddle, two areas of discussion were the after school program and a response to intervention framework that the school has been implementing (field notes, March 27, 2009). This led me to interview participating teachers (interviews, March 27, 2009, \& March 30, 2009), observe their implementation (field notes, April 8, 2009, April 28, 2009, \& April 29, 2009) and review documents in relation to their implementation (artifacts, April 20, 2009).

\section{Data Collection}

Data were collected over a 10 week setting and on 22 occasions with each observation period ranging in length from 8 hours to 2 hours. This timeframe was established to ensure that I observed one complete grading cycle. Data were collected through interviews, observations, and artifact reviews as one means of triangulating information (Merriam, 2009).Data were collected through various means: structured interviews, informal interviews, observations, artifact reviews, and a parent focus group. All field notes were documented in notebooks and were kept on my person while at the site. All interview tapes and field notes were securely stored in a locked filing cabinet within my home. The tapes were marked with the interview date and time. A separate tape was used for each interview. Recorded interviews were transcribed within seven days. Any data transcribed into electronic form was stored on a secure computer with a password. Back up discs and hard copies of data will continue to be kept in a secure filing cabinet at my home for five years following completion of the study.

Interviews and observations. The first step of data collection was a structured interview

of the school principal. The principal worked at Valley Elementary as a teacher or principal since 
1978. Her experiences made her perceptions of the evolution of the school culture over the past three decades critical to this study. The purposes of initial structured interviews were as follows: a) to investigate the school culture and b) to build rapport with the participants so that I could build the foundation for future interviews and observations. The interview protocol for the structured interviews can be found in Appendix D. This interview guided the subsequent observations and interviews that provided the depth of investigation needed in this case (Merriam, 2002). I conducted the 12 structured interviews using open ended questions related to the principal's role in shaping the school culture and also recorded and transcribed the interviews. The protocol for the structured interviews can be found in Appendix D.

Based on information revealed during the structured interview with the principal, I identified, observed, and interviewed additional participants. For example, the principal shared a great deal of information regarding the after school program and the persons who directed the after school program. Based on this information, it was important to interview persons involved and to observe the after school program. This method of investigation was vital in formulating a complete picture of the school from multiple perspectives.

I conducted one structured interview with the principal, Mrs.Riddle. I also conducted 11 structured interviews with teachers who were either content area teachers, special education teachers, or reading teachers. The teachers had a range of experience, and I interviewed teachers with 1 year of experience to teachers with 30 years of experience. I also interviewed teachers who have taught in four schools to teachers who have only taught at Valley Elementary. Table 8 provides a list of interview participants, their years of experience, and area of instruction. 
Table 8

Structured Interview Participants Current Placement and Experience

Interviewee Number Years Experience Current Teaching Placement

1

29

Principal

2

5

Title 1

3

32

$2^{\text {nd }}$ Grade

4

2.5

Counselor

5

2

Physical Education

6

18

Music

7

30

$3^{\text {rd }}$ Grade

8

29

$5^{\text {th }}$ Grade

9

30

$4^{\text {th }}$ Grade

10

22

Special Education

11

23

$5^{\text {th }}$ Grade

12

1

Interventionist 
Information and rapport gained from these structured interviews led me to further unstructured interviews and observations. This type of interview technique was central to the understanding of a school culture because this form of interview allowed me flexibility in questioning, and thus, enhanced the in depth investigation of the culture (Patton, 2002). The topics or questions of the conversation were determined based on my need for a deeper understanding or clarification of a particular occurrence. The purpose of the unstructured interviews was to collect data from multiple sources, and to further the understanding of the culture of Valley Elementary and the role the principal plays in creating this culture. Unstructured interviews occurred as brief and casual passes in the hallway to 30 minute lunchtime discussions in the teachers' lounge. As an example, while attending a luncheon honoring the school secretary, I had the opportunity to speak with the school dental hygienist. She began speaking with me about a grant she wrote to obtain disposable toothbrushes with dry toothpaste on the bristles for every student in the school. The students took part in a six week study in which they brushed their teeth after lunch every day. Before and after pictures submitted for evidence of grant success to the sponsor were shared with me following the luncheon (field notes, May 1, 2009). The relaxed nature of unstructured interviews did not permit me to take copious notes or tape record the sessions, however, field notes were composed soon after the interaction.

During the course of this study I observed multiple settings and interactions over the 10 week period on 22 different days. On one of these days, I spent the entire day observing and interacting with the principal. The purpose of the observations was to allow me to become a participant observer within the culture. Spradley (1980) differentiates a participant from a participant observer in that a participant takes part in the setting or environment and understands 
that procedures and social norms for that setting or interaction. A participant observer, however, must observe all aspects of the environment including people, actions, and the structure itself in an attempt to interact in the environment appropriately. Being a participant observer afforded me the opportunity to analyze the environment, interact with students, and test a theory of what I perceived to be appropriate engagement in the culture.

I observed the daily workings of the school, the daily procedures of the principal, parent conferences and teacher collaboration periods. I also observed school wide assemblies, parent teacher organizational meetings, and extracurricular events. Observations in these settings supported my understanding of the interactions between participants. During extracurricular activities, parent conferences, and parent teacher organizational meetings, I documented the topics presented to parents and the interactions between teachers, parents, and administration. During teacher collaboration periods, I made note of the topics presented. I also noted the interaction between teachers and administration as they planned to meet the needs of all students under their instruction, as well as, the impact the principal had on the structure and guidance of these meetings. During school wide assemblies and parent conferences, I documented the level of collegiality and the steps taken by the principal and teachers to build supportive relationships. I documented an overview of general discussion topics, and I also documented specific comments related to the guiding research question to provide details as part of a rich, thick description.

Artifact review. Data were also collected through artifact review. The purpose of the artifact reviews were to support triangulation of data and to open a wider view of the culture during times at which I could not be at the school. For example, it had been reported to me through multiple interviews that the teachers participate in grade level, data based, collaborative 
planning sessions. It was reported to me by the principal and teachers that they are given an agenda to follow and data to analyze. The collaborative groups took notes and returned them to the principal for review. One afternoon, the principal allowed me to review the binders of notes from these grade level meetings. I was presented with a three inch binder for each grade that was nearly full of handwritten notes in response to guiding questions and data printouts from Acuity (the school system standardized benchmark assessments), and DIBELS (Dynamic Indicators of Basic Early Literacy Skills, benchmark reading assessments for grades kindergarten through third grade). Throughout the notes were green, yellow and pink highlights indicating if the child was on level, at risk, or below level respectively (field notes, April 27, 2009).

I collected and reviewed artifacts over the 10 week period. Artifacts reviewed include: principal's memos, faculty meeting minutes, the minutes of the parent teacher organization, and communications with parents, such as, newsletters and teacher notes. These artifacts supported a complete investigation of the school culture and helped triangulate data. I looked for consistency between written communication and observed actions. For example, in an interview with the principal, she stated that she produces a newsletter to teachers every Friday as a means of keeping them abreast of schedule changes, special events, celebrations, and timelines. I was also sent copies of these weekly electronic newsletters. Some artifacts provided me with information about events that could not be observed, such as, upcoming events, messages to parents, and summaries of meetings.

Focus group. Finally, a parent focus group was held in which five parents spoke with me about their perceptions of what they and their children think and feel about the school, the teacher and the principal. Focus group questions can be found in Appendix D. Interviewing the parents was a necessary component because to completely investigate a multi-faceted 
phenomenon such as a school culture the researcher must investigate as many perspectives from as many key players as possible (Hesse-Biber, Leavy, 2006). The purpose of the parent focus group was to get the parents' perspective on the school culture including the teachers and principals. Parents are an integral part of the culture in a school (Peterson, et al., 2001). How parents are included or excluded, how the principal and teachers interact with the parents and how the parents perceive the school culture were key to painting a complete picture of Valley Elementary School. The use of multiple informants and comparison of their answers and perspectives also supports triangulation of data. For example, during both teacher and principal interviews I was told that the "GOLD star" program was a school wide discipline program based on a color system. The parents were informed of their child's behavioral progress on a daily basis. During the parent focus group, this data were supported when a father of a first grade student stated, “My kid's here to get an education. He knows he better listen to them teachers. They see me every day. First thing my boy gots to tell me after school is his color so I can see the teacher if it is blue or red 'cause that means he was bad” (transcript, May 8, 2009). This statement by the parent was supporting evidence of the assertion made by the principal and teachers that parents were informed and aware of their child's behavior performance.

Organization of data. All of the data that I collected were stored in notebooks. A pagination system organized documentation by the utilization of simple codes, for example, I for interview, $\mathrm{O}$ for observation, and $\mathrm{D}$ for document. Each page in my research log was numbered in the upper-right hand corner with these codes as well as the date and time. For example, an interview conducted January 3 at 11:30 am was numbered I_0103_1130, a document with the publication date of March 13 was referenced as D_0313. If there was more than one document with the March 13 date, they were referenced as D_0313a, D_0313b etc. 


\section{Design}

Student performance data on the state assessment highlighted Valley Elementary School as one school in particular where students with high incidence disabilities were performing better than comparable subgroups at the state and local school system levels. Thus, purposeful sampling procedures were used to select this school and its principal for investigation. The process of creating a school culture that supports the achievement of students with disabilities is a process of relationship building between the principal and her staff as well as the relationship building between each of the staff members who serve all students including the students with disabilities. To investigate the school culture and in particular the role the principal plays in influencing that culture, a qualitative case study approach was implemented. Data collection included informant interviews, observations, artifact reviews, and a parent focus group. Utilizing a case study approach allowed this researcher to become a participant observer, making numerous visits to the site to build an in depth understanding of the culture (Hesse-Biber, Leavy, 2006) and to provide a rich, thick description of the school context (Merriam, 2009). This detailed, concrete description of the culture provided insight to the environment in which the study took place (Patton, 2002).

Methods of Data Analysis

Data analysis in qualitative research is based on an ongoing interaction of data collection, data reduction, data display, and drawing conclusions (Miles \& Huberman, 1994; Merriam, 2009). Throughout this case study I collected, transcribed, organized, and analyzed data as a means of drawing conclusions as to the specific characteristics or initiatives that build and support an inclusive culture of success for all students. To discern the role the principal played 
in this process, I reduced data by "selecting, focusing, simplifying, abstracting, and transforming the raw data that appear in edited field notes” (Miles \& Huberman, 1994, p. 10).

My research logs contained observational field notes written on loose leaf and were formatted with the location, time and persons involved. This information was clearly indicated in the upper right hand corner. I then analyzed these notes for key points and recorded the key points on a summary sheet that also listed the type of contact and with whom the contact occurred, the location, and data. A summary sheet was completed following each interview, observation, or artifact review as not only a first level of data analysis, but also as a guide for reflection. The template for the summary sheet is included in Appendix E. I also referenced the key points documented on the summary sheet according to pages in research logs which were the basis for generating codes from the coding manual (Miles \& Huberman, 1994). I created a coding manual to frame the analysis and reduction of data. An example of a coding chart based on the research question of this study is included in Appendix F. As themes emerged from the research, I defined and documented codes in the coding manual along with the definition of the code. It was possible for one statement to have more than one code. Research codes were added and revised throughout the course of data analysis. I completed all coding without the use of an electronic coding program.

Once the data were reduced, coded, and categorized, I created a matrix. This matrix served as a visual representation of the interactions within the data and specified how codes were clustered into themes or patterns (Miles \& Huberman, 1994; Merriam, 2009). The matrix encompassed key persons, values, roles and responses from multiple perspectives. The interaction of data reduction, collection, display, and conclusions cyclically re-occurred throughout the study and added to the confirmability of the results (Miles \& Huberman, 1994; 
Patton, 2002; Merriam, 2009). Application of the matrix supported the investigation of linkages between principal's roles and school's culture. The columns of the matrix organized key elements of the school culture of Valley Elementary that emerged from the research, and the rows organized principal roles that emerged from the research. Relevant data serving as examples of the coding themes and patterns were entered into the cell where each specified row and column intersected. This cell reflected the interaction between the principal's role and elements of school culture. A framework for this matrix is included in Appendix G. As part of this data analysis, I looked for patterns and inconsistencies in data compiled through interviews, observations and artifact reviews within the data from individual participants, as well as, across the data from all participants (Merriam, 1999; Merriam, 2002).

Qualitative data analysis occurs on three levels beginning with the most basic level of a thick, rich description, presented in a narrative format. The second level of qualitative data analysis moves the researcher to coding data into emerging themes presented within the context of the study. The third level of qualitative data analysis is that of "making inferences" based on the data collected (Merriam, 2009, p. 188). I analyzed data on all three levels and will present such analyses in Chapter four by providing a thick, rich description of the culture and the principal's role within the culture and by delineating emergent themes generated throughout the research and providing the data that supports each of those themes of the principal's role in the culture of the school. I will present further analysis by drawing linkages between the principal and the school culture through the use of a matrix that supports the confirmation of overarching, essential elements of how one principal shapes a school culture that fosters achievement of students with high incident disabilities. In chapter five I will present applications and extensions 
of current literature as well as the third level of data analysis, making inferences based on data collection.

Throughout the research period I discussed the data with members of my doctoral committee. At week eight I felt as though I was getting to a point of saturation and had a lengthy discussion with a committee member who had completed a similar study. We discussed the signs of saturation, “you realize no new information, insights, or understandings are forthcoming - you will most likely be thinking in a more deductive rather than inductive mode” (Merriam, 2009, p. 183). I then reviewed the data to ensure that multiple data sources had been collected on key findings. The last two weeks were spent gathering supporting evidence and searching for disconfirming evidence of emergent themes and codes. For example, as the school year came to a close I was privy to many rituals and celebrations including the school carnival, fifth grade promotion, and preparation for transitioning students to the middle school which provided supporting evidence to the intent of events that were celebrated within the school. An in depth review of the data at that point also alerted me to questions of clarification that may need to be addressed. For example, during no observation or interview was there any evidence of materialistic, tangible rewards other than paper certificates and books. I asked the principal about this and she stated that, "We keep trying to drive home that you have to do this to show and prove that you are smart and that you have learned a lot this year. That has got to be enough, that will get them through life. We are here to learn, not for a raffle prize. When you start doing that stuff, you start cheapening the whole reason we are here” (transcript, May 22, 2009).

\section{Trustworthiness}

Trustworthiness of this research was enhanced through triangulation, member checking and disconfirming evidence. Triangulation was achieved through the use of a large number and 
variety of data sources and clearly defined methods of data analysis (Merriam, 2002). This study was based on interviews and observations of multiple informants; including, faculty employed by the school system and parents who are independent of the school system. In addition, artifact reviews also served as a source of data comparison. These multiple data sources, participants, and data collection methods added to the triangulation and credibility of the results of this study (Patton, 2002).

Furthermore, credibility was increased by employing regular member checks. Member checks serve as a means of checking for clarity and understanding (Kuzel \& Like, 1991; Merriam, 2009). For example, during interviews, I used phrases, such as, “am I understanding you to say..?”; and then I restated what the interviewee said. Also, during interviews, I asked questions to clarify vague language by asking for specific examples from the interviewee.

Moreover, I conducted member checking by sharing results including emerging codes and themes with the principal and other key stakeholders to ensure accurate representation. I met with the principal on a weekly basis to review data outcomes and gain clarification on evidence being collected. Each week the principal would set aside 20 minutes in her schedule to discuss the progress of the study, debrief with me on observations and interviews, and discuss implications of events. For example, I attended a conference with the principal on new special education eligibility procedures presented by the West Virginia Department of Education. The following day, the principal and I discussed the implications of the meeting in terms of how she planned to share the information with her staff concerning the anticipated changes in light of the revised policy. In these conversations I became aware of the private thoughts and planning of the principal leading this culture. Member checking through this type of respondent validation 
of appropriate interpretation and perspectives ensured “internal validity or credibility” (Merriam, 2009).

Finally, confirmability was strengthened as I actively sought out disconfirming evidence that contradicted my observations or informant responses. Once again member checks ensured accuracy in my depictions of the school culture and the role the principal played in influencing the culture. For example, the principal reported that coplanning sessions occur weekly, therefore, an artifact review was conducted as I reviewed the coplanning documentation binders kept by the principal. The documentation corroborated her statement, and the fidelity of program implementation was evident.

\section{Ethical Issues}

I reviewed and followed Patton’s (2002) areas of consideration when embarking in qualitative research, and followed his protocol. I began by ensuring that all individuals who chose to participate were given a clear explanation of the methods of study, and these individuals were informed of any possible risk associated with their participation in the research. I also went to great lengths to maintain confidentiality by keeping all data in secure locations. I had the support of colleagues not involved in the study and doctoral committee members if any ethical issues were to arise, and no ethical issues occurred.

Bracketing my beliefs. "Because human beings are the primary instrument of data collection and analysis in qualitative research” (Merriam, 2002, p. 214), qualitative researchers begin with a clear presentation of their beliefs including the lens with which they view the phenomenon they are studying. The presentation of life experiences and beliefs unfolds possible subjectivity presented by the researcher among the interpretation of data (Hesse-Biber, 2006). 
Making the researcher aware of their beliefs through bracketing, therefore, allows for a less biased interpretation of results (Merriam, 2002).

A clear representation of my lens began with the fact that I serve as the regional Director of School Improvement and Special Education for the Regional Education Service Agency (RESA). RESA provides services to counties in a variety of areas: technology repair, public service training including technical assistance, Medicaid billing, adult education, tobacco prevention, and assistance with educational data entry. The key role of the regional special education director is to serve as a liaison between the West Virginia Department of Education and local districts and schools to ensure that information is disseminated to the school, and to offer technical assistance in data analysis, instructional strategies and professional development as needed. Though as a regional director, I provide services and offer suggestions about best practices, I do not evaluate any school personnel. In essence, the goal is to serve as outside support to meet the needs of local schools and districts. For example, my role as RESA director has afforded me the opportunity to work with the faculty of Valley Elementary over the past two years providing targeted professional development on Wilson Reading series and developing individual behavior plans.

Not only is it important to bracket my beliefs in my current role, it is also critical to share my past experiences as a teacher and administrator to completely "reflect critically on the self as a researcher, the human as instrument” (as reference in Lincoln \& Cuba, as cited in Merriam, 2009, p. 219). As I reflect upon my 13 year career in education in relation to this study, it is important that my 8 years of teaching be specifically addressed. I began my teaching career at the age of 21 in a self-contained classroom with middle school students with learning disabilities and behavior disorders. The year was full of personal growth, and I employed teaching methods 
based primarily on trial and error. During this year's experience, the principal visited my classroom on two separate occasions; once to give me a revised daily schedule to include the instruction of a remedial math course for eighth grade students, and a second time to observe the remedial math class. Incorporating this remedial math course into my schedule, meant that the students in my class were rescheduled into a remedial reading course taught by another special educator during that time. During this year, I had limited interaction with the principal, and she had limited interaction with the students in my class. The students in my class were of average intellect and only slightly below average performance. All of our text books were grade level texts, and the students read fluently from them and comprehended at a slightly below average level with only minimal accommodations, such as, extended time. Looking back on that year, I feel that the performance of the students in that class were of low priority to the principal as evidenced by the lack of engagement she had with the students and her limited interest in the curriculum with which they were presented.

Subsequently, I taught students with learning disabilities and behavior disorders in an elementary school. During this seven year period, the school experienced four principal changes, all of whom influenced the performance of students with disabilities in some way. For example, as I began teaching the school's overall student performance met the state guidelines. The principal maintained a philosophy of inclusion and was insistent that the students with disabilities participate with their nondisabled peers to the maximum extent possible. At the onset of my first year in this school, I primarily cotaught reading and mathematics in grades three through six and worked with students in a special education separate class in grades kindergarten through second. The purpose of this separate classroom setting was to provide supplemental reading and mathematics instruction in addition to instruction provided in the general education 
environment. The schedule was arranged in this configuration of student support for the school year.

At the end of my second year of teaching in this school, a new principal was assigned to my school when the current principal was relocated to a larger elementary school. After the opening faculty meeting, the new principal met with the special education faculty and presented a new service delivery model. Services shifted to primarily a resource model based on providing remedial services to students with disabilities in a separate special education classroom. I provided reading and mathematics instruction for all students in grades kindergarten through sixth and my colleague served all students who were in need of behavior services. By the end of year two of this principal's tenure, the school was placed on academic probation by the state department of education based on student performance on the state assessment. At this point, the other teacher of students with disabilities elected to transfer to another school.

At the end of her second year, the principal took a leave of absence and an interim principal was assigned. This principal visited my classroom, and every classroom, on a daily basis. I distinctly remember him calling all of the students by name, including the students with disabilities. After receiving the October child count report, he asked my special education colleague and me to meet with him and asked us how we perceived the special education program at the school. During our dialogue, we discussed restructuring the program. This collaborative approach led to the review of students, individualized education plans (IEP) including academic performance data. We worked to align the program to meet each child's need. The result was the development of a new service configuration that was presented to faculty and parents. This plan was contingent on instituting monthly staff meetings to discuss our thoughts and to address any concerns from faculty members. At the conclusion of his second 
year of administration, the school was no longer on academic probation because student performance on the state assessment improved.

At the beginning of my sixth year at this school, a fourth principal was hired. During the two years that I worked with this principal, he was very observant and made few changes to established school procedures. A shift in the persons attending the monthly meetings occurred however; for example, general education teachers were invited to join our group, but the new school principal rarely attended and did not actively participate in the meetings.

While reflecting on the interactions with principals during the first eight years of my teaching career and how they affected the configuration of instructional support services to students with disabilities, the importance of acknowledging my experiences and biases, and exploring the lens with which I am researching became vividly clear. I realized the importance of defining my biases and my own viewpoints to make certain that the reader has a translucent view of how they my biases and viewpoints may impact the study (Merriam, 2009). I realized I bring to the research an underlying belief that students with disabilities should be included into the general education environment to the greatest extent possible. I also came to believe that if a student is removed from the general education environment, the services they are provided should be content focused and specific to the child's weakness. Through the reflection of my interactions with the principals with whom I have worked, I also came to realize my strong belief that a principal has a direct influence on the education of children with disabilities.

\section{Assumptions and Limitations}

In conducting this research, a number of assumptions had to be made. First, I made an assumption that informants were forthright in stating opinions and discussing aspects of school culture and did not try to answer questions in a "correct" manner that may be pleasing to me or 
parties who may read the research. It was reasonable to assume that my perspectives as an experienced special educator, administrator, teacher, and school psychologist, allow for the recognition of effective practices of inclusion. I also formed the assumption that sampling procedures gathered unbiased information from the informants who are teachers, parents, and administrators, and permitted the researcher to gather a diversity of opinions from each group of informants. A final assumption was made that my current professional role did not impact the research. This was assumed because my views have no bearing on administrative or evaluative decisions related to school personnel.

All research has limitations, and my study is no exception. As with any case study, one limitation was that the findings are specific to this school and under the circumstances present during the time of the study. Because of these constraints, one should take caution in generalizing any findings to other environments or circumstances. The results of this case study are a reflection of the culture of one elementary school; its teachers and administrators, parents; general education students; and students with learning disabilities, behavior disorders, and mild mental impairments. The results of this case study are also specific to the level of teaching expertise and instructional strategies applied in the classrooms at this elementary school.

\section{Conclusion}

The purpose for conducting this qualitative case study was to examine the context of a successful elementary school culture and the role the principal played in influencing that culture. The rationale for employing a qualitative case methodology in this study was that examining the dynamics of a school culture and the role the principal plays in influencing the school culture requires interviewing participants with multiple points of view and observing routines and activities within the school day to develop a rich, thick description of the context. Research 
investigating the influence the principal has on a culture that has produced a high level of student achievement for students with disabilities is absent from the literature, therefore, to gather a clear picture of role the principal plays in shaping the culture, the culture of the school and the influences of the culture had to be studied by examining the perspectives of parents, students, teachers, one administrator; by observing the interactions of members of this learning community; and by recognizing the values of the learning community . 


\section{Chapter IV}

Research Findings

Purpose of the Study

The purpose of my study was to investigate the administrative impact in creating a school culture that fosters achievement of students with high incidence disabilities. Data were collected and analyzed to investigate the research question: What role does the principal of one elementary school play in shaping a school culture that fosters academic achievement of students with high incidence disabilities? I began by selecting an elementary school whose students with high incidence disabilities performed well on state assessments. I then defined school culture and its components, and submersed myself into the culture as a participant observer. My findings include five components of the culture in the school that are foundational supports for student success including: rituals, collaboration, an individualized instructional focus, community and social emotional support. Each of these findings are defined and discussed based on data collected throughout the study. Data also supports four additional findings related to the roles the principal plays to develop, support, and enhance each of the components of school culture. The roles of the principal are as follows: serving as an administrator, an instructional leader, a community liaison, and a child advocate.

\section{Findings of School Culture}

"Culture is the underground stream of norms, values, beliefs, traditions, and rituals that builds up over time as people work together, solve problems, and confront challenges. This set of information, expectations, and values shapes how people thinking, feel, and act in schools” (Deal and Peterson, 1998, p.28). This definition of school culture was the basis for the investigation at Valley Elementary. I presented this definition of school culture at the onset of 
the initial interviews with the principal and teachers to clarify the concept of school culture in comparison to ethnic or racial cultures or with the concept of school climate. As I investigated the culture at Valley Elementary, the gathered data provided evidence that the culture was based on rituals, collaboration, an individualized instructional focus, community, and social emotional support. The five characteristics of the culture at Valley Elementary were defined and data to support their evidence are presented. The presentation of findings on the aspects of culture and the role of the principal complete the investigation of the research question: What role does the principal of one elementary school play in shaping a school culture that fosters academic achievement of students with high incidence disabilities?

\section{Rituals}

The first of the five prevailing characteristics of the school culture at Valley was the importance of rituals. For the purpose of this study, rituals were defined as the procedures within the school including celebrations and rites of passage within the school. For the purpose of this study, rituals can happen on a daily basis in the school such as morning announcements, or less frequently such as monthly celebrations of the number of books read, or at the end of the students’ elementary career such as graduation ceremonies.

At Valley Elementary rituals were woven through the culture as daily, weekly, monthly, and yearly events as well as those serving as rites of passage at specific periods of the student's educational career. Daily rituals at Valley Elementary began with the morning announcements provided by the principal and two students leading the Pledge of Allegiance. The morning announcements always consisted of: teachers absent for the day (the principal said she does this because other teachers will then continually check on the class and it helps the substitutes be more successful); this week's happenings (this week was youth appreciation week and today was 
crazy sock day, the following day was wear your school colors day); awards including classes who were "caught being good in the hallway" (today there was a special announcement that Valley won second place in the county recycling competition); reminders for students (today's reminder was about the upcoming anchor field trips); birthdays (birthdays for today's date in both April and July); and the Pledge of Allegiance led by two students (field notes, April 27, 2009). Each Friday, the morning announcements also included an award for “exceptional hallway behavior". Throughout the week, all of the classes who were "caught being good" in the hallway were entered into a drawing. The class whose name was drawn received a visit from the principal on Friday afternoon. Mrs. Riddle presented the class with a certificate for “exceptional hallway behavior”, and read a book to the class. The book became part of the class library (field notes, March 27, 2009; field notes, April 20, 2009). According to the principal, the reward consisted of the principal coming to

“your room with a book and reads, gives a certificate to the class to hang up and spends a half an hour with them. And it has worked. I have been in every classroom at least once this year. I have gone into preschool and fifth grade classes alike. It is just appealing to them”(transcript, May 8, 2009).

As I was walked through the hallway on one of my visits I noticed an award from the principal for "exceptional hallway behavior" displayed on the door of one of the fourth grade classrooms (field note, April 20, 2009).

The "excellent hallway behavior" ritual grew out of a pre-existing program at the school that formed many of the daily, weekly, and monthly rituals of the school: the GOLD star program. According to the principal, the GOLD star program was adapted from a program developed by a school district in Ohio. The program was called “GOLD star” which stands for 
"goals of learning and discipline, students and teachers accepting responsibility" (transcript, May

8 , 2009). The program was defined in the student handbook as a program in which "the student may receive a "warning" (yellow card) or "time out" (blue card) for behaviors that disrupt the learning in the classroom. If these interventions are not successful, a child receives a red card, and an office referral. All cards except green must be signed by a parent and returned to school the next day. The child will begin the new day on a "green card" (artifact review, March 27, 2009).

The effect of the GOLD star program on the culture of this school was evident as it was mentioned in all 12 structured interviews and the parent focus group. One teacher explained the program,

"Each classroom sets its own goals every month. Maybe three or four, as to behavior, academics, anything that we decide but those are the major two things. One goal might have to do with the green, yellow, blue, red card system we have and every class, well, the whole school does the cards. The goal is always be on green, yellow is a warning, blue is the teacher calls your parents, and red is when you go to the principal. You take the child there. That has worked tremendously. Maybe one of the goals would be that $80 \%$ of the class would have a green card the whole month. We do monthly goals. At the end of the month we go to the multi-purpose room and we have an assembly. Each grade level stands up and Mrs. Riddle will read the goals of the class and say if they made their goals. If we made our goal everyone will applaud for us. It isn't to rewards with stickers or rewards by toys. The reward is that you are proud of what you have done in your classroom and your individual goals and you know how much that means to the school and they applaud for one another” (transcript, March 27, 2009). 
During one of the monthly GOLD star assemblies, the principal walked up to the microphone, did not speak a word, and the room became quiet. The principal said, “Good afternoon.” The students and teachers said in unison, “Good afternoon Mrs. Riddle” (field notes, May 8, 2009). I later asked the principal about this interaction, and she said this exchange is how she taught the students to begin all assemblies. The appropriate interaction is for people to become quiet when someone is about to speak or present, therefore, it must be the appropriate way to engage in such a forum at school (field notes, May 8, 2009). Following this brief exchange of greetings, the principal began acknowledging class accomplishments. As the principal announced each class, they stood and she presented how many goals the class set, how many of the goals were met, what the accomplished goals were, and gave encouraging words for future performance. For example, the principal announced for Mr. Blake’s class to rise. She then said, "Mr. Blake's class met two out of three goals. They met the goal of skip counting by 5's to 100. Mr. Blake's class would you please skip count for us? I'll start with you at five. Five . .." and the class continued to skip count by fives. When they said 100, the audience clapped. Mr. Blake's class continued to stand. The principal said, "Mr. Blake's class also met the goal that $80 \%$ of students will stay on green for the month." The audience clapped. "Mr. Blake's class narrowly missed their third goal, $90 \%$ of the class will return homework $80 \%$ of the time. I know the weather is nice right now, but do your homework before going out to play. You can do it Mr. Blake's class", and the audience clapped (field notes, May 8, 2009).

School rituals occurred on a daily, weekly, and monthly basis in the school. In addition, some rituals occurred in the form of a rite of passage for the students. Two examples of these rites of passage included the fifth grade graduation, and the "anchors away to fifth grade" dinner. The fifth grade graduation ceremony was open to all students, parents and family members of 
fifth graders and was held at 1:00 in the afternoon so that all students could observe the ceremony. As I entered the gymnasium, eight 10 feet long bleachers had been reserved for parents and family; the entire section was filled when the ceremony commenced. The ceremony began as the principal began her customary approach to the microphone and stood silently before saying, "good afternoon”. The students became quiet and said in unison, "Good afternoon Mrs. Riddle." The parents continued to speak, but at a much quieter level (field notes, June 5, 2009). The principal announced individual fifth grade awards including all eight of the students with perfect attendance, and she announced a special award for one fifth grader who had perfect attendance for four years in a row. Fifth grade students were also recognized for participating in school functions such as choir, anchor, and band. The music teacher then came to the microphone and asked that the school choir please assemble. The students in the choir stood in rows on the gymnasium floor aligned to the center of the audience. They led the audience in the school song and one additional song. The audience applauded, and the choir returned to their seats. The principal announced each fifth grade graduate who proudly walked to the microphone area, shook the principal's hand and had their picture taken with the principal as they were given their "certificate of promotion" (field notes, June 5, 2009).

In addition to the fifth grade graduation ceremony, fifth grade students who attended the anchor program where involved in another rite of passage; the anchors away to fifth grade dinner. The anchor program was an afterschool program for students attending Valley Elementary. Its name is from the grant project's title, "anchored in the community, setting a course for the future” (artifact review, April 20, 2009). This grant funded project allowed Valley students the opportunity to stay for the afterschool program and rotate through the weekly stations of: snack and tooth brushing, homework time, technology lab and gym (two times a 
week), the public library, enrichment including drama, music, hands on science, etc. (field notes, April 8, 2009). The anchors away to fifth grade dinner was a family style dinner in which the fifth grade anchor participants ate with the principal and anchor directors. In preparation for the dinner, the enrichment station the evening prior to the dinner was food preparation led by the school secretary and the preschool teacher (field notes April 28, 2009). The night of the celebratory dinner, 14 students were honored. They were all given an "Anchors Away" award presented by the principal and the school system assistant superintendent. The dinner lasted one hour, and after the dinner the students were taken home by the after school program's bus (field notes, April 30, 2009).

Throughout this study, rituals were defined as the procedures, celebrations and rites of passage occurring within the school. At Valley Elementary, daily, weekly and monthly rituals were woven through the school culture. Students were also honored at Valley Elementary School with rituals in the form of rites of passage as the fifth graders exit the school and continued their educational career at the middle school. Rituals were one of five components that shaped the culture of Valley Elementary.

\section{Collaboration}

The second of five influential characteristics that shaped the school culture at Valley was collaboration. For the purpose of this study, collaboration was defined as having all team members including students and parents, but most specifically teachers working together to plan and deliver instruction based on student need. Based on this definition, interactions such as grade level meetings between teachers and parent teacher conferences were coded as collaboration. 
Data collected throughout this study revealed that parents and students felt they had a voice in the educational process at Valley Elementary. During a fifth grade class meeting, the principal facilitated a conversation with the class on the topic of finishing things you start. The class had been discussing reasons why they enroll in programs such as football or choir only to quit a few weeks later. The students gave a multitude of reasons which began to evolve into complaints when the principal asked them to give suggestions for improvement that would support their sustained participation. The students gave the principal suggestions on how to improve organizations at the school. One female student said "Maybe you should think about having ..." and continued to make a suggestion that Mrs. Riddle have the adults plan practices for chorus during anchor instead of before school. One male student suggested that, "you (the school) should have more different things to do in the gym part of anchor.” The principal asked the student to give some suggestions. The boy said, "Well, I know we can’t play dodge ball with hard balls but maybe we could use soft ones. How about if you get done with homework you ain’t got to do school games you could go to the gym?” Four other students in the class gave suggestions on improving extracurricular activities and the principal told them she would discuss their suggestions with the teachers (field notes, April 7, 2009).

Parents also felt comfortable being engaged in the school. During the parent focus group, one parent said, “Teachers let you know what's going on. You can come in anytime to see them” (transcript, May 8, 2009).

Although collaboration of teachers with parents and students is valued in the culture of Valley Elementary, collaboration among teachers in instructional planning and delivery was the most evident. One teacher remarked about the changes instituted from the Department of Education, 
"We have had to shift gears. With the testing, it used to be CTBS (was administered) in third and sixth grades. Everybody would have them (the students) but in third and sixth grade, those teachers were responsible for the scores (on state accountability assessments). This was years ago. I mean, we are all responsible for their scores now. If you teach first grade, second grade, and they don't start testing until third, it doesn’t matter. I am as responsible for them (student scores) and how they are doing. It isn't just the third grade or fourth grade. We are all in this together” (transcript, March 27, 2009). Teacher collaboration in the instructional planning and delivery process was observed in the culture of Valley through coplanning, coteaching, and including all personnel in the instruction of students. The teacher of students with learning disabilities at Valley School described the culture as “very supportive.”

"I believe that what we do is to really work to meet the needs of the student. We look at research. We look at what works. We very much work off of each other with like grade level meetings and things like that. (We ask each other) What ideas do you have? What ideas do I have? What has worked for you? I think there is a lot of, just through the course of the year, talking to the teacher what the students have had in the year previous also find characteristic and what has worked for them” (transcript, March 30, 2009). During three of the initial formal interviews of the study, teachers mentioned the use of coplanning time and the effectiveness of the planning time. The principal also spoke with me about the evolution of the master schedule that supported coplanning. I observed coplanning sessions on three occasions, and each observation was comprised of the same key players and a similar agenda. The meeting consisted of the two grade level teachers and the interventionist for that grade level. Some of the grade level teams met with a teacher whose sole purpose was to 
provide intervention groups for the school, other grade level teams met with the teacher of students with learning disabilities who also provided interventions. The teachers began with an agenda for the meeting. At the April 29, 2009 meeting the agenda consisted of "techsteps, tier groups, acuity, four square writing, and writing assessment.” The three teachers followed the agenda closely and the interventionist took notes of the meeting which were turned into the principal. The teachers made decisions concerning the selection of the students who would be in specific intervention groups for the following week. Intervention groups were derived from student performance on the school system wide benchmark assessments. Both grade level teachers presented their benchmark assessment results and students who were the lowest performing. The interventionist said, "will you put their DIBELS data in my box so I know where to start” (field notes, April 29, 2009). The meeting was an example collaborative planning because of the sharing of information and decision making as the general education teachers presented student performance, and the interventionist asked for more detail so that she could further individualize instruction to remediate student specific weaknesses.

The collaborative efforts of planning for instruction were carried out in many classrooms within Valley Elementary through the collaborative delivery model of coteaching. One teacher spoke about coteaching said,

"Two teachers in one classroom, what a benefit that is to all the students that are there. Because a lot of the techniques that we use from highlighting information to you know when a kid has 12 vocabulary words that they have to fit on the page, and it is so overwhelming to them that they don’t know where to start. To just even say you know there are three columns, A, B, C. Look in Column A for number one, look in Column B for number two. You know, that is a strategy that non LD kids need. I think we were 
leaving children behind. I think with two teachers in there, there are the personnel to really meet the needs of the kids” (transcript, March 30, 2009).

Teachers at Valley Elementary believed in the power of coteaching and cotaught with their peers, observers, and student teachers. A second grade teacher reported during a formal interview,

"I have a student teacher now and when she came in I told her, ’let’s get something straight here, I am not going to leave you in here alone, because, I know in other schools they come in and the teacher is out the door and, that is not my goal or role’ and I said, 'I am not going to have you just go up there and start teaching, we are going to bounce off of each other and coteach” (transcript, March 27, 2009).

The teacher continued that there were too many students with specific learning deficits to be met. She and her student teacher worked together to decide how they could best meet these needs through instructional planning based on DIBELS results. The results were reviewed by the student teacher and classroom teacher to plan for station teaching and tiered intervention groups to meet each students needs (transcript, March 27, 2009).

Collaboration was evident throughout the culture at Valley Elementary through collaborative planning and instruction along with the belief that the education of students was a collaborative effort of all faculty and staff. This belief was evident during the first two days of interviewing the teachers. When interviewing the physical education teacher, she illustrated the responsibility of all personnel in the accountability of the education of Valley Elementary students. She discussed with me a book study that was provided to the faculty as a means of professional development on the inclusionary instructional program of response to intervention (RTI). When I asked if as a physical education teacher she opted to participate, she said, "Yes I 
have to intervene even as a gym teacher. Mrs. Riddle expects me to address academics” (transcript, March 27, 2009).

Throughout the interview with the music teacher, it became evident to me that the physical education teacher was not the only instructional specialist who felt accountable for the educational performance of students at Valley Elementary. The music teacher reported,

"I am often asked to find ways to help them with their math problems through music and rhythms. If they (the students and teachers) are studying a culture of another county the teacher will collaborate with me, and I will teach them some Caribbean music or teach them some music from West Africa or in that niche. I always take the opportunity to do that. Say dinosaurs or whatever. I always ask them in Faculty Senate; 'tell me what you are covering.' I can adapt my concepts to fit songs to cover. There are a lot of times that their textbooks come with a song, and they feel that they are walking on two left feet. And they will come to me saying, can you cover this song for me. I am more than happy to do that. We all try to work together”(transcript, March 27, 2009).

On a separate occasion I observed the importance of instructional specialists as a fourth grade teacher was escorting her students to the music classroom. The student in the front of the line was carrying the "wheel" that tracks student behavioral performance in the GOLD star program and handed it to the music teacher. I asked the teacher why the GOLD star wheel traveled with her students to music class. The teacher conveyed the belief that, "students learn in music class.” The teacher added that, "However the kids behave in my room, is how they should behave in music class” (field notes, April 20, 2009).

The collaboration in planning and delivery of instruction for students supporting the school culture at Valley Elementary also applied to the service personnel in addition to general 
education teachers and instructional specialists. I had the opportunity to observe the secretary provide instruction at the anchor program as she provided homework assistance and cotaught the enrichment station of cooking for the anchors away celebration. Teachers agreed with the utilization of service personnel in the instruction of students. One teacher reported that, "The aides are wonderful teachers. They are part of our faculty. They learn with us and are teaching students too. They really are. They have a group when we are doing the DIBELing” (transcript, March 30, 2009). I also had the opportunity to observe an instructional aide provide small group instruction to a small group of students as a means of tier II instruction. The instructional aide sat in the back of the third grade classroom with three students, providing drill and practice flash cards on the sounds of vowels and diagraphs (field notes, March 30, 2009).

One teacher commented on the collaborative efforts of the school culture by saying, "You have to be here to make a difference. I haven’t seen that everywhere (in every school). Everyone works together here”(transcript, March 30, 2009). Another teacher expanded those beliefs by stating, “We are all in the same boat and if we don’t row together we won't get anywhere. You know, we all have the same job and it can be overwhelming at times. But, any way that we can help each other we do”(transcript, March 27, 2009). The collaborative efforts of the school were also evident to parents and students as they appeared in the school mission that was posted in all classrooms as well as the school handbook. The mission of the school was “The Valley community will work together to learn, be responsible, and show good behavior” (artifact review, April 30, 2009).

Individualized, Instructional Focus

Providing individualized instruction for all students was the third of the five characteristics present in the school culture at Valley Elementary. For the purpose of this study, 
an environment with an individualized instructional focus was defined as providing instruction based on specific needs of the student in the areas of behavior and academics, specifically built upon a framework of data based decision making. Providing individualized instruction was not limited to academics, providing individualized instruction to students on behaviors considered appropriate in school were also coded as examples of individualized instruction. Individualized instruction for academics and behavior was completed by addressing the students’ background knowledge and explicit direct instruction based on data based decision making.

The focus on academic and behavioral achievement was evident in the Valley School goals that were posted in every classroom and in the school office. The school goals were: improve reading, writing, and math, improve behavior, improve attendance and be here on time (field notes, April 30, 2009). Teachers in the school were very proud in telling me that, "kids are dealt with on an individual basis. Kids get what they need” (transcript, March 27, 2009). That philosophy rang true in the story relayed by a fourth grade teacher who was working with a student who transferred into Valley Elementary in January.

"I have a unique situation right now. I have a little girl who came from Mississippi, her grandma decided to home school her and she didn't do it the way you home school kids, she just went to the library and got books and kind of tried to teach it herself. This little girl has no phonics, no math skills, addition, subtraction, basic facts. She is struggling right now. I taught first grade in another school. So, I know phonics and I know all those things and so, I teach her. We (the fourth grade class) are doing multiplication and division, long division and this child hasn't had any of this basic background. It is so sad because she is trying so hard though. That is the thing about this kid. She is not getting 
frustrated you know. She is willing to do whatever you ask her to catch up (transcript, March 30, 2009).

I later observed this fourth grade teacher working independently with this student while her class attended music class. This was the time period when the fourth grade teacher was scheduled to have her personal planning time. She gave up her planning time to work with the student. As I saw them walking down the hallway I thought maybe the child was being punished, and she was not allowed to attend music class. This thought prompted me to go to the fourth grade classroom for an observation. I walked into the classroom approximately ten minutes later for the observation and saw the fourth grade teacher giving the student a "high five”. The teacher and the student were both laughing as they reviewed phonics flashcards. The teacher invited me to sit down so that the student could "show me her stuff". The teacher proceeded to review the letter flashcards with the student as I observed (field notes, April 21, 2009).

Background knowledge. Recognizing and addressing student needs was an overarching theme in many interviews and observations. One teacher who taught at Valley for over 20 years reported on the changes in the background knowledge of the students when they enter Valley School. She said,

"Since when I first started teaching here, our population has shifted. It used to be that three fourths of them (the students) were on level or above and maybe one fourth of them (the students) weren’t on level. And now it has turned itself around and maybe a fourth of them are on level and three fourths are not when they come to us (Valley School). Or, maybe I should say they don't have the background knowledge that students in previous 
years have had. We get them on level they just don’t come to us on level” (transcript, March 30, 2009).

This recognition of the lack of background knowledge was recognized by one of the preschool teachers as well. When I entered the preschool classroom I observed a classroom arranged with a variety of experience based situations that I later came to understand was for the building of background knowledge through experience based play and interactions. The class contained a make shift green house, a sand and water station, a paint station, foam letters and numbers, and a station for building with foot long plastic bricks. I asked the teacher about the structure of her classroom and the students whom she serves. The teacher began speaking with me about some of her most challenging students and instructional hurdles when she said, “The challenges in this class are not usually my IEP kids (students with disabilities on individualized education plans), they are just good old Valley students who are hugely under developed in background and vocabulary. But this is where they need to be, and we will get them caught up. We have to start young” (transcript, March 30, 2009). A second grade teacher and a Title I teacher also expressed the importance of recognizing and addressing this background knowledge. When asked for an example of weaknesses in background knowledge displayed by the students, the second grade teacher gave me an example of one student in her class who did not know his birthday. She said,

“We have to build background with these kids. You just can’t stand up and start talking about something because they don’t always know about it. I had a child yesterday; we were doing months of the year, birthdays, and things like that, just to put them in order. He couldn’t remember his birthday, and he was in second grade” (transcript, March 27, 2009). 
During her interview, the Title I teacher also referenced background knowledge when she discussed the culture of Valley Elementary stating that,

"We are trying to build background into their education that a lot of schools don't have to teach. They (students at other schools) come to school and know. Whereas, we still have to teach the regular curriculum and build in some other experiences. I think we know, we are dealing with a different set of children than some other schools. Sometimes the approaches are a little different here. We know they are going to require more to get them to the point they need. So, we you know, with the children, maybe have to take that extra step. The teachers push that little extra mile” (transcript, March 27, 2009). I observed explicit instruction related to students lack of background knowledge during the anchor program as students were preparing the meal for the "Anchors Away to Fifth Grade" celebration. The students were given romaine lettuce, cherry tomatoes, whole carrots containing the greens, and yellow, red and green peppers. The school secretary, who was one of the instructors for the station, said that the vegetables were chosen intentionally in variations that the students may not have been exposed to in their homes. The students were given "lettuce knives", a six inch long, three inch wide plastic knife with a handle; serrated knives; and carrot peelers. The secretary and the preschool teacher, the two instructors for this station, instructed the third and fourth grade students individually or in small groups on how to use the utensils appropriately. The preschool teacher taught one male student about the "veins" in the peppers and taught other students what the word "serrated" meant (field notes, April 28, 2009).

Explicit, direct instruction. This method of using instruction to increase the level of experience based background knowledge of the students at Valley Elementary was also carried over into the instruction of behavioral expectations and academics. A teacher who had been at 
Valley since it opened said, "I really think that behavior and the attention to academics much greater in this building than it was when I first came here” (transcript, March 27, 2009). The level of attention to behavior and academics was also evident in an interview with another teacher who stated,

"We have to teach things like manners and respect. We cannot assume that they (the students) are acting the way they do or speak the way they do to purposefully be disrespectful, they don't know how to act in school and what is appropriate in school unless we teach them. The way they are acting might be ok at home, they just need to learn that is not the way we do things here, if it's ok at home, then it's ok at home, not school” (transcript, March 27, 2009).

I observed an example of teaching the school's behavioral expectations during the transition between lunch time and recess as a kindergarten teacher conversed with a student who was inappropriately running in the cafeteria. The child emptied her lunch tray into the garbage and ran back to the table to sit down. The teacher called the student back to her. She said, "Kylie what rule did you just break?" The student said, "Running.” The teacher said, "Why do we walk?" The student said, "Because I could run into someone or fall." The teacher said, "Right, now walk to your seat" (field notes, April 21, 2009).

The unmitigated focus on instruction extended beyond the four walls of the classroom. I observed the environments of the occupational therapy room and the playground support direct instruction. The door to the occupational therapy room was open so I walked in to observe a therapy session. The therapist was in the process of working with one child with autism. The therapist was completing hand over hand prompting as she assisted the student to trace sand paper letters with his first finger (field notes, April 30, 2009). This academic focus was also 
evident during an observation completed on the playground where a map of the United States approximately 12 feet long is painted on the blacktop ground. One of the teachers was surrounded by six students. She asked the students in what city they lived, and then she asked in what state they lived. She next asked the students to go stand on that state. The game continued as the teacher would announce a state and the students would move and stand on that state (field notes, April 12, 2009).

Data based decision making. The cultural characteristic of individualized, instructional focus was apparent through teachers recognizing students’ deficits in background knowledge and utilizing all environments for instructional purposes. This focus was supported by the use of data to make instructional decisions that focus on the needs of each child. One teacher said that, “All children are capable of learning. Our goal is to help them to meet the goals that we have set for them and expect the best from each” (transcript, March 27, 2009). The school counselor also expressed the need for high expectations for all students when she said, "No one lowers their expectations. If they did our test scores wouldn’t be as high as they are” (transcript, March 27, 2009). Another teacher reflected goal setting and instruction based on data in her interview when she said,

"I think teaching today is much more geared toward content standards and objectives than it was 16 years ago. You find in classrooms that everything is more skill oriented with the things that we are doing now with the implementation of tier groups. I think we are certainly going in the right direction in the sense that even from kindergarten when we see those kids have a reading problem, through DIBELS (Dynamic Indicators of Basic Early Learning Skills, benchmark assessment for literacy skills), we are looking at 
those kids data and saying that reading is so important, so let's pull those kids out who are having difficulties and teach them” (transcript, March 30, 2009).

A third grade teacher also referenced the use of DIBELS in making data based and individualized instructional decisions.

"What we have done here is try to look at their DIBELS score along with their benchmarking. Because some of the kids who read very well orally have no clue what they are reading. And you know just to assume they are o.k. because they are green doesn't cut it. Then we try to group them. It is not individually by skill, but the group needs. Like there is a group, they don't read fluently enough yet to understand. Then we have a group that's like pretty fluent, but don't have a clue what they are reading. So, we try to break them up, you know. We only have five or six in each of our groups for 45 minutes a day” (transcript, March 27, 2009).

The use of DIBELS in grades kindergarten through third grade was mentioned in five interviews. Interviewees in fourth, and fifth grades even referred to the use of DIBELS scores even though they were not directly involved in its administration, they still realized the importance of the assessments. When I asked the principal about the use of DIBELS she replied, “They (the teachers) love to come point out growth in the DIBELS charts to me. Before I have a chance to go in and see (on the computer), they bring their charts to me. "I want you to see what my class can do. Oh my gosh, look at this. I have never had a class like this” (transcript, May 8, 2009).

The importance of the DIBELS data, which was collected by the use of palm pilots, was also felt by students to some degree. As the principal and I were walking up the stairs, a male first grade student stopped the principal as we met him on the steps. He said to the principal, "I'm half way 
through first grade." The principal called him by name and said, "I think you are further than that." He said, "Nope. The palm said half way” (field notes, April 7, 2009).

I also spent time reviewing notes taken by the teachers during the grade level team meetings. These notes were assembled in grade level binders in the principal’s office closet. I reviewed the content of these binders and saw entries such as: October 24, 2008 every grade was given the assignment by the principal of reviewing the acuity benchmark (grades three, four and five) and/or DIBELS (grade kindergarten through third) data. The grade level teams were to list all students who performed below benchmark. The data of all students performing below benchmark were to be analyzed and documented on a given chart identifying personal weaknesses and strengths. An entry from the kindergarten teacher about one male student was that he: "knows 15 letters fluently and accurately." It was also noted that this student “consistently miscued M N B and L.” The team also commented that, “other letter recognition was sporadic at best” (artifact review, April 27, 2009).

Driving past the school, the school marquee reads, "Valley Elementary Making a Difference One Minute at a Time” (field notes, March 27, 2009). This theme is continued as you enter the school and are met with, a wooden and glass display case of approximately six feet by six feet filled with clocks and the words, “Making a Difference One Minute at a Time” (field notes, April 20, 2009). This theme was not only printed on the student agenda, school marquee, and display cases, it was evident of the efforts taken by the staff to recognize possible gaps of background knowledge the students may have, and address those gaps for each student based on data based decision making without lowering the expectations for any student. 
The fourth of the five characteristics of Valley's school culture was that of social emotional support. For this study, social emotional support was defined as providing such supports as counseling and clothing, as well as, understanding what the students are experiencing in their home lives (drugs, murder, molestation etc.), and exhibiting an overall concern for student welfare. Social emotional support was exhibited through direct services such as counseling or providing for basic needs such as food or clothing. It was also provided through general concern for students, giving the students someone to talk to, or a conscious effort by the teacher to be more patient with the child in light of problems they are experiencing at home that may affect their academic and behavioral performance.

Recognizing home environment. Data collected at Valley Elementary School showed the teachers and administration recognizing the needs of the students, working to support the fundamental needs of students, and providing the students with emotional support structures. The principal explained the need for social emotional support structures at Valley Elementary: "Well I guess, you could say that you meet their basic human needs, which is the family part, you have to start there before learning can occur. I guess that is the connection. I am not so sure that happens everywhere (other schools within the school system). We (the faculty at Valley Elementary) can tell you all about their lives, I don’t know at other schools they (the faculty and staff at the school) know much about their (the students') personal lives. Maybe they know it but they don't address it. But we have to, that is who these kids are. If we don't address it, we can't get to the learning. We share a lot of information among our staff on a need to know basis. The teachers who are directly involved with the kids, we always strive to update them on the latest trauma in their lives. I think that makes the teachers acutely aware of what they need to do and what can they 
expect today from that child without lowering expectations. But still approaching that child in a different way than maybe you would have on Friday, before the latest trauma occurred over the weekend” (transcript, May 22, 2009).

A third teacher described the culture of Valley Elementary School as one that addresses basic students needs when she said,

"Priority (of this culture) is going to be survival skills and that is because of what they go through at home. Do I know where my parents are? Do I even have two parents present? Probably not. The majority of homes do not have that. Do I know where my next meal is coming from? Do I know if I am going to be safe all night long? That is basically the culture of the school. For me as a teacher, and other teachers have also voiced this, it is like we are charged with teaching academics to these children and yet we know the stress that they are under from their home life and their priorities are like where am I going to sleep tonight, who is going to be home when I go home, and we are trying to teach them. We have to meet both areas” (transcript, March 30, 2009).

The school faculty took steps to recognize the individualized basic needs and the lack of social emotional supports facing the students at Valley Elementary School. One fifth grade teacher, the school counselor, and the principal each informed me of a time when during a fifth grade meeting led by the teacher, counselor, and principal, the students began speaking of the times that their parents were incarcerated. The story was told to me by all three persons on separate occasions, but the details remained consistent with what the fifth grade teacher said, "In one of our class meetings we were talking about fears, what is your greatest fear? Through that conversation one of the kids said that 'my greatest fear is ending up like my family member who is in prison and I don't want to end up like that.' This was a group 
of 18 kids. (So we asked) How many of you have had or currently has a parent who is incarcerated? And minus the one little boy who just moved here from China, who may not have understood the question I asked, 16 of the 18 kids, minus that little boy, 17 ” (transcript, March 27, 2009).

The school counselor and a second grade teacher spoke specifically of the alleged drug use in the homes of some students during their interviews. The school counselor said that she had a student report to her that, "my dad's very favorite thing to do is smoke weed. He loves it. And it is all the time" (transcript, March 27, 2009). In speaking of the home environments of the students at Valley Elementary, one of the second grade teachers said, "Our second graders, these are eight year olds, can tell you about full use of weed, pot, pipes, joints, like it is nothing. They know this stuff. They are in the thick of it every day. It just amazes me” (transcript, March 27, 2009).

After observing the principal speak with a female fifth grade student who was sent to the office following an accusation from peers that she was swearing and threatening them, Mrs. Riddle discussed with me some of the situations being faced by some of the students. She said, "Right before you came, I had a third grade teacher in. We were talking about two kids, one little girl is going through hell right now. She was allegedly sexually abused by the parents but they still have visitation on the weekends. Then she comes back to school. The teacher said she is a mess right now. And the test (state assessment) is next week and we have so much more to cover and she is getting so little out of being here. So it is back to I know, I understand, but we can't fix that mess in her life. What else can we do to help her? The baggage that our kids bring is astounding. We have major things. We have two sisters here, one in fourth and one in fifth whose identity has been changed, 
they are in foster care. Their parents are on trial for murdering a family member, and the trial starts today” (transcript, May 22, 2009).

Five teachers interviewed referred to the continual study of the writings of author Ruby Payne. One teacher said that because of those book studies, "I really think that people (the faculty) truly try to understand the children from their world view and even though most of the staff did not grow up in poverty, we are really trying to have that empathy and put ourselves in those children's shoes or those parent's shoes and not pass judgment too quickly from our middle class glasses” (transcript, March 27, 2009).

Providing supports. The faculty at Valley Elementary School took great pride in recognizing situations in the lives of students requiring additional material, instruction or support. They use the information gained and strive to provide for the fundamental needs of the students through material objects as well as counseling services. Valley Elementary School had a dental hygienist on staff five days a week, and a dentist who works in the school based dental clinic every Tuesday and Thursday. The dental hygienist also wrote a grant and was awarded funds to buy thousands of prepasted toothbrushes (field notes, April 3, 2009). The afterschool program, anchor, began with all students in the cafeteria for a snack and tooth brushing each day. The students took the toothbrush home each day (field notes, April, 8, 2009).

The recognition that students needed to be well nourished was also evident within the culture of Valley Elementary School. On three separate occasions I observed students tardy for school. Upon entering the school, each student was asked by the secretary if they had eaten breakfast or they were hungry. Each of the students accepted the secretary's offer for breakfast. She escorted them to the cafeteria, and returned shortly with the student, cereal, milk, and a 
spoon. The students sat in the office and ate their cereal before reporting to class (field notes, March 30, 2009, April 8, 2009, and April 27, 2009). The need for students to be well nourished was also addressed during lunch. Each day at lunch, students took any unwanted, untouched or unopened food and placed it on a stainless steel table adjacent to where the students emptied their lunch scraps and stacked the used trays. Any student who wished to, raised their hand and asked for additional food placed on this table (field notes, April 21, 2009). Valley Elementary students who attend the afterschool, anchor program, were provided an afterschool snack and milk. They were also transported to a nearby church for dinner before being transported home for the evening (field notes, April 8, 2009).

In addition to recognizing and providing for the nutritional needs of the students, I observed instances of faculty providing materialistic support structures such as clothing, and eye glasses. While completing an observation of the physical education class, I noticed a rack containing 22 pair of shoes. Upon entering the gym, one student in the class went to the rack, sat on the floor, and put on a pair of the tennis shoes. The other students went on with the directions from the teacher and paid no attention to what the student was doing. I later asked the physical education teacher why the student did that. The teacher told me that sometimes students live in multiple homes due to split custody or frequent moving, and that having the correct shoes for gym is not a "high priority" in their parents' lives. The teacher said that she approached the principal with the idea to have shoes available for the students. Mrs. Riddle found some money, and the teacher bought shoes in various sizes for the kids to use (field notes, April 20, 2009). On another occasion, two students walked into the office, said, "Good Morning Mrs. Schrader" to the secretary. The secretary handed each student a pair of reading glasses and told them to "have a good day". The secretary later told me that the school "got them glasses through the lions 
club" so the kids kept the glasses at school. The students returned the glasses to the secretary before they went home each day (field notes, April 27, 2009).

Providing social emotional support for the students at Valley Elementary School was addressed in more ways than providing material objects. The faculty was observed several times providing social emotional supports for the students. One fifth grade teacher stated, "We have become a social service agency. You know because we have the folks from the mental health clinic come in and they do group counseling with our kids. We have the dental clinic. We just offer them so much. They are with us when they are involved in the after school program from 8:00 in the morning until after 6:00 and they are delivered home” (transcript, March 27, 2009).

The social services aspect of the school was enhanced by the involvement of full time counselor, a part time counselor provided by the school district, and counselors and a social worker from a local mental health agency funded by a partnership grant. The social worker from the mental service agency was on site one day a week to work with students and their families. One of the counselors and the social worker were resubmitting the application for the funding for the next school year (field notes, March 27, 2009).

One of the school counselors recognized a social emotional need in six female students who were in the fifth grade. The counselor reported to me that she approached the principal about the need to intervene with these students based on the frequency of disciplinary procedures. The principal supported the formation of a weekly group counseling session called, "Salvaging Sisterhood" (field notes, March 30, 2009). I observed the fourth session in this six week series of one hour group counseling sessions. As the girls trickled into the session that was held at 8:30 am, the students reviewed their journal entry comments with the counselor. Each 
child was given a journal topic by the counselor. They responded to the journal prompt on their own time and were asked turn the journal response sometime before Friday. The counselor read the journal entries and responded with written comments to each girl. The counseling session began with a vocabulary lesson on "relational aggression”. The counselor asked the girls what they thought the words meant, and what words they knew that sounded like relational and aggression. The lesson continued with each girl, including the counselor and myself, making a horizontal line in the center of the paper and numbering it from one to ten. We were directed to write the words, "less hurtful" beneath numbers one and two. We were directed to write the words "hurts forever with jail or severe consequences" under numbers nine and ten. Numbers five and six were labeled "might hurt for a year and remember for a while." Numbers three and four were labeled "hurts sooner, if you did it you would probably get into some trouble." Finally, we were directed to label numbers seven and eight "lots of trouble". The counselor read scenarios. The girls and I wrote them on the continuum beneath the number or descriptor we thought was the most appropriate. The counselor read the scenarios of, "stick tongue out, eye rolling, name calling, ignoring, graffiti, rumors, note passing, three-way calling, excluding, backstabbing, hitting, threats, lying, school shooting." The counselor then used the girls' responses to facilitate discussion. For example, she said, "you have excluding as more hurtful than ignoring, what's the difference." She would compare the responses of two students and ask them why they rated the scenario where they did on the continuum. The students gave examples of times the aggressive act had happened to them, and why they rated it as they did (field notes, April 8, 2009).

Students are also taught to build a repertoire of strategies for supporting their own social emotional development. I observed the teacher of students with behavior disorders interact with 
a student on the subject of utilizing such strategies. A student entered the resource room and said, "We got a sub, I ain't said nothing all day and I can't do it anymore so I left." The teacher sat down by him and told him that he made a good decision in leaving before he "got in trouble". She continued to ask him, "How did you leave?" The student said, "I walked out." The teacher said, "What would have been some better ways to leave?" She and the student talked about asking to be excused or turning in a "break card" etc. (field notes, April 30, 2009). During an interview, one general education teacher discussed strategies she employs to get students to leave their "baggage" at the door. She said,

"Well, I have certain students who come in (to the classroom in the morning) and they always have to talk. We (the class) can't unpack and go to our lockers and get settled in the way we are supposed to. We always have to talk. So, I let them come up to my desk and I say, "OK, you have one or two minutes go ahead and tell me what is on your mind and then I say I am sorry, I have to move on because I have a job to do. If there were something weighing on my mind I would have to voice it, sound it, write it down, do something or otherwise I can't move on with the day” (transcript, March 30, 2009). Although the basic needs and social emotional needs of students are recognized and addressed, school must continue to forge on. One teacher said, “Some of our kids have a very difficult life. I don’t think that it's that they don't value school, It's just there are so many other things on their minds going on that take priority. I think that most of them do the best they can. But, if I had to live through what some of those kids do, I wouldn't be spelling either. I would be wondering who would be home tonight and what's going to happen to me. Some families are very strong. We have a mixture. We have some very strong families, and a lot of families where there is a lot 
going on. This makes it real hard for these kids to concentrate” (transcript, March 27, 2009).

The overarching characteristic of recognizing and addressing the social emotional needs of students was shown through the observations and interviews of multiple participants. The characteristics of the culture of Valley Elementary of rituals and celebrations, collaboration, academic and behavior, an individualized instructional focus, and social emotional support the final characteristic of a culture of community.

\section{Community}

The fifth and final characteristic influencing the school culture at Valley Elementary School was community. In this study, community was defined as parents, students, teachers, and community members taking pride in working together to support the school as it serves as a pillar of the broader community; displaying a commitment to the school. This definition encompassed more than a link to the community at large, it was the pride for the school and how parents, teachers, students, and community members display that pride. Data showed that community was built through inclusion, and parent engagement.

The pride and sense of community was apparent when I walked into Valley Elementary School. Bulletin boards in the hallway displayed flags with "U.S. Department of Education School of Excellence” and another banner illuminated by the light from the skylight at the top landing of the staircase reading, "West Virginia Blue Ribbon School Valley Elementary” (field notes, April 20, 2009). Connections to the community at large were prominently displayed in the conference room with framed, signed, certificates formal partnership agreements of the eight "Partners in Education” partnerships with the school (field notes, April 2, 2009). On another wall in the conference room hung photos of floods occurring in 1994, 1996, and 2004 that 
ravaged the school and the community. There were photos of the school engulfed in water over the lawn, front steps, and about one foot up the entry doors. Beside these photos hung a plaque from the parent teacher organization reading "Presented to the staff and volunteers of Valley and its students during the flood of 1996. We say thank you” (field notes, April 2, 2009). A fifth grade teacher reflected on the floods in her interview and stated, "The flood...I mean we came and cleaned up and then we went out and helped others, you know, clean up. I can’t imagine working in a place where it is strictly business. You know because it sure isn’t like that here” (transcript, March 27, 2009).

When discussing the culture of the school with the principal, she stated, "I would say the culture would be family atmosphere in terms of the community. The hub of the community. The heartbeat of the community. The parents, the families know that the most important thing going on in this neighborhood is going on here. They may not always understand it but they accept that and respect that. Very few people who have lived in the community for any length of time don’t have some respect for the school” (transcript, May 22, 2009).

Inclusive culture. This sense of community was inclusive in nature. Valley Elementary served students with learning disabilities, behavior disorders, mental impairments, and preschool special needs. One teacher said, "We take everyone, MI, LD, BD, you name it, we take all students and we love them and help them no matter what” (transcript, March 27, 2009). One fifth grade teacher said,

"Well, I would describe the culture of this school as very accepting, very accepting culture. We, I guess, we take these students and the families where they are and work with them from there trying to bring them to a different level where they are able to learn 
and succeed. We are successful with most and not as successful with some but it is the stories that we have that keeps the teachers going” (transcript, March 27, 2009).

Another fifth grade teacher supported the same philosophy when she stated,

"We teach all children. We teach all children from everywhere they are. I think we feel that they all can succeed to some degree. Maybe not to the degree that the State would like for us to succeed, but we see advancement from where they started to where they are when we finish with them each year, every child” (transcript, March 27, 2009).

I observed these inclusive efforts, two of which prominently support the inclusive community that I found to be a prominent characteristic of the culture. I observed three response to intervention, tier II instructional groups. After the sessions commenced, I informally spoke with the interventionist regarding the group composition and the lessons. Out of the five students in each of the intervention groups, the first intervention group contained two students with learning disabilities, the second tier group contained one student with a learning disability, and the third group contained two students with mental impairments. These tier groups were not exclusively for students in the general education population, they were for students displaying difficulty on a specific topic or skill, regardless of any special education label they may carry (field notes, April 28, 2009).

Another observation distinctly supported the inclusive nature of the culture reported by the teacher and principal. I attended an IEP meeting for a child with a mental impairment who transferred to Valley Elementary School to receive special education services. The parent began the meeting insisting that her daughter receive "special education" all day, that is "what we moved her for". The principal explained to the parent that, "we include our children in the general education classroom to the greatest extent possible." The parent said, "I want all the 
special attention I can get" (for her child). The principal reminded her that all students in the school are special, and her daughter's performance "will be closely monitored and if we need to meet and change her IEP we will." The principal was not going to concede to the parent and allow the child's IEP to place her in a self contained special education class if the child could be included with her peers. The parent agreed to the least restrictive environment, and the meeting continued (field notes, April 27, 2009).

Parent involvement. The characteristic of community supported by an inclusive environment also extended to the involvement of parents within the school culture. In every formal interview I conducted, I was told that one way the culture could be improved would be through an increase in parental involvement. Each interviewee gave examples of how parents were involved in the school, but each interviewee also strived for more extensive involvement from parents. I observed efforts on the part of the teachers and the principal to make the parents feel welcome in the school. On one occasion, parents were entering the gymnasium for an assembly. At the front door of the school, a teacher greeted each parent and directed them to the gymnasium. As the parents entered the gymnasium, I observed three teachers standing by the entrance of the gym. They greeted me and the parents as we walked in. They greeted me by my first name and the gentleman behind me by saying, "You are Iesha's dad right?" and shook his hand (field notes, June 5, 2009).

Another encouragement of parent involvement was observed during an observation of a fifth grade class meeting led by the principal in preparation for transitioning students to the middle school, some students told the principal that they would be going to a middle school out of their local school district. The principal responded by saying, "If your parents are planning on you going to another school there is a process to go through so have them call me, and I will help 
your parents out” (transcript, April 4, 2009). The effort to build rapport with parents was also highlighted by the school counselor when she reflected on how to improve the culture of Valley Elementary. She stated,

"I know a lot of the parents come to a school with a preset agenda of things they have experienced in school themselves, whether they have had a negative experience with teachers or they are school dropouts and they just don't trust us for one reason or another. But, if there were some way we could meet them in study groups on how to involve parents in more appropriate ways, but when we do things like have an educational night, learn how to do this or that with that child, our parents do not buy into that stuff. We will keep trying though” (transcript, March 27, 2009).

One example of how the staff "keeps trying” is through the study of a book by Dr. Ruby Payne, Working with parents: Building relationships for student success. This book study was addressed in 10 of the 12 interviews when discussing means of improving the culture of Valley Elementary. The Title I teacher described the book and book study as, "It (the book) gives us many different ways that you can involve parents. It breaks the strategies into subgroups. It's not a one size fits all for parent involvement. We (the teachers) each did a project to help reach one of these groups. My own project, I am trying, is to send little notes home on the good things that the kids do. Like, my goal is a phone call, because the only time parents get phone calls is like when their child is bad. I want to work the opposite of that. So, in these phone calls you do not mention anything negative. If you have to do that, that is a totally different time and place. This is school wide. So, every teacher has a parent project” (transcript, March 27, 2009). The counselor discussed with me the book study and the parent involvement projects 
resulting from the book study. The counselor said,

"As part of our how to work with parents study group from the Ruby Paine book that we had in the fall, we talked about unique ways to get parents involved in the school that will actually bring them in. For one project we focused on some single parents. The idea was to give them a night off from cooking dinner and we invited the people, and $100 \%$ of the people that RSVP'd came. That was only 18 people, but still, that never happens that everyone who said they were coming did come and we cooked them a spaghetti dinner and a salad. We sat with them for about an hour and ate dinner. We talked with them and got to know them and that was really nice. Things like that that aren't necessarily come in and learn. It was so the parents feel more comfortable, they could learn through conversations informally and we can learn so much about them. We actually had two moms at the dinner who never really looked at me in the hall now when I pass them, they say, "Hi, how are you doing today?” So that relationship is there. I think that if anything would ever happen that those two women would feel comfortable coming to me and talking to me about something” (transcript, March 27, 2009).

An enhancement to parent-school communication was built into the GOLD star program. As discussed previously, the GOLD star program was the school wide discipline program at Valley Elementary. The program was based on school wide rules and expectations that were documented through designated colors which represent the students’ performance level. The teacher of students with learning disabilities spoke of the impact the GOLD star program had on parent-school communication. She stated, "We contact the parents and work with the parent to try to get all the information from them that we can. With programs like the GOLD star program we are working with the 
parent. The parents know what went on in school today. If there has been a problem they know immediately and I think we all work very well collaboratively” (transcript, March 30, 2009).

During the parent focus group, one parent reiterated the sentiments of this teacher. He said, "My kid's here to get an education. He knows he better listen to them teachers. They see me every day. First thing my boy gots to tell me after school is his color so I can see the teacher if it is blue or red cause that means he was bad" (transcript, May 8, 2009). This dialogue between teachers and parents elicited through the GOLD star program was also presented by the principal when she stated,

"We watched the dialog with parents and their child and parents would immediately ask 'what color are you on today' as soon as the child comes out the door. The teachers and I see that as an opportunity to meet with parents. If the child gets their card turned, many parents will ask the teacher right there what happened. It took away the vagueness of 'what kind of day did you have' 'well it was ok' 'well what does ok mean.' It (the conversations) turned into ‘what color card are you' 'yellow' 'so why did you get a warning' or 'blue, ah, you didn't have a good day because you had two chances and you blew it'. Of course red, is always that phone call from me or the teacher. So they may not totally understand the system but they have some meaning to the colors that is simple and we try to keep things simple enough for the parents can understand" (transcript, May 22, 2009).

During the parent focus group, one mother commented on the visibility of the teachers 
during school dismissal. She stated, "I like seeing the teachers every day. They work the kids hard here, but we got great teachers here” (transcript, May 8, 2009). A fourth grade teacher expanded on the use of these curbside meetings during dismissal as she stated, "I do a lot of meetings on the street when they (parents) come in to get their kids. We have the agenda going home every day. I think a lot of other people do this too. We have the agenda going home every day and their parents are supposed to sign it. We are having a tough time this year, in fact, really tough. We have made it a goal for our GOLD star program every month and it I don't think we've met it yet but we're not giving up. I have kids who say, 'I do, I beg her (the mother) to sign it and she won’t.' So, you know, it's not their fault really. I told them if you have a problem like that, come see me and we will work it out. But catching them on the street is a good way to do it. It’s a good way to catch parents” (transcript, March 27, 2009).

Another teacher used curbside meetings in conjunction with note home programs and sharing data. She said,

"I believe that one way I have conferences out on the sidewalk. You know, I will just go out there and meet someone. I just think the one on one personal contact walking out and talking to them. I don’t just do it when I am having a problem, you know, I send home positive notes also. Nothing fancy, I will take a note card. I sent home the fluency from the DIBELS and they know where their kid is and where they need to go" (transcript, March 27, 2009).

The fifth and final characteristic of the school culture evident at Valley Elementary School was community. This sense of community was built through community involvement, inclusion, and parent engagement. The teacher of students with disabilities stated, "Most of the 
people basically know that this school is a safe haven for their kids. I think that for the most part, parents feel that we communicate with them. If they have a question or problem they know someone here can give them an answer” (transcript, March 30, 2009). This sense of community extended into the classroom as well. During the parent focus group, one participant said, "I have been a crossing guard here since 2001. I come in the morning and for after school. I ain't got no kids here. I ain't had kids here for four years, but this is a great place so I still help” (transcript, May 8, 2009). One teacher said, “Some schools probably don’t want parents there. But we do. Here we are just open you know. Come on down and see what we are doing anytime, we have nothing to hide” (transcript, March 30, 2009).

Data supports five elements of school culture at Valley Elementary including rituals, collaboration, an individualized instructional focus, community, and social emotional support. The principal played a vital role in setting expectation, implementing and monitoring all 5 cultural characteristics. Her roles in establishing and maintaining this culture were also researched and analyzed.

\section{Findings of the Principal's Role}

The principal at Valley Elementary played four key roles in shaping the culture of the school into one built on rituals and celebrations, collaboration, an individualized instructional focus, social emotional support, and community. The principal's roles at Valley that supported this culture were the principal as: an administrator, an instructional leader, a community liaison, and a child advocate. As an administrator, the principal created the school schedule, enforced policy, enlisted personnel, assigned roles, and other administrative jobs. As an instructional leader, the principal provided professional development to the teachers, modeled expected behavior and monitored instructional practices and academic and behavior progress of students. 
As a community liaison the principal, supported a community of learning and collaboration between parents, teachers, and children. Finally, the principal at Valley Elementary served as a child advocate as she reflected upon what was best for the children and acted accordingly.

\section{Principal's Role as an Administrator}

As an administrator, the principal completed mandated responsibilities as determined by state and local policy. She created the school schedule, enforced policy, enlisted personnel, assigned roles, and other administrative jobs. When speaking with the principal about her role as an administrator in the school she stated, “It's a big chess board matching personalities, timing, being an instructional leader and making sure you understand curriculum which is so important, and making sure that everyone is getting their proper staff development hours” (transcript, May 8, 2009). Two areas of strength for this principal as an administrator were just that, scheduling and assigning the right person to the most appropriate role.

The principal made sure that all staff members were aware of upcoming events within the school. One bulletin board in the office was designated for a three feet by four feet calendar for the current month and one subsequent month. The principal also wrote what she called the “Friday Focus", a one page newsletter, and distributed it to each staff member via email. The Friday Focus contained upcoming events, policy changes or alerts, and recognitions of school personnel (field notes, March 27, 2009).

While wearing her administrative hat, the principal created a master schedule for the school that supported effective instruction through tiered instructional groups and coplanning.

The principal made the schedule and then reflected on how to improve the schedule of events for the future. In one interview, the principal reflected on her scheduling and necessary changes. 
“There was a particular time of the week, 1:30 on Wednesday afternoons. And I would say to myself, 'my god what did you do to the master schedule?' I would go out and I must have had six classes in transit somewhere. There was so much noise so I knew I had to fix that” (transcript, May 8, 2009).

During an interview with the principal, we discussed the administrative duty of scheduling and how sometimes the schedule required adjustment, however, the principal must also execute persistence in scheduling and follow through to support the most effective instructional practices for the students.

"I spent a summer in my mind trying to figure out how that was going to work (team meeting times into the schedule) and I came up with a plan but it was so new and foreign to the teachers. Initially these GOLD star meetings, teachers didn’t come, they stayed and met with one another. I had the whole student body myself (in an assembly) so that they (the teachers) could have coplanning. I had the whole school and a couple of helpers that was it, aides, and the PE teacher. It worked well and it was an hour at least. I did the GOLD star part first and then I lined up some type of educational entertainment. That time did not take away from their other planning time during the day. I knew that they needed a normal planning period and I would shoot myself in the foot if it was during their regular planning period. I put so much time in making the agenda, getting the presenter, giving them a protocol to follow, I spent hours on these agendas to make sure they were zeroing their coplanning conversations in on the right thing. The notebooks (from the coplanning meetings) would come back to me and I would read the minutes and I would want to cry. I used to think I would give up. I spent endless hours getting ready for these meeting and I am over there in an assembly with 300 kids by 
myself! I cannot be everywhere and this is all the teachers did? I would think to myself, these teachers don't get it (how to have team planning). I would tweak my wording on the agenda for the next month and I would get things back to me like 'Title I needs to take Jimmy and Suzie' and so on. That was our mindset in education for so many years. Honest to god, I was ready to throw in the towel but I knew this (the way teachers coplan) had to change. I didn’t give it up, I persisted. Here we are seven years later and we are still doing it. We do it on ISE days now, I had to change my format because it became too difficult to manage all of those kids myself and my help dwindled, and I ran out of money to pay for programs and couldn’t find any more free programs. I couldn’t just give them a half an hour though. If you are just going to give them a half an hour to sit and talk, you're cheating them. So I moved away from the assemblies to using ISE (instructional support and enhancement) days, two hour delay days. The gentlemen whose idea this was, I ran into him and I told him I was ready to quit and I told him why. He was great, he said 'Don’t quit, you have made great progress. Don’t give up it takes time. You need to get out and drop in to those meetings.' I told him I couldn't I was watching 300 kids. He said you have to get yourself out of there, can’t anybody else do that (watch the kids at the assembly)? I said I don’t think so, I can’t put that on anyone else. So we thought about the times changing etc. The format did not. I would never drop that” (transcript, May 8, 2009).

In addition to scheduling the events and following through on the events and routines that are perceived to be the most important to student achievement, another administrative role of Valley's principal was to choose the right person for the right job. She concurred with this statement in saying, "You must be a master of finding the right person for the right job. It helps 
them gain ownership of the project at hand and supports its success” (field notes, May 5, 2009). I observed the Valley’s principal delegate menial assignments so that she could continue with more administrative assignments. During one morning observation, two students (one male, one female) entered the office at 8:08 am with a female guardian. When they walked in, the principal called them both by their first names and said, "Are you coming back? We'll be glad to have you." The principal asked the school counselor to escort them to breakfast and told the guardian she would speak with her after school, and that she was glad to have the family back in the school community. While the children were at breakfast with the counselor, the principal spoke with teachers about enrolling the students into the appropriate homeroom and paged the custodian who promptly appeared in the office and asked him to have chairs and desks ready for the new students upon their arrival to their new homeroom (field notes, April 27, 2009).

During the aforementioned progression of events, at 8:10am another mother came in with her daughter and said, "She's having' trouble with a few girls in her class." The principal asked them to have a seat and told them she would find the counselor to talk with them. The principal came back into the office and escorted the mother and daughter across the hall to the counselor's office where they spoke with the second school counselor (field notes, April 27, 2009).

In speaking with Valley’s principal regarding her role as a school administrator, she noted that although schedules and events may intrude, you must follow through on what you plan and be true to your word as an administrator. She said,

"If we believe a program is good and bought into it, I think the worst thing an administrator can do is let it dwindle down to nothing. I remember that as a classroom teacher. On paper we had the best programs and we would send newsletters home to parents telling them how great we are, look with what we are doing. I remember reading 
those newsletters thinking, if we are really honest with ourselves, this program has fallen apart, this is half baked, and this is not what it used to be. I never wanted to be that kind of administrator. And so I paired down, I believe that less is more. You can't do them all well, there is too much. When I came into this job I promised the teachers and myself that I would pare down things and choose a handful of the best stuff, really stick to it and really do them well. For example, these compliments in the hall that are new this year. I have a chart that hangs by the PA system and I start with the first week of school keeping track of which class won. That chart is a visual reminder to me. Even though I have a crazy, busy Friday, I have to keep up with this every single week of the year. For myself, to live with myself, I have to honor what I said I am going to do" (transcript, May 8, 2009).

In completing her administrative duties as determined by state and local policy, Mrs. Riddle was cognoscente of the cultural expectations with which she was working. As she completed the school's master schedule, she maintained the cultural components of collaboration and community. She reflected on how to improve upon these administrative duties from year to year and continually looked for areas of improvement.

Principal's Role as an Instructional Leader

Positive cultures are productive cultures where the principal puts student learning first and involves teachers in monitoring student learning. Without a child centered culture, reform will not be attained, staff morale diminishes, and student achievement declines (Fullan, 2002). At Valley Elementary, Mrs. Riddle put student learning first while serving as an instructional leader. The principal provided professional development to the teachers, modeled expected 
behavior, monitored instructional practices, and tracked the academic and behavior progress of students. One school counselor spoke of the principal's role in shaping school culture in saying, "The principal is key in shaping the culture of our school. She is our leader. Just the whole demeanor of the school is on her shoulders, if she is negative, critical, if she handles people with meanness and unkindness all the time, then that is going to influence the attitude of the staff. Our principal is very proactive in moving us to where we need to be. She can see where we are going to have to be, and even though we are not required to be there yet, she is like let's just go ahead and take those steps so that when it is time we will be ready. For example, RtI. We are ready to roll and we are going to be ahead of the game. She is very positive about that” (transcript, March 27, 2009).

A third grade teacher reiterated the comments of the school counselor in saying, "She (Mrs. Riddle) is more than a principal handling discipline and stuff, she is an instructional leader. She has the foresight to know what's coming down the pike and prepares us. We were a year ahead with RtI. We started studying it and talking about it and then a year later the state says we have to do it. We were ready. By in large she is our instructional leader. She sees what is coming; it's almost eerie" (transcript, March 27, 2009).

One way Mrs. Riddle was an instructional leader was through providing professional development to the staff. While attending a training session on the West Virginia Department of Education’s standards for principals, Valley's principal turned to me and said, “Standard three (faculty and student learning) should be the first standard. That is our ultimate goal as a principal. If you can do that, the others follow suit” (field notes, May 5, 2009). The principal was observed acting upon this belief as she scheduled and planned summer reading for her 
teachers. She planned a teacher learning academy to greet her teachers in August, and she arranged for ongoing training throughout the semester on WESTEST, online writing assessment, RtI, and data analysis (field notes, March 27, 2009).

Teachers also commented on the principal's role as an instructional leader and her ability to provide effective professional development. A fourth grade teacher said, "You know many of the teachers here, I hate to say old, but we have been here a while. The principal keeps us up on the latest ways of teaching though so we are still on top of it” (transcript, March 30, 2009). The physical education teacher reiterated the comments from the fourth grade teacher when she said, "She strives for us to move in the direction that will help every child. She makes it possible. She provides us with professional development that will increase our knowledge” (transcript, March 27, 2009). A third grade teacher also spoke about the principal’s role in providing professional development,

"She brought coteaching into our classrooms, you know a teacher will come in and teach with us. We are coteaching, it is not an aide. It is someone that will come in and we will teach off of one another. We will bounce off of each other. The principal enabled us to do that. She has enabled us to have grade level meetings, gotten us training in instructional programs. She has brought this school to just a different atmosphere, one that is focused on learning (transcript, March 27, 2009).

The principal and I attended a training provided by the West Virginia Department of Education on making special education eligibility determinations based on the response to intervention framework. During the training I observed Mrs. Riddle marking lightly in the manual that was provided as part of the training. In her manual she wrote lightly in pencil an X, a question mark or a check as the presenter reviewed each step of eligibility based on RtI. 
During lunch I asked Mrs. Riddle what she was writing in her book and why. She said that she was going through each step of the process and thinking about the professional development needs of the teachers at Valley. The check marks designated what was already in place at the school, the question marks were areas in which she felt her staff needed more training, and the X's were areas that had not begun at Valley Elementary. Mrs. Riddle was concerned about the teachers' ability to “dig deeper” into assessments as well as their ability to administer a variety of assessments to determine specific student weaknesses. She then stated that she would, “carefully feed this information” to the staff “ in little bites”. As she spoke with me during lunch she developed a plan of first presenting to the teachers the "pieces they are already doing well” and then show them the components of this new process that "we need to tweak". The professional development plan the principal was developing ended with a "hard look at the pieces we haven't even begun”. She said that she will work with her teachers to build a plan together "with clear steps so they don't feel overwhelmed" (field notes, March 27, 2009).

The principal expanded upon these thoughts during later interviews and discussions regarding the principal serving as an instructional leader. Mrs. Riddle went on to relate the feedback she receives when the teachers return from county wide grade level meetings or special education meetings on current topics. Valley teachers tell other teachers that Mrs. Riddle already informed them of the information presented at the meeting. The teachers also asked Mrs. Riddle why other teachers around the county didn't know about the topic being presented. The principal said, “They (the other teachers in the county) were like, “How did you know about that?”, and my teachers say, "Well our principal told us about it after she got it." I think they like that. They like being a step ahead” (field notes, May 22, 2009). In speaking of the need for professional development, the principal said that, 
“You want a comfortable place where people don't feel threatened. The teachers here are confident, but they know they still need more. They (the West Virginia Department of Education) had a math webcast last week, and I just put it out on the email a week early saying that some of you are still asking for professional development hours if anyone is still in need I am staying for this, and you are welcome to join me. We had 13 teachers most of whom did not need the hours, they just wanted to learn more. We had a study group of 20 some people on RtI. I just ordered these books with left over money. We are going to use it for the teachers' academy. I am going to give the teachers this book as a 'present' for summer reading but if you are coming to the teachers' academy in August, we are going to use this book. It is amazing that people are just signing up for things and it's not because they need hours and the money is not that much, if they are even getting paid at all, but they want to understand and do better” (transcript May 8, 2009). In addition to planning and providing professional development for the staff at Valley Elementary School, as an instructional leader, Mrs. Riddle also modeled expected behavior for interacting with and instructing students. For example, the principal wanted the school to run as a community in which problems are discussed and addressed by multiple stakeholders. The principal was interacting with fifth grade students during a class meeting when I observed her make the students realize their ownership in how the school could be improved. A female student was voicing her opinion about a teacher who was "short" with her. After talking the scenario through with the principal and the group, the student’s closing statement was, "Well I was rude too, I guess." Mrs. Riddle said, "I'm glad you recognize that sometimes our attitudes and the way we talk to others are reflected in how they talk back to us” (field notes, April 7, 2009). I also observed the principal serving as an instructional leader as she modeled the 
expected adult to student interactions when a student entered the office on his birthday. The principal saw a boy in the office with his teachers and said, "Good morning Jordon, happy birthday." She directed him to the small book rack in the office and told him to choose the book he wanted for his birthday. She then asked him, "How old are you?" The boy held up four fingers. The principal took the book from him and read the title to him. She told him to have a great day and to listen for his name on the morning announcements (field notes, March 30, 2009). I observed the principal modeling the type of teacher behavior she expected on a third occasion upon entering the school. Mrs. Riddle was in the hallway monitoring hallway noise behavior in the positive manner she would expect her faculty to monitor hallway behavior. She observed the students and acknowledged the children exhibiting appropriate hallway behavior (field notes, March 27, 2009).

In addition to these observations of the principal modeling the positive adult to child interactions she expected, the teachers also commented on Mrs. Riddle's ability to set the stage for the method of interacting with persons among the school community. One teacher spoke of the principal's leadership in saying,

"She cares for every child in this school, and she wants to see them succeed. She is here for the children. The same thing, she has that bar up here. She doesn't lower it. She expects everyone else to do the same, so we do. And, without that leadership, you wouldn't set your bar so high. She does do that; she expects you to expect” (transcript, March 27, 2009).

The Title I teacher spoke of Mrs. Riddle’s leadership in saying, "She definitely sets the tone for all of us. She understands our struggles and everything that is on our plate. I don't know how she keeps it all together. She is so calm, and then so are we” (transcripts, March 30, 
2009). Mrs. Riddle commented on her own thoughts of how a principal should model expected behaviors. She said,

“The kids need to see that you are true to your word, but the staff needs to see it too. If you want them to buy into something they need to see that you are committed too. Steven Covey says to make deposits in to their emotional bank accounts and when it is your time to make a withdrawal, it will happen. It works” (transcript, May 8, 2009). As an instructional leader, the principal at Valley Elementary coupled the modeling of expected behaviors for students and staff with continual monitoring. For example, in order to prepare for response to intervention, Mrs. Riddle saw value in giving teachers time to analyze data. This time was not easily found in the school schedule, therefore, the principal worked with a group of staff members to come up with a solution, one that left Mrs. Riddle in charge of all of the children in the school for an hour each month.

"We used to have team meetings monthly for an hour. The teachers would have grade level meetings and Mrs. Riddle would take every student in the school into the multipurpose room for an assembly. She knew we needed that time together and was going to do whatever she could to make it happen, so that's what she did. Now this year we do them on ISE days (instructional support and enhancement days) and we have longer to meet. We have a notebook and she has in there what we are to discuss during our time together. It's not a free for all. She gives us goals for the meeting, we take notes, and she goes back and reads them. Everything is goal oriented here. I truly mean this. Our school makes the scores we do because of Mrs. Riddle. She believes that every student can learn and deserves the right to be loved and accepted. She supports us and encourages us and because of that, we all believe it now too. She is so involved and not 
afraid to ask for help so we do too. She leads us and 95\% or more of us follow her lead. She knows the DIBELS scores for the whole school so you better believe I know the scores for my class” (transcripts, March 27, 2009).

I reviewed three of the grade level binders, kept in the principal's closet. There was one three inch binder per grade level containing hand written notes in response to guiding questions presented by the principal (field notes, April 7, 2009).

One fifth grade teacher reflected on Mrs. Riddle’s modeling and monitoring and said, "It is so different from other schools. If you come to school and the administration is squashing you down, you don't want to work as hard. When you come to work and you are supported and appreciated and the administration works as hard as you, it makes you want to work harder and put forth more effort" (transcript, April 30, 2009).

The music teacher supported this teacher's feelings in saying, "She definitely makes every minute count. When we have any kind of teachers meeting, it is usually geared towards closing that gap. Any kind of in services that we do has a lot to do with us being educated, not only to learn how we can reach them academically, but also how we can close the achievement gap that there might be and learning more about our students' way of life and it has really become her mission to that. So, it is working obviously” (transcript, March 27, 2009).

As an instructional leader, the principal at Valley Elementary provided professional development to the staff, modeled expected behaviors and interactions and monitored student progress. In modeling a calm, dedicated demeanor, the staff felt supported and encouraged, which was evident in their interviews, and my observations of their work. The principal commented on the importance of modeling behavior, 
"The feedback I get constantly from student teachers, and substitutes is that we have the most helpful staff. People are so willing to answer questions, ask what I need, and if they can help. They step in when they see kids misbehaving, those kinds of things. And I sometimes forget that but that's part of who we are. I would like to believe that that has to start at the top. I wonder if we would be that way towards each other if I wasn't” (transcripts, May 8, 2009).

As an instructional leader, Mrs. Riddle put student learning first and involved teachers in monitoring student learning. She connected this instructional leadership to all of her administrative duties as she built a culture of collaboration and individualized instruction for students. She provided the professional development to support teacher growth as well as the administrative monitoring to ensure its application.

Principal's Role as a Community Liaison

To develop positive cultures, principals become more than instructional leaders in the school, they become moral leaders who can build positive cultures that support learning communities (Peterson, 2002). As a community liaison, the principal supported a community of learning and collaboration between parents, teachers and children. One teacher commented that, "There are a lot of things that make this school tick and I believe the principal, the secretary, the janitor, we all work together. We treat each other with respect. I don't see a line that says, 'well we are the professionals, and you are not'. You know like the aides. Mrs. Riddle has them all involved working with the children. Whenever we have staff development or anything like that she invites them, and they become a part of what we do like our study groups. We just did the RTI study group and the aides were part of 
it as well. She believes they are so much a part of the school. She believes that they (the aides) are to know what we are doing and be a part of it” (transcripts, March 27, 2009). Numerous teachers addressed the topic of Mrs. Riddle supporting a positive, learning community as they discussed her support and engagement of teachers. One fifth grade teacher stated,

“The administration is behind the teachers $100 \%$. The teachers actually feel like he or she is on a level place here with the principal. Our ideas are listened to, discussed, taken for their value, maybe adapted in some way, but the good points are there. Whereas the school that I came from, it was a hierarchy, and you knew that the principal was the level above you, and if there was discussion about how can we improve the school, the principal wanted no discussion, and he just said, 'No, it is my decision.' Even though it was put into faculty senate and should have been discussed, it was like, I don't want to say dictatorship, too strong of a word, but machinations were totally different with that school than this school. This one, I know my efforts are appreciated. I know that whatever my concerns are they will not be taken lightly” (transcript, March 30, 2009). Another teacher noticed increased collaboration in the school culture since Mrs. Riddle became principal. She said,

"I have seen a change in the climate here since she has been head of the helm. Because she is very teacher friendly. She doesn’t mince words and gets to the heart of the matter when things need to be addressed. She has really made this place a more pleasant place to be, for the students, and for the teachers. She is calm, and so are we then. We will work through any issues together so that’s nice” (transcript, March 27, 2009). A third grade teacher gave an example of Mrs. Riddles’ ability to facilitate a learning 
community in which decisions are made by the majority and not by one person.

"We talked with the principal about hallway behavior at the end of last year because we thought the kids were too noisy in the halls. So we set up a system whereby the kids really want to earn these compliments from the teachers and principal. Did you hear her announcement this morning? If you get a compliment from another teacher or principal, for hallway behavior, you send it to the office, and the principal reads it on the intercom and puts it in the barrel. Then on Fridays the principal has a drawing, and the class that wins, Mrs. Riddle comes up to the room and gives them the principal's award, and she sits and talks to them and reads a book to them and interacts with them. They love it. On Friday in our class they were just, crossing their fingers that their name gets called. And the older kids like it too" (transcripts, March 27, 2009).

The Valley Elementary School principal retold this story in an interview when she was talking about the importance of a learning community.

"We ended last year reflecting on what we would like to change, what should be improved. The teachers said, and I totally agreed, that we needed to work on hallway noise during transitions between classes. So we came up with this idea that we would have a compliment jar. We would publically recognize classes every morning and then at the end of the week we would recognize the winning group” (transcript, May 8, 2009). I also observed the principal engage with parents as part of the learning community. She strived for parents to be involved in the education of their children in whatever capacity they felt comfortable. She was very forthcoming with parents and had to have difficult or uncomfortable conversations with them to provide what she felt to be the most appropriate service for the student. I observed the principal waiting in the school entry way to hold a difficult conversation 
with a parent. In order to go on the fifth grade trip, parents have to be an "approved volunteer". One of the questions on this sheet, written by the county office personnel, was "Have you been convicted of any felonies?" It was reported by one student that her mother said that was "none of the school's business”, and she was not going to fill out the paper. Mrs. Riddle said the child was "noticeably upset" all day the day before. The principal greeted the parent by her first name while holding the parent volunteer form. Mrs. Riddle said, "Angela said you were upset by some questions on this form." The mom said, "I don't want to be a volunteer, so I ain't going." Mrs. Riddle said, "You don't have to be a volunteer, we will not call and ask you to come help out, you just have to fill this out to be able to ride the bus for the fifth grade trip." The parent quickly completed and turned in the form (field notes, April 7, 2009).

Faculty reflected on the principal's ability to facilitate a positive learning community among teachers, parents and students. A third grade teacher said, "I am not naive, there are maybe two people who are here for the paycheck. They might not put in 10 to 12 hours days like many of us, but when they are here, they work and do what's right for the kids. Mrs. Riddle would have it no other way. We work together here. She will support and motivate them because it is all about the kids” (transcript, March 27, 2009).

The school counselor said, "You can get the bitch sessions going in the teachers' lounge and that can pull down the whole morale of this building. But Mrs. Riddle squashes that. She immediately addresses the problem. Everyone knows she is taking care of it. People feel like she is doing everything she can to validate and hear their concerns. We are all in this together and must work together” (transcript, March 27, 2009). 
The music teacher summed up the learning community based on modeling, monitoring and collaboration when she said,

"She (the principal) is on top of her game. She fore thinks long before we do and she prepares us for it. Mentally, physically, whatever it takes to get her staff all onboard, working together. She really does try to be flexible. People like me are always coming in, with an idea can I do this or can I do that? She hears us, she listens, and she tries to work with everybody’s needs around here. I see that she is shaping us every day, you know, with the different things she is doing. You have a lot of different personalities here, you know, but we have to work together. She handles us all, including me” (transcript, March 27, 2009).

\section{Principal's Role as a Child Advocate}

I observed the principal at Valley Elementary perform administrative duties such as scheduling. I observed the principal at Valley Elementary act as an instructional leader through providing necessary professional development, modeling and monitoring teacher and student performance. I also observed her serve as a liaison between stakeholders in the facilitation of forging a community of learners. All of these roles were built upon the foundation of doing what she felt was "best for kids" (field notes, May 22, 2009). As a child advocate, the principal reflected upon what is best for the children and acted accordingly.

I observed the principal make decisions that created more work for her, but were in the best interest of the child. The fifth grade classes were having a difficult time with arguing and teasing classmates. The principal and one of the school counselors decided to combat these issues proactively by holding a weekly “class meeting.” These class meetings were co-led by the principal and the counselor. The teacher remained in the room for the discussion as well. The 
counselor was absent for one of these class meetings yet the principal led the group alone. She said it was important for the students to be able to rely on a consistent schedule as well as the adults in their lives (field notes, April 7, 2009).

While speaking with the school's dental hygienist, she spoke of the role the principal played in maintaining the once grant funded dental program at the school when the grant funding subsided. The hygienist said the principal, “approached, well, hounded” the county office personnel until they continued to fund the program in lieu of the grant. The hygienist said, "she (Mrs. Riddle) knows how important it is for these kids to have their basic needs covered and fights for it” (field notes, April 3, 2009).

During another observation, the principal was summoned by the teacher for children with behavior disorders. The principal and I walked to the classroom to find a child sitting off to the side of the room with the teacher for students with behavior disorders. The child was sitting on the floor, spitting with his shoes off, ripping his socks. The principal knelt down to the child's eye level and said, "Tim what happened?" She listened to his story, continued to be at his eye level and asked, "What strategies do you have to help you calm down?" (Later the principal told me that she asked him this in front of the teacher because it is an area that needs improvement in that class, and the teacher should teach more strategies, therefore, Mrs. Riddle wanted to model this brainstorming of strategies in front of the teacher. In addition, Mrs. Riddle's intercession most likely helped the student.) The principal stepped away from the student and spoke with the other two students in the room, putting her hand on each of their heads as she stood over their seats and spoke with them. Before leaving the room Mrs. Riddle walked back to Tim, knelt down and said, "Are you feeling any calmer?" The student responded with no words, only a visual cue of two fingers, his first finger and thumb, and held them about one inch apart 
indicating a little bit calmer. The principal assured him he would get his lunch, and she would come back to check on him (field notes, April 27, 2009). In this situation, the principal modeled how she expected the teacher to interact with the student, was not distracted by his spitting or tearing of clothes, and calmly engaged the student in techniques of de-escalation so that he could complete his day at school. By the end of the day, the principal had followed up on the behavior of this student three times, each time speaking calmly with him and recognizing any positive choices he had made. She told me that she realized it would have been easier to just send Tim home for his behavior, but school was the safest, best place for him so she was going to do whatever she could to keep him in that environment (field notes, April 27, 2009).

This involvement with individual students included the mental and physical well being of the children as well. During one of my visits, Mrs. Riddle was called to the nurse's office to witness an inspection of bruises on a child's body. A third grade student had reported to the nurse that she was bruised because her foster parents physically abused her. Mrs. Riddle stood as a witness to the inspection, she documented the bruises, and she made a report to child protective services. Mrs. Riddle reported that during the previous school year, 14 families had children removed from the home and 10 had been removed thus far for the current school year (field notes, April 27, 2009). In another instance of acting in the best interest of the child's physical and mental health, Mrs. Riddle and I attended a counseling session with a girl whose parents were on trial for murder. The student's name was changed, and she was placed in foster care. The principal knew she was meeting with the school counselor at that time, and Mrs. Riddle wanted to check on the child's progress (field notes, April 27, 2009).

One teacher spoke of the principal's role as a child advocate when she said, “The administration is fantastic. I can compare because I have been in four different schools. The 
principal here and the administration truly cares about the kids, and the kids know that” (transcript, March 30, 2009). Mrs. Riddle reflected on her own desire to serve as a child advocate when she said,

"I think my role is to make sure that we always remain first and foremost for the students, our main purpose is to understand the needs of the kids and the families and to maintain that. Model it for everyone else on the staff. We have our days when we get frustrated and yeah that kid is on my last nerve, however, let’s step back and be grateful that our own kids are not going through what these kids are going through. And the day I lose that I need to leave” (transcript, May 22, 2009).

\section{Key Interactions of Findings}

Data were collected and analyzed to investigate the research question: What role does the principal of one elementary school play in shaping a school culture that fosters academic achievement of students with high incidence disabilities? Five components of the culture in the school that were foundational supports for student success included: rituals, collaboration, an individualized instructional focus, community and social emotional support. Data also supported four additional findings related to the roles the principal played to develop, support, and enhance each of the components of school culture. The roles of the principal were as follows: serving as an administrator, an instructional leader, a community liaison, and a child advocate. One would be remiss to conclude that the school culture and the roles of the school principal operate without interacting, therefore, key interactions among the nine findings were entered into a matrix. The matrix framework, found in Appendix G, was used as a visual display to organize the interactions among findings. 
The most influential interactions as represented by the data were the convergence of four of the five components of the culture of Valley Elementary with the two of the four principal's roles. At Valley Elementary, the principal most strongly served as an instructional leader and administrator. Through these two roles, she provided the most influence over the culture through engagement in rituals, collaboration, instruction, as well as, the focus on social emotional and physical well being of the students. This is not to say the remaining two roles of the principal and the one remaining element of school culture were not important, but the most influential components based the analysis of the data were her engagement in the roles of an instructional leader and administrator who supported rituals and collaboration with a focus on instruction and the social emotional, and physical well being of her students.

Instructional leadership affects the culture. The principal's impact as an instructional leader was evident in the areas of rituals, collaboration, instruction and social emotional and physical support in a multitude of ways. For the purpose of this research, an instructional leader was defined as providing professional development, modeling expected behavior, and the monitoring of instructional practices and the academic and behavior progress of students. As an instructional leader, the principal assured that the school rituals have a link to academics. For example, the GOLD star assemblies were recognitions of academic and behavioral achievements. The fifth grade anchor's away dinner and the fifth grade graduation ceremony were tributes to the academic and behavior performance of the students during their tenure at Valley Elementary. Even the daily rituals, such as morning announcements, highlighted positive classroom behavior and the recognition of school wide accomplishments. 
As an instructional leader, the principal also fostered a culture of collaboration at the school. It was clear that the school depended on all parties to work together to support the students and their learning. One teacher summarized this instructional leadership in saying, “There are a lot of things that make this school tick and I believe the principal, the secretary, the janitor, we all work together. We treat each other with respect. I don’t see a line that says, 'well we are the professionals, and you are not'. You know like the aides. Mrs. Riddle has them all involved working with the children. Whenever we have staff development or anything like that she invites them, and they become a part of what we do like our study groups. We just did the RTI study group and the aides were part of it as well. She believes they are so much a part of the school. She believes that they (the aides) are to know what we are doing and be a part of it” (transcripts, March 27, 2009).

During another interview, Mrs. Riddle clearly discussed her role as an instructional leader who impacts the collaborative culture of the school as an "instructional change agent”. She spoke with me about how the “excellent hallway behavior” ritual that grew out of a pre-existing program at the school, which is the basis of many of the daily, weekly and monthly rituals of the school: the GOLD star program. She presented the scenario in which she was guiding a discussion with her staff as they reflected on the school year's strengths and areas for improvement. The teachers were concerned about the behavior of students in the hallway, therefore, the principal and staff worked collaboratively to devise a plan to meet their needs (transcript, May 8, 2009).

Would the collaborative nature of this school culture be as prominent if it were not for the instructional leadership of Mrs. Riddle? I observed her on numerous occasions teaching adults and students the necessary components of collaboration. She facilitated discussions with key 
players to make decisions impacting the school. I observed her facilitating a discussion with the fifth grade class, and she listened carefully to suggestions as to how to improve the school. Students, teachers, parents, and staff were all considered part of the school culture (field notes, March 27, 2009; field notes, April 7, 2009).

As an instructional leader, Mrs. Riddle encouraged appropriate instruction for students as she set standards of instruction for all students and teachers. Every teacher at Valley Elementary was expected to to focus on instruction of skills both academic and behavioral. This was clear to not only the classroom teachers, but also teachers of extracurricular classes, such as music and physical education. These teachers understood the expectation of academics being interwoven into physical education and music classes, and the teachers integrated academics into their instruction. Both teachers commented that Mrs. Riddle made it clear that educating children is the job of the entire school, including them. The physical education teacher stated that, “ I have to intervene even as a gym teacher. Mrs. Riddle expects me to address academics” (transcript, March 27, 2009).

Mrs. Riddle also extended her role as an instructional leader to promote the third key component of Valley’s school culture: individualized instruction. I observed her as she planned professional development focusing on meeting the individual needs of each student. In debriefing with Mrs. Riddle about the importance of individualized instruction she said, “Meeting a child’s individualized instructional needs is what is best for every child so that is what we must do here. It may be more work for us, but that doesn't matter. I will give my teachers every support I have available to make sure this happens. I am not naive, I know that not everyone feels as strongly about this as I do, that is why I have to get into the classrooms and monitor, reinforce, and model. You have to give as must 
support as you give pressure to your teachers and they will make it happen” (transcripts, May 22, 2009).

Mrs. Riddle’s instructional leadership, focusing on individualized instruction, was evident from the first day of school when students were sent home with the school's yearly calendar. The first page of the agenda book contained a letter from Mrs. Riddle and a list of the school's core beliefs stating, "instructional leadership is a catalyst for success” and that "all students should be held to high, challenging standards” (artifact review, March 27, 2009).

The principal's role as an instructional leader also strongly impacted the culture of concern for a child's social emotional, and physical wellbeing. I observed Mrs. Riddle take an active role in investigating and supporting the wellbeing of students. She co-led a weekly "fifth grade class meeting” in which the students talked openly with she, the counselor, and the teacher about issues, such as appropriate behavior, anger management, drug use, and transitioning to another grade. Mrs. Riddle also commented on her role in getting teachers to understand what children were going through, but to still hold the students to a high standard. She commented that she guided her staff to understand that they must be cognoscente of situations occurring in a child's life, such as abuse or neglect, but still "expect them to follow rules and complete work, we may just need to give them more support than normal and understand that we may see more acting out than usual” (field notes, April 29, 2009). During an interview the principal again spoke to her role as an instructional leader who instills in the staff the need to consider the social emotional, and physical well being of the students.

"Well I guess, you could say that you meet their basic human needs, which is the family part, you have to start there before learning can occur." "I think my role is to make sure that we always remain first and foremost for the students, our main purpose is to 
understand the needs of the kids and the families and to maintain that. Model it for everyone else on the staff." "And the day I lose that I need to leave” (transcript, May 22, 2009).

The principal's role as an instructional leader was interwoven in the culture framework of Valley Elementary through rituals, collaboration, individualized instruction and concern for the social emotional, and physical well being of the students. As the principal modeled her expectations for students, parents and staff, she also monitored and supported others within the culture to assure that they were acting within the guides set forth through the school culture.

Administrative decisions affect the culture. In addition to being an instructional leader, the principal at Valley Elementary also performed a plethora of administrative duties. For the purpose of this research, an administrator was defined as creating the school schedule, enforcing policy, enlisting personnel, assigning roles, and other administrative jobs. It was evident through the application of the data matrix that as she completed these administrative duties, to build the components of school culture evident at Valley Elementary.

As an administrator, the principal impacted the school rituals as she scheduled their occurrence, assigned the roles of participants within the ritual, and sent notifications to those who were expected to attend. Without those key components would the ritual occur at all? The principal also followed through to make sure that the rituals actually occur as scheduled. For example, each morning Mrs. Riddle recognized classrooms with appropriate hallway behavior. If she was absent for a day, she had all of the information prepared and hanging by the loud speaker so that the school secretary could lead the ritual with consistency (field notes, May 22, 2009). Another example of Mrs. Riddle’s administrative duties supporting the implementation of rituals was the weekly newsletter that she distributed to the school staff called the "Friday 
Focus”. This newsletter was distributed via email to all faculty and staff to alert them of upcoming events, areas of concern, and recognitions of personnel (artifact review, March 27, 2009).

In addition to scheduling rituals, Mrs. Riddle also built time in the school's master schedule for teacher collaboration. The administrative duty of scheduling time in the master schedule for teachers to meet with one another and to discuss student achievement and instructional methodology directly supported the collaborative nature of the school culture. In addition to arranging time for the teachers to meet, Mrs. Riddle monitored the content of these meetings as the teachers completed an agenda and meeting notes for each collaborative teaming meeting. The notes were reviewed by Mrs. Riddle and were kept in binders in the principal's office (artifact review, April 27, 2009; transcript, March 27, 2009).

As an administrator, the principal supported the instructional focus of the school culture by scheduling, organizing, and delivering professional development based on meeting the individual needs of all students, as well as, making time in the master schedule for individualized instruction to occur. For example, I attended training on the response to intervention model with Mrs. Riddle. As the training progressed, she analyzed each component of what was presented and weighed its implementation fidelity within the school. Immediately upon being trained, Mrs. Riddle began to apply the content to her school and teachers, analyzing what further training they needed, changes in the schedule, and how she would deliver this new material to the teachers (transcripts, March 27, 2009; field notes, March 27, 2009).

The roles of the school administrator as defined in this research include crafting schedules, enforcing policy, and enlisting personnel. Mrs. Riddle fulfilled these roles as a means of supporting appropriate instruction for every student at Valley Elementary School. She crafted 
a master schedule that contained response to intervention tiered instructional times, quarterly benchmarking using acuity and writing roadmap, as well as, times to analyze the data collected through this type of instruction and assessment (field notes, May 22, 2009). While enforcing the policy of teacher evaluation, Mrs. Riddle assessed teacher performance as it pertained to instruction. I accompanied Mrs. Riddle on two teacher observations mandated by WV policy. She shared with me her comments on each of the observations and commented on her belief of giving teachers direct and specific feedback on their performance. For example, on one teacher's observation she noted how the teacher complimented students on appropriate behavior rather than reprimanding inappropriate behavior. Mrs. Riddle also complimented one teacher on her ability to engage all students in the activity (field notes, April 27, 2009). Although Mrs. Riddle was following policy, she used the mandatory observation sessions to reinforce what she saw as appropriate instructional techniques for children.

Finally, the principal also applied her administrative role to support a culture in which a child's social emotional and physical well being were addressed. The role of an administrator seems very policy driven and schedule oriented. Mrs. Riddle created a schedule that included time for group, individual, and class counseling. Once a week a small group of girls were scheduled into group counseling, the fifth grade class has a "fifth grade class meeting" that was built on the foundation of group counseling and individual students were scheduled into individual counseling sessions with the school counselor.

The principal also encouraged her staff to write grants to enhance the social emotional and physical well being of the students and used her administrative resources to support such initiatives. A grant at the school funded the dental hygiene program, the after school program, and additional individual counseling from an outside agency. I also observed the principal meet 
with the school counselor and outside agency social worker as they applied for a continuation of a mental health grant for the school (field notes, April 27, 2009). If grants were not available, Mrs. Riddle worked with the limited resources a school principal has to find the support systems needed for children. One example was the use of school funds to purchase 22 pair of shoes for the physical education teacher to keep so that students without proper physical education attire would not be penalized (field notes, April 20, 2009). Another example of her using her administrative role to assist in the support of the wellbeing of the children is the clothes closet. The clothes closet was open on a scheduled basis and is manned by volunteers. The clothes closet offered clothes, toys and school supplies for children in need (field notes, March 30, 2009).

\section{Summary}

The purpose of my study was to investigate the administrative impact in creating a school culture that fosters achievement of students with high incidence disabilities. Data were collected and analyzed to investigate the research question: What role does the principal of one elementary school play in shaping a school culture that fosters academic achievement of students with high incidence disabilities? My findings included five components of the culture in the school that are foundational supports for student success including: rituals, collaboration, an individualized instructional focus, community and social emotional support. Data also supported four additional findings related to the roles the principal plays to develop, support, and enhance each of the components of school culture. The roles of the principal were as follows: serving as an administrator, an instructional leader, a community liaison, and a child advocate.

The five components of school culture evident at Valley Elementary were documented through structured interviews, unstructured interviews, observations, artifact reviews, and a focus 
group. The cultural characteristics found especially evident in the core beliefs of the school which were posted in every classroom as well as in the office. The beliefs were:

- "All students can learn and succeed

- All students should be held to high, challenging standards

- Instructional leadership is a catalyst for success

- Students, parents and school personnel are supportive partners in the learning process

- Technology is a tool that can enhance learning

- Community-School partnerships promote ownership and strengthen the school

- Students should be engaged in a learning environment that is safe, welcoming, and promotes character building" (artifact review, March 27, 2009).

Through the facilitation of a school culture that fosters achievement of students with high incidence disabilities, the principal displayed four roles including being an administrator, instructional leader, community liaison, and child advocate. These four roles were conveyed to parents in a letter written by the principal and presented as a front page in each student's planner on the first day of school. The letter read,

"The theme for this year is Making a Difference One Minute at a Time. Our highly talented staff is prepared to meet the educational, physical, and emotional needs of growing children. Valley offers a variety of programs, activities, and services to ensure that our students develop to their maximum potential. We hope that you will take advantage of the many opportunities that are available. I look forward to meeting and working with all of you. Please feel free to stop in and watch us as we begin our journey for learning" (artifact review, March 27, 2009). 
Principals improve schools by building a culture that encourages effective instructional practices and offers avenues for communication and support for faculty. Effective principals facilitate discussions of instructional strategies and student performance and provide supports such as student assistance teams, professional development and data tracking (Anfara, Roney, \& Mahar, 2003). 


\section{Chapter V}

Conclusions and Discussion

\section{Introduction}

The purpose of my study was to investigate the administrative impact in creating a school culture that fosters achievement of students with high incidence disabilities. Data were collected in a variety of methods including interviewing persons within the culture, observing the daily operations of the school, and analyzing artifacts and documents from the school culture. Results indicate that five foundational supports were evident in the school culture. These included: (1) rituals, (2) collaboration, (3) an individualized instructional focus, (4) community and (5) social emotional support. Intermingled with these five elements of the culture, data also supported four roles the principal played to develop, support, and enhance each of the components of school culture. These roles of the principal were: (1) serving as an administrator, (2) assuming the role of the school's instructional leader, (3) acting as a community liaison, and (4) becoming a child advocate.

Qualitative data analysis occurred on three levels beginning with a thick, rich description, presented in a narrative format and extending to the second level of coding data into emerging themes presented within the context of the study. This resulted in a visual representation of a matrix that highlighted the interactions of these findings. In this chapter, the third level of qualitative data analysis of “making inferences” based on the data collected (Merriam, 2009, p. 188), and interpreting the data through a theoretical framework that connects and extends the current literature on the principal's role in influencing a school culture is outlined. Also, possible implications for schools and recommendations for future research will be shared.

\section{Theoretical Framework}


A theoretical framework includes the "assumptions, expectations, beliefs and theories” that are the foundation for all research (Merriam, 2009, p.66). While building a theoretical framework, researchers should bracket their beliefs and explicitly articulate the lens with which the research is being conducted. Although researchers strive to present unbiased data, qualitative data analysis includes a lens with which all observations, interviews and interactions are filtered. Researching and presenting one's theoretical framework is the first step in reducing the impact of researcher bias.

In examining my lens I realized, due to my life experiences, the success or failure of a school community was something of great interest to me. I was a teacher of students with disabilities for eight years prior to working as a college professor and currently as a regional Director of Special Education. As a teacher, my experience with five different principals highlighted the impact a principal has on the inclusion, exclusion, and success or failure of students with disabilities. These experiences shaped my future research in the area of administration and school culture and led to the following question: How can a principal shape a culture of success and inclusion for students with disabilities? I researched and reflected on this question throughout my administrative coursework and doctoral studies and led me to complete a case study of one school culture that fosters high achievement for students with high incidence disabilities.

"Because human beings are the primary instrument of data collection and analysis in qualitative research” (Merriam, 2002, p. 214), qualitative researchers begin with a clear presentation of their beliefs including the lens with which they view the phenomenon they are studying. Making the researcher aware of their beliefs through bracketing, therefore, allows for a less biased interpretation of results (Merriam, 2002). As I embarked on the current study I 
maintained an awareness of the lens with which I viewed the school and the underlying belief that I uncovered by bracketing my beliefs; that the actions of the principal indirectly effect the performance of students, including those with disabilities. With this in mind, I sought to strengthen confirmability through additional interviews and observations throughout the data collection period (Merriam, 2009). I also actively sought to uncover disconfirming evidence that contradicted my initial codes and developing themes and patterns. For example, the principal reported that coplanning sessions occur weekly, therefore, an artifact review was conducted as I reviewed the coplanning documentation binders kept by the principal. Following this artifact review, I observed two coplanning sessions to ensure that what was being reported to me through interviews and what is being documented through teacher notes was actually occurring. The documentation corroborated her statement, and the fidelity of program implementation was evident.

After examining any assumptions, expectations and beliefs brought to the research, I began to build a foundation of theories from which results were analyzed. The work of Schein (2004) and Deal and Peterson (1998) informed the theoretical framework under which data were analyzed and specifically focuses on school culture and the principal's role in creating effective school cultures . School culture for this study was defined as, "the underground stream of norms, values, beliefs, traditions, and rituals that builds up over time as people work together, solve problems, and confront challenges. This set of information, expectations and values shapes how people think, feel and act in schools” (Deal and Peterson, 1998, pg. 28). Furthermore, Schein (2004, p. 25-26) states that organizational cultures are comprised of three levels: "artifacts, espoused beliefs and values, and underlying assumptions.” 
Schein (2004) states that artifacts are the attributes of a culture that an observer can hear or see upon entering the culture. Upon entering Valley Elementary, I could see the school pride as I walked through the halls to see glass cases and bulletin boards prominently displaying the honoraries of school of excellence and blue ribbon school (field notes, April 20, 2009). I also reviewed artifacts that included the school mission, which was posted in every room, the school office and within each student's agenda and clearly supported the core belief that all students will learn and collaboration is expected (artifact review, March 27, 2009). Driving past the school, the school marquee read, "Valley Elementary Making a Difference One Minute at a Time” (field notes, March 27, 2009). This theme was apparent physically throughout the school, including a wonderful wooden and glass display case prominently displayed and filled with clocks and the words, “Making a Difference One Minute at a Time” (field notes, April 20, 2009). Schein's second level of understanding school culture was investigated by understanding the espoused beliefs from which the values of the culture have derived. Schein (2004, p.28) states that, “all group learning ultimately reflects someone’s original beliefs and values, their sense of what ought to be.” Through interviews, but most importantly being a participant observer, I was afforded the opportunity to speak with members of the culture and examine how their personal beliefs we influenced by Mrs. Riddle’s leadership. When investigating the values and beliefs within this school culture, key evidence was uncovered in an interview with Mrs. Riddle. In this interview she discussed how she personally had a transformation from being a teacher at Valley to the principal at Valley. Initially, as indicated in the quote below, she watched and observed much of the culture without making many changes during her first year as principal, 
"I had worked in this school for so many years as a teacher and I knew that could work for or against me. I really wanted to take advantage of that. Now that I was the principal, I had the opportunity to get into classes and see things I couldn't see when I was in my own classroom. I could see what programs were broken and needed tossed out, which ones needed tweeked and which ones we needed to build. I soon perfected the art of listening to comments and concerns of my staff and we started acting on them” (transcript, May 22, 2009).

During this first year, Mrs. Riddle made observations, monitored and modeled the level with which her own values and beliefs corresponded with those exhibited in the school. She evaluated the importance of existing programs and their impact on the education and culture of Valley Elementary.

Mrs. Riddle began to model the strategies she expected her staff to employ when they interacted with parents, students, and one another. One teacher spoke of the principal's leadership and modeling of expected behavior,

"She cares for every child in this school, and she wants to see them succeed. She is here for the children. The same thing, she has that bar up here. She doesn't lower it. She expects everyone else to do the same, so we do. And, without that leadership, you wouldn't set your bar so high. She does do that; she expects you to expect” (transcript, March 27, 2009).

Mrs. Riddle believed that all students should be held to high expectations, afforded good instruction, and that their basic needs should be met. These beliefs were evident in her actions as she sought to develop the basic assumptions of the culture by exerting and attempting to “influence the group to adopt a certain approach” through collaboratively solving problems and 
engaging teachers to address the unattended needs of students (Schein, 2004, p. 28). These beliefs and basic assumptions serve as the foundation of Schein's (2004) third level of culture. These assumptions are developed when espoused beliefs and values have been successfully implemented and continue to provide positive outcomes. The basic assumptions at Valley Elementary are built upon the espoused beliefs that Mrs. Riddle applied through program development including the 3 school wide programs highlighted in this study; the GOLD star program, collaborative planning times, and an extended day program. As these programs were successful implemented and maintained, their underlying purposes became basic assumptions of the culture; high expectations, meet the needs of all students including their "basic needs" so that learning can most effectively take place.

To begin the GOLD star school wide discipline program, Mrs. Riddle and a team of teachers visited a school in Ohio who currently implemented one such program. Mrs. Riddle said, "I knew we had to do something to improve student behavior. The kids needed to value and appreciate that they come to school to learn” (field notes, May 22, 2009). Mrs. Riddle worked with the faculty to create buy-in for the new discipline program and customized the GOLD star program to meet the needs at Valley Elementary school (transcript, May 22, 2009). Mrs. Riddle and the staff all reflect on the benefits and challenges of the GOLD star program yearly and continually make improvements (transcript, May 8, 2009). Mrs. Riddle suggests the “excellent hallway behavior” ritual grew out of the GOLD star program. She presented the scenario below in which she was guiding a discussion with her staff as they reflected on the school year's strengths and areas for improvement. The teachers were concerned about the behavior of students in the hallway, therefore, the principal and staff worked collaboratively to devise a plan to meet their needs (transcript, May 8, 2009). 
A third grade teacher reiterated this reflective discussion during her interview in saying, "We talked with the principal about hallway behavior at the end of last year because we thought the kids were too noisy in the halls. So we set up a system whereby the kids really want to earn these compliments from the teachers and principal. Did you hear her announcement this morning? If you get a compliment from another teacher or principal, for hallway behavior, you send it to the office, and the principal reads it on the intercom and puts it in the barrel. Then on Fridays the principal has a drawing, and the class that wins, Mrs. Riddle comes up to the room and gives them the principal's award, and she sits and talks to them and reads a book to them and interacts with them. They love it. On Friday in our class they were just, crossing their fingers that their name gets called. And the older kids like it too” (transcripts, March 27, 2009).

In addition to implementing a school wide discipline program that set high expectations for students, Mrs. Riddle also instituted collaborative planning times and coteaching in her second year as principal. This change aligned with her beliefs that students' needs should be the focus and supports to meet these needs should be embedded throughout the school in a variety of ways. Mrs. Riddle stated that, "people have to learn to work cooperatively” and that it took time for her to teach her staff to do so (transcript, May 8, 2009). "We have to work as a team. No one person can know all of the best strategies. If a child is falling behind, we have to intervene immediately. It’s not ok for one child to not learn to read or write” (transcript, May 8, 2009). During the first year of collaboration she was ready to "throw in the towel." She would create agendas for the collaboration meetings and the notes would come back with comments like “Title I needs to take Jimmy and Suzie.” Though frustrated, Mrs. Riddle continued to modify the agenda and look for more frequent opportunities for collaboration (transcript, May 8, 2009). 
"I spent a summer in my mind trying to figure out how that was going to work (team meeting times into the schedule) and I came up with a plan but it was so new and foreign to the teachers. Initially these GOLD star meetings, teachers didn't come, they stayed and met with one another. I had the whole student body myself (in an assembly) so that they (the teachers) could have coplanning. I had the whole school and a couple of helpers that was it, aides, and the PE teacher. It worked well and it was an hour at least. I put so much time in making the agenda, getting the presenter, giving them a protocol to follow, I spent hours on these agendas to make sure they were zeroing their coplanning conversations in on the right thing. The notebooks (from the coplanning meetings) would come back to me and I would read the minutes and I would want to cry. I used to think I would give up. I spent endless hours getting ready for these meeting and I am over there in an assembly with 300 kids by myself! I cannot be everywhere and this is all the teachers did? I would think to myself, these teachers don't get it (how to have team planning). I would tweak my wording on the agenda for the next month and I would get things back to me like 'Title I needs to take Jimmy and Suzie' and so on. That was our mindset in education for so many years. Honest to god, I was ready to throw in the towel but I knew this (the way teachers coplan) had to change. I didn’t give it up, I persisted” (transcript, May 8, 2009).

Because of her personal belief that educating children should be collaborative in nature, Mrs. Riddle continued to monitor and modify the collaboration time agendas. As she persisted, the teachers began to accept Mrs. Riddle’s belief in collaboration as well.

“Here we are seven years later and we are still doing it (collaboration). We do it on ISE days now, I had to change my format because it became too difficult to manage all of 
those kids myself and my help dwindled, and I ran out of money to pay for programs and couldn't find any more free programs. I couldn't just give them a half an hour though. If you are just going to give them a half an hour to sit and talk, you're cheating them. So I moved away from the assemblies to using ISE (instructional support and enhancement) days, two hour delay days. The gentlemen whose idea this was, I ran into him and I told him I was ready to quit and I told him why. He was great, he said ‘Don’t quit, you have made great progress. Don't give up it takes time. You need to get out and drop in to those meetings.' I told him I couldn’t I was watching 300 kids. He said you have to get yourself out of there, can't anybody else do that (watch the kids at the assembly)? I said I don't think so, I can't put that on anyone else. So we thought about the times changing etc. The format did not. I would never drop that” (transcript, May 8, 2009).

According to Mrs. Riddle, as the teachers accepted the importance of collaborative planning, they began to use the time more efficiently and effectively.

"For seven years they have been having these once a month we call them Team Level Collaboration Meetings (TLC) they have been doing this for seven years. Also, this year for every grade level that had a team teacher, they have two additional planning periods a week so that they can work together, beyond their standard planning period. A voice in my head said 'you can't ask people to team if you don't give them time to talk and to plan'. They will come back at you and say how could we team if we don't have the time in our schedule? They are so sophisticated at it now because they started this concept seven years ago but it took time and it took me not giving up. The notebooks, that you read, they are three inches thick full of agendas and documentation. I take time to get these all ready and put them on the table, the teachers pick them up and return them when 
they are done. I read them and they know it. I would tell a young administrator not give up. If you really believe that an idea is good, and you believe in it, don't give up. If you persist with it, it all works out” (transcript, May 8, 2009).

She continued to monitor the meeting notes from the collaboration meetings and give constructive feedback (artifact review, April 27, 2009). After seven years of continued implementation, support and monitoring, the collaboration meetings are driven by data based decision making which is the foundation for individualized instructional planning for all students in the school, including students with disabilities. The teacher of students with learning disabilities said,

"I believe that what we do is to really work to meet the needs of the student. We look at research. We look at what works. We very much work off of each other with like grade level meetings and things like that. (We ask each other) What ideas do you have? What ideas do I have? What has worked for you? I think there is a lot of, just through the course of the year, talking to the teacher what the students have had in the year previous also find characteristic and what has worked for them” (transcript, March 30, 2009). During three of the initial formal interviews of the study, teachers mentioned the use of coplanning time and the effectiveness of the planning time. The principal also spoke with me about the evolution of the master schedule that supported coplanning. I observed coplanning sessions on three occasions, and each observation was comprised of the same key players and a similar agenda. The teachers followed the agenda closely and took notes of the meeting which were turned into the principal. The teachers made decisions concerning the selection of the students who would be in specific intervention groups for the following week. Intervention groups were derived from student performance on the school system wide benchmark 
assessments. Both grade level teachers presented their benchmark assessment results and students who were the lowest performing. During one collaboration period, the interventionist said, "will you put their DIBELS data in my box so I know where to start” (field notes, April 29, 2009). Mrs. Riddle reflected on her staff's ability to coplan in stating, “They are so sophisticated at it because they started this concept seven years ago but it took time and it took me not giving up” (transcript, May 8, 2009).

The GOLD star program and the team level collaboration meetings (TLC) supported Mrs. Riddle’s belief that high expectations must be set for all students. Continued success through these two programs solidified the beliefs into cultural assumptions. A third program, the afterschool "anchor” program also reflected and embraced the core beliefs that a child's basic needs must be met before learning can occur. The "anchor" program is a grant supported after school program that began in 2004 and provides enrichment, homework assistance, wellness, and nutrition for students at Valley Elementary. During one interview Mrs. Riddle spoke of the need to consider the social emotional, and physical well being of the students.

"Well I guess, you could say that you meet their basic human needs, which is the family part, you have to start there before learning can occur." "I think my role is to make sure that we always remain first and foremost for the students, our main purpose is to understand the needs of the kids and the families and to maintain that. Model it for everyone else on the staff.” “And the day I lose that I need to leave” (transcript, May 22, 2009).

The anchor program afforded students the opportunity to stay after school and rotate through the weekly stations of: snack and tooth brushing, homework time, technology lab and gym (two times a week), the public library, enrichment including drama, music, hands on science, field 
trips, karate, cooking, art, and community service. Following the anchor program, students were transported to a nearby church for dinner before being transported home for the evening (field notes, April 8, 2009). Mrs. Riddle’s beliefs were evident to her staff. The hygienist said, “she (Mrs. Riddle) knows how important it is for these kids to have their basic needs covered and fights for it” (field notes, April 3, 2009).

In reviewing the 3 levels of culture presented by Schein, it is evident that the principal's personal beliefs have shaped the school culture. Her belief that although a student's basic needs must first be met, all students should be held to high expectations, and teachers should work collaboratively to support students in achieving these goals was applied to school wide programs that fostered increased student success. Her beliefs were visibly evident in bulletin boards, the school marquee and mission statement. Mrs. Riddle modeled her expectations and beliefs from the onset of her prinicipalship and these core values became more explicit as she began instituting school wide programs in her second year. These programs are still in place and the underlying purpose of the programs has become embedded into the daily fabric of the school culture as the underlying assumptions are "unconscious, taken for granted beliefs, perceptions, thoughts and feelings,” (Schein, 2004, p. 25-26) that guide the mission fo the school.

\section{Extension of Current Literature}

Current literature supports the views that positive school cultures reflect a common mission, and the collective members work hard to achieve the goal of increased student achievement (Anfara, Roney, \& Mahar, 2003). Recent research suggests that schools with a

positive culture also create a community where colleagues discuss instructional practices to focus on attaining success for every student (Carrington \& Elkins, 2002). These three components of school culture were evident at Valley Elementary School (Schein, 2004) and included a mission 
statement to "provide educational opportunities that will enable each student to build a foundation of success” (artifact review, March 27, 2009). This mission statement is provided to parents in the daily agenda and is posted in every classroom. A pivotal word in this mission statement is the word “each”. Upon entering classrooms and intervention groups at Valley, I could not discern which students were students with disabilities and which were not. These tier groups were not exclusively for students in the general education population, they were for students displaying difficulty on a specific topic or skill, regardless of any special education label they may carry (field notes, April 28, 2009). This data coupled with the improved WESTEST scores suggest that Valley had been successful in developing inclusive school change by creating a school culture that embraces all learners by providing targeted instruction to meet their individual needs. This was evident as teachers discuss instructional practices and focused on success for every student. Therefore, this study has the potential to add to the literature base on how a principal can positively impact school cultures. At Valley Elementary, the principal's role as instructional leader and administrator supported the development of the culture and five components essential components of school culture: (1) rituals, (2) collaboration, (3) an individualized instructional focus, (4) community and (5) social emotional support. As an administrator and instructional leader, Mrs. Riddle allotted time in the master schedule for teacher collaboration and monitored the collaborative time through meeting agendas and minutes. She was also an instructional leader who continuously wanted to improve her faculty. She did this by offering suggestions after observing her teachers and monitoring appropriate instructional practices in an effort to improve student learning. In addition, she took the time to learn about inclusive strategies such as coteaching and response to intervention that could help 
move the school towards the purpose outlined in the school mission,. In order for these ideas to take root, Mrs. Riddle tapped into the collaborative nature of the faculty.

Current research on inclusion practices report that to implement effective inclusionary practices, such as a tiered instructional program in the model of response to instruction, special education teachers and general education teachers must come together in a learning community to meet the needs of all students (Ferguson et al., 1998). Much of the research on response to intervention is theoretical in nature. While there have been findings on single students or groups of students and the positive effects of response to intervention, there is limited published research based on school wide implementation of response to intervention practices, and its impact on students with disabilities as a group within the school culture. One of the selection criteria for this research was to find a school with above average performance of students with high incidence disabilities as measured by high stakes assessments. Valley Elementary is in their third year of building a structure of response to intervention implementation. During this study, the data suggested that the four roles of the principal and five components of school culture supported inclusive practices including tiered instruction that is the foundation of the response to intervention model. When asked about building an RTI program Mrs. Riddle said,

“Three years ago, I had this idea over the summer that I was going to start teaming Title I and special education people in the general education classrooms for the core. I think I had heard that this was going to be a movement coming down the road. They did that for a year and the next year was when the tier groups started. I figured, 'Well, that first part worked and is a comfortable shoe now so let's try the next part.' I try to sell everything to them like 'here's what's in it for you.' So now we are really into our third year of implementing the pieces of RTI. Soon each piece became a comfortable fit and now they 
are not afraid of it. When we need to work on next, is to truly become an RTI team that is prepared for special education referrals. We have been dabbling in that part but in my opinion have not been doing it as well as we could” (transcript, May 8, 2009).

Mrs. Riddle’s early preparation and enduring persistence has supported a response to intervention framework built upon teacher collaboration and data based decision making. As the teachers continue to develop these “comfortable fits,” Mrs. Riddle applies another component of response to intervention.

Furthermore, research has examined schools with positive school cultures that effectively promote student achievement. Schools with high minority and poverty rates were part of the effective schools research of the 1980s that presented broad "attributes" of high performing schools. The schools were studied because of their high minority and poverty rates, as well as, their level of adequate or above student achievement. It was found that these effective schools expected quality and equity, provided research based professional development programs, and used data based decision making when planning instruction (Lezotte \& Bancroft, 1985). This research became the springboard for many school reforms in the late 1980s and 1990s under the premise that effective schools are lead by an instructional leader, have a clear mission, and high expectations. This research, however, had limited association with the performance of students with disabilities. The data presented in this study supported many of the findings of the effective schools research, including principal role in monitoring of staff performance, professional development based on staff need, frequent benchmarking, involvement of the staff in decision making, parent involvement, multileveled instruction, extended school day, and inclusion. In this study, however seeks to extend the effective school research by studying a school based on the performance of students with high incidence disabilities. Students with disabilities in the 
effective schools research targeted for inclusion were students with mild to moderate mental impairments. However, the focus of their schooling was participation in the general education environment not student achievement that is expected in today's schools.. Today, according to federal law and local policy, students with disabilities must have access to and make progress in the general education environment to the greatest extent possible (Unites States Department of Education, 2002; United States Department of Education, n.d.; West Virginia Department of Education, 2007).

This study confirms much of Barbara Sizemore’s seminal study of three high achieving schools in Pittsburgh, Pennsylvania whose enrollment was predominantly African American. (Sizemore, 1985). She cited 12 strategies employed by the school principal that foster a culture based on student achievement:

1. increased student responsibility for attendance and discipline

2. daily visits by the principal to monitor teacher and staff performance

3. professional development based on evaluation of teachers and staff

4. frequent benchmarking of student achievement in reading and mathematics

5. staff involvement in decision making

6. parent involvement

7. the office was "central business command post”

8. multileveled instruction in reading and mathematics

9. extended school day that included tutoring opportunities

10. use of materials or programs in addition to county issued textbooks

11. inclusion of students with mental impairments (the only disability category included in the study) to the greatest extent possible 
12. selectivity in the types of programs instituted within the school

Of Sizemore's 12 findings, all were present at Valley Elementary with the exclusion of “inclusion of students with mental impairments." The principal prided herself in being in the classrooms to monitor student performance and instructional fidelity. She also presented plans for program improvements to parents, student and teachers to increase involvement in decision making. The RTI tiered instruction groups were prime examples of multileveled instruction in reading and math, but yet again, they included all students, even those with high incidence disabilities. The principal was very selective as to which programs would be instituted in the school, however one of the three major programs employed was an after school program which was also evident in Sizemore's work. Based on the comparison of data collected through this study to Sizemore's findings, it can be inferred that the 12 strategies employed by the school principal to foster a culture based on student achievement in a school with high poverty and minority should also be considered in a school to foster high achievement of students with high incidence disabilities.

\section{Implications for Practitioners}

Mrs. Riddle has been a part of the culture of Valley Elementary for 29 years, serving as the principal since the 2000 - 2001 school year. When she spoke with me about her first years as a principal, she said that she spent much of her first year observing and modeling her expectations. She then began to review programs and determine means of school improvement. "I push myself to stay on top of programs. If we believe this program is good and bought into it, I think the worst thing an administrator can do is let it dwindle down to nothing.” She went on to say that, "When I came into the job I promised people and myself that I would pare down things and choose a handful of the best stuff and really stick to it and do them well. For myself, to live 
with myself I have to honor what I said and I am going to” (transcript, May 8, 2009). Since she assumed the role of principal, Mrs. Riddle initiated three programs: a school wide discipline program, coteaching and teacher collaboration, as well as an after school program. The increased academic achievement of students with high incidence disabilities during this same time cannot be ignored. Mrs. Riddle spoke of how she spent her first year as a principal assessing the school's current state of operation including the programs and procedures in place. She also spoke of how the school wide programs have been reflected upon yearly and improved; so has the achievement data of students with high incidence disabilities.

Every school culture has components that support its growth; both positive and negative. School administrators should reflect upon the cultures of their own schools and compare their development to that presented in this and other research. Fellow researchers could use the framework of this study to replicate a case study of another school whose achievement of students with disabilities is above or below average and investigate the nature of the culture and the principal.

In their review of 40 studies of the principal's role in school effectiveness, Hallinger and Heck (1996) found that 30 of them related school effectiveness to the principal's ability to be an instructional leader. Blase and Blasé (1999) surveyed 809 teachers asking them to describe characteristics of their principals that directly improve student achievement. Their data supports instructional leadership practices of supporting teacher reflection and supporting the professional growth of teachers. Based on the interaction of the nine findings in this study, I also believe that principals must most importantly be sound in their administrative practices and first and foremost focus on being instructional leaders whenever possible. These two administrative characteristics applied to four of the five areas of school culture including rituals, collaboration, 
instruction and the well being of students were key to the success of students with disabilities in this culture. For example, when Mrs. Riddle completed administrative tasks such as completing a school schedule, she did so with an instructional focus; she developed a schedule which supported teacher collaboration time. Mrs. Riddle assured that rituals had an instructional focus, for example, GOLD star celebrations were based on student goal attainment. These areas of interaction may be a place for current administrators to begin analyzing their own school cultures for areas of improvement. Current principals should analyze the instructional focus of current practices within their schools.

\section{Limitations of the Study}

Case study research methodology provides an in depth look into one group and findings are specific to that group. While the findings in this study are an extension to current literature, one must always take into consideration that the outcome is based on one school with a specific group of personnel and a specific principal. What is successful in one environment, while at its core may be applicable to other environments, should never be overlaid into an existing school culture and be expected to flourish.

While case study research provides an in depth study of one environment, it is virtually impossible to observe every “critical event” occurring within the sample (Patton, 2004, p. 563). Extending the length of the study would have allowed for an observation of additional events at the school, however, it would still be impossible to observe every "critical event” in the environment.

Finally, case study research is dependent upon observations as documented by the researcher and participant reporting (Patton, 2004). In order to reduce the impact of researcher 
or participant bias, substantial measures of triangulation and disconfirming evidence were elicited.

\section{Recommendations}

Recommendations for future research. Future researchers could replicate the methodology of this study to investigate other schools whose students with high incidence disabilities are succeeding. Findings of a replica study of school culture and principal characteristics could be compared and used to support future application to policy and practice. A researcher could also study a culture in which students with high incidence disabilities are not performing at adequate levels as per state achievement data and determine the components of school culture that are lacking.

This study focused on one research question relating to the school culture and how the principal created that culture; therefore findings were narrowly focused. Future research should be conducted with principals who foster cultures proven to be effective for students with high incidence disabilities and the skill sets they employ to build that culture. For example, what specific coursework did the principal find applicable to building effective school cultures? What skill sets did they enter the field with and what skill sets were they lacking. Common responses across multiple cultures in which students with disabilities are achieving could enhance current administrator preparation programs.

Suggestions for policy and practice. Through this research, two key characteristics were found to substantially interact with the components of school culture that supported success of students with high incidence disabilities; administrator and instructional leader. Institutions of higher education who prepare future principals may want to review their program content to ensure that emphasis is placed on concrete factors supporting effective administrative practices, 
such as designing schedules to include time for collaboration. Principals to be may need to experience the difficulty of a simulated school schedule to create a schedule that supports time for collaborative planning and problem solving. Many components of the positive culture found at Valley Elementary School supporting the achievement of students with high incidence disabilities were contingent upon the master schedule providing time for rituals, individualized instruction, and collaboration to occur.

Additionally, the importance of the principal understanding current instructional practices is a key component of effective instructional leadership because to ensure effective instruction for all students, including students with disabilities, the school principal must facilitate professional development and monitor instructional practices. If principals are unaware of current best practices in instruction, they cannot effectively monitor instructional practices. Policy makers should consider requiring principals to maintain their licensure by attending professional development on a periodic basis. The focus of the professional development would be on best instructional practices and monitoring procedures.

According to Kouzes \& Posner (2002), successful leaders model, inspire a shared vision, challenge the process, enable others, and lead from the heart. All of these characteristics were emulated through Mrs. Riddle. She modeled how she expected persons within the culture to engage with one another and monitored their progress in doing so. Over her tenure as principal, she inspired a shared vision that all students will learn at Valley Elementary and that all teachers will work together to make that happen. She challenged the process as she engaged her teachers, students and parents in to reflecting on how to improve the school and the workings within the school such as the afterschool program, the school wide discipline program, and response to intervention. She enabled her teachers and students as she provided them with the professional 
development necessary to understand and implement instructional practices that support the academic achievement of all students. Finally, she led with the heart as she acted upon what she perceived to be best for the student, even though it may have been more difficult for her. These characteristics of effective leadership were the backbone of Mrs. Riddle’s effectiveness, and should be a focus of instructional preparation for future administrators and areas of continual monitoring for practicing administrators. I must question if the school would have been as effective for students with high incidence disabilities if Mrs. Riddle did not believe a in individualized instructional focus, collaboration, community and the social emotional well being of the students. If she did not encourage others from the heart and inspire a shared vision through enabling others and modeling would the school be as successful?

While limited in scope to one school, Valley Elementary and to one principal, Mrs. Riddle, this study underscores the importance of the key elements of effective schools established in the research literature to achievement of students with high incidence disabilities. This study documented the key roles of a principal as an administrator and instructional leader in influencing a positive school culture. I think the factors of effective school leadership and instructional support in a positive climate explain the above average performance of students with high incidence disabilities on high stakes testing. 


\section{References}

Anfara, V., Roney, K., \& Mahar, R.(2003). Painting a school portrait with data: One middle school's attempt at school improvement. Chicago, IL: American Educational Research Association. (ERIC Document Reproduction Service No. ED478068)

Barnett, K., \& McCormick, J. (2004). Leadership and individual principal-teacher relationships in schools. Education Administration Quarterly, 40(3), 406-434.

Blase, J., \& Blase, J. (1999). Principals’ instructional leadership and teacher development: Teachers’ perspectives. Education Administration Quarterly, 35(3), 349-378.

Bradley, R., Danielson, L., \& Doolittle, J. (2005). Response to intervention. Journal of Learning Disabilities, 38(6), 485-486.

Burns, M., Vanderwood, M., \& Ruby, S. (2005). Evaluating the readiness of pre-referral intervention teams for use in a problem solving model. School Psychology Quarterly, 20(1), 89-105.

Chen, G. (2007). School disorder and student achievement: A study of New York City elementary schools. Journal of School Violence, 6(1), 27-43.

Clubine, B., Knight, D., Schneider, C., \& Smith, P. (2001). Opening doors: Promising lessons from five Texas high schools. Washington, DC: Department of Education. (ERIC Document Reproduction Service No. ED465000)

Council for Exceptional Children (2008). Position on response to intervention (RtI): The unique role of special education and special educators. Retrieved November 3, 2008, from http://www.cec.sped.org

Carrington, S., \& Elkins, J. (2002). Comparison of a traditional and an inclusive secondary school culture. The International Journal of Inclusive Education, 6(1), 1-16. 
Danielson, L., Doolittle, J., \& Bradley, R. (2005). Past accomplishments and future challenges. Learning Disabilities Quarterly, 28, 137-139.

Deal, T., \& Peterson, K. (1999). Shaping school culture: The heart of leadership. San Francisco, CA: Jossey-Bass.

Ferguson, D., Meyer, G., Dalmau, M., Droege, C., Ferguson, P., et al. (1998). Reinventing schools research project: Collaborative research project on the merger of general and special education. Eugene, OR: University of Oregon. (ERIC Document Reproduction Service No. ED460443)

Ferri, B., \& Connor, D. (2005). Tools of exclusion: Race, disability, and (re)segregated exclusion. Teachers College Record, 107(3), 453-474.

Fuchs, L., \& Fuchs, D. (2006). What is scientifically-based research on progress monitoring? Retrieved June 7, 2006, from National Center on Student Progress Monitoring Web site: http://www.studentprogress.org

Fuchs, D., \& Fuchs, L.(2005). Responsiveness to intervention: A blueprint for practitioners, policymakers and parents. Teaching Exceptional Children, 35(1), 57-61.

Fullan, M. (2002). The change leader. Educational Leadership, 59(8), 16-20.

Friend, M., \& Bursuck, W.(2002). Including students with special needs: A practical guide for classroom teachers. ( $3^{\text {rd }}$ ed.). Needham Heights, MA: Allyn and Bacon.

Gaffney, M., Higgins, N., McCormack, J., \& Taylor, N.(2004, July). Developing a more positive school culture to address bullying and improve school relationships: case studies from two primary schools and one intermediate school. Report to the Ministry of Social Development, Children’s Issues Centre.

Garner, P., Faggella-Luby, M., \& Fritschmann, N.(2005). An overview of responsiveness to 
intervention: What practitioners ought to know. Topics in Language Disorders, 25(2), 93-105.

Goddard, Y., Goddard, R., \& Tschannen-Moran, M.(2007). A theoretical and empirical investigation of teacher collaboration for school improvement and student achievement in public elementary schools. Teachers College Record, 109(4), 877- 896.

Graham, P. (2007). Improving teacher effectiveness through structured collaboration: A case study of a professional learning community. Research in Middle Level Education Online, 31(1), 1-17. Retrieved September 30, 2008, from Academic Search Complete database.

Hall, S.(2008). A principal's guide: Implementing response to intervention. Thousand Oaks, CA: Corwin Press.

Hallinger, P., \& Heck, R. (1996). Reassessing the principal's role in school effectivebness: A review of empirical research. Educational Administration Quarterly, 32(1), 5-44.

Heacox, D.(2002). Differentiating instruction in the regular classroom. Minneapolis, MN: Free Spirit Publishing.

Hoover, J., \& Patton, J.(2008). The role of special educators in a multitiered instructional system. Intervention in School and Clinic, 43(4), 195-202.

Kouzes, J., \& Posner, B. (2002). The leadership challenge ( $3^{\text {rd }}$ ed.). San Francisco: CA: Jossey Bass.

Kowal, P. (2002). Vertical teaming: Making connections across levels. Middle Ground, 6(1), $1-4$.

Levine, T., \& Marcus, A.(2007). Closing the achievement gap through teacher collaboration: Facilitating multiple trajectories of teacher learning. Journal of Advanced Academics, 19(1), 116-138. 
Lezotte, L., \& Bancroft, B.(1985). School improvement based on effective schools research: A promising approach for economically disadvantaged and minority students. The Journal of Negro Education, 54(3), 301-312.

Lezotte, L, \& Bancroft, B.(1985). Growing use of the effective schools model for school improvement. Educational Leadership, 42(6), 23-27.

Leithwood, K, Seashore, K., Anderson, S., \& Washistrom, K. (2004). Review of research: How leadership influences student learning. New York: The Wallace Foundation.

Lindsay, G.(2007). Educational psychology and the effectiveness of inclusive education/mainstreaming. British Journal of Educational Psychology, 77, 1-24.

Mamlin, N. (1999). Despite best intentions: When inclusion fails. The Journal of Special Education, 33(1), 36-49.

McGregor, G., \& Vogelsberg, R.(1998). Inclusive schooling practices: Pedagogical and research foundations. Pittsburgh, PA: Allegheny University. (ERIC Document Reproduction Service No. ED306368)

McNamara, K., \& Hollinger, C.(2003). Intervention-based assessment: Evaluation rates and eligibility findings. Exceptional Children, 69(2), 181-193.

Mellard, D. (2004). Understanding responsiveness to intervention in learning disabilities determination. Retrieved June 7, 2006, from http://www.nrcld.org/publications/papers/mellard.shtml

Merriam, S.(2002). Qualitative research in practice: Examples for discussion and analysis. San Francisco, CA: Jossey-Bass.

Merriam, S. (2009). Qualitative research: A guide to design and implementation. San Francisco, CA: Jossey-Bass. 
Miles, M., \& Huberman, A.(1994). An expanded sourcebook: Qualitative data analysis (2 ${ }^{\text {nd }}$ ed.). Thousand Oaks, MD: Sage.

Moore, C., Gilbreath, D., \& Maiuri, F.(1998). Educating students with disabilities in general education classrooms: A summary of the research. Eugene, OR: Western Regional Resource Center. (ERIC Document Reproduction Service No. ED419329)

National Association of State Directors of Special Education, Inc.(2005). Response to intervention: policy considerations and implementation. Alexandria, VA: Author.

National Center for Response to Intervention.(n.d.). What is rti? Retrieved October 1, 2008, from http://www.rti4success.org

National Joint Committee of Learning Disabilities.(2005, June). Responsiveness to intervention and learning disabilities. Retrieved June 5, 2006, from http://www.ncld.org

Nind, M., Shereen, B., Kieron, S., Collins, J., \& Hall, K. (2004). Methodological challenges in researching inclusive cultures. Educational Review. 56(3), 259-270.

Patton, M. (2002). Qualitative research and evaluation methods (3 ${ }^{\text {rd }}$ ed.). Thousand Oaks, CA: Sage.

Peterson, K. (2002). Positive or negative? Journal of Staff Development, 23(3). Retrieved September 19, 2006, from http://www.nsdc.org

Peterson, K. (1999). River of values and traditions can nurture or poison staff development hours. Journal of Staff Development, 20(2). Retrieved September 19, 2006, from http://www.nsdc.org

Peterson, K., \& Deal, T. (2002). The shaping school culture fieldbook. San Francisco, CA: Jossey-Bass.

Peterson, K., \& Deal, T. (1998). How leaders influence the culture of schools. Educational 
Leadership, 59(8), 28-30.

Peterson, K, Feen, H., Tamor, L., Silagy, M., Gibson, R., et al. (2001). Whole schooling: A study of schools linking inclusive education and school reform in urban and rural communities research project. Detroit, MI: Wayne State University. (ERIC Document Reproduction Service No. ED479813)

Prasse, D. (2006). Legal supports for problem-solving systems. Remedial and Special Education, 27(1), 7-15.

President's Commission on Excellence in Special Education. (2002, July). A new era: Revitalizing special education for children and their families. Retrieved June 6, 2006, from http://www.ed.gov/pubs/edpubs.html

Pritchard, R., Morrow, D., \& Marshall, J (2005). School and district culture as reflected in student voices and student achievement. School Effectiveness and School Improvement, 16(2), 153-177.

Quiambao, J. (2004). An analysis and comparison of school culture with academic achievement of middle school students with specific learning disabilities. Unpublished doctoral dissertation, University of Central Florida, Florida.

Rammer, R.(2007). Call to action for superintendents: Change the way you hire principals. The Journal of Education Research, 101(2), 67-76.

Reeves, D. (Ed.). (2007). Ahead of the curve: The power of assessment to transform teaching and learning. Bloomington, IN: Solution Tree.

Riehl, C. (2000). The principal's role in creating inclusive schools for diverse students: A review of normative, empirical and critical literature on the practice of educational administration. Review of Educational Research, 70(1), 55-81. 
Sailor, W., \& Roger, B. (2005, March). Rethinking inclusion: Schoolwide applications. Phi Delta Kappan, 503-509.

Schein, E. (2004). Organizational culture and leadership ( $3^{\text {rd }}$ ed.). San Francisco, CA: Jossey Bass.

Seaton, M., Emmett, R., Welsh, K, \& Petrossian, A. (2008). Teaming up for teaching and learning. Leadership, 37(3), 26 -29.

Sergiovanni, T. (1984, September). Leadership and excellence in schooling: Excellent schools need freedom within boundaries. Educational Leadership, 4-13.

Sergiovanni, T. (1982, February). Ten principles of quality leadership. Educational Leadership, 330-336.

Sizemore, B. (1985). Pitfalls and promises of effective schools research. The Journal of Negro Education, 53(3), 269-288.

Skrtic, T., Harris, K., \& Shriner, J. (2005). Special education policy and practice: Accountability, instruction and social challenges. Denver, CO: Love.

Somson, B. (2007). The early learning success initiative. Educational Leadership, 65(2), 42-43. Spradley, J (1980). Participant observation. Fort Worth, TX: Harcourt College Publishers. Stainback, S., \& Stainback, W. (1997). Inclusion: A guide for educators. Baltimore, MD: Brookes.

Stine, D. (2000, April). The opening of a new high school: The emergence of a culture. Paper presented at the annual meeting of the American Educational Research Association, New Orleans, LA.

Strahan, D. (2003). Promoting a collaborative professional culture in three elementary schools that have beaten the odds. The Elementary School Journal, 104(2), 127-146. 
Strahan, D., Carlone, H., Horn, S., Dallas, F., \& Ware, A. (2003). Beating the odds at Archer Elementary School: Developing a shared stance toward learning. Journal of Curriculum and Supervision, 18(3), $204-221$.

Turnbull, A., Turnbull, R., \& Wehmeyer, M. (2007). Exceptional lives: Special education in today’s schools. Columbus, $\mathrm{OH}$ : Pearson.

United States Department of Education .(2002). No child left behind: A desktop reference. Jessup, MD: Education Publication Center.

United State Department of Education. (n.d.). Building the legacy: IDEA 2004. Retrieved September 1, 2008, from http://idea.ed.gov

University of Texas System / Texas Education Agency. (2004). 3 - tier reading model:

Reducing reading difficulties for kindergarten through third grade students. Austin, TX: Author.

Welding, J. (1996). In-class support: A successful way of meeting individual student need? Support for Learning, 11, $113-117$

West Virginia Department of Education. (2008). Characteristics of tiers at elementary levels.

Retrieved November 1, 2008, from http://wvde.state.wv.us.us/ose/RtI.html

West Virginia Department of Education. (2008b). West Virginia education information system.

Retrieved January 15, 2009, from http://wveis.k12.wv.us/nclb/pub

West Virginia Department of Education. (2008c). SETLA tiered instruction- July 16, 2008.

Retrieved January 15, 2009, from http://wvde.state.wv.us/ose/RtI.html

West Virginia Department of Education. (2007). Policy 2419: Regulations for the education of students with exceptionalities. Retrieved September 4, 2008, from http://wvde.state.wv.us/osp/policy2419.html 
Wright, P. (2004). 20 U.S.C. 1414 evaluations and IEPs. Retrieved November 1, 2008, from http://www.wrightslaw.com

Yell, M., Katsiyannas, A., \& Shiner, J. (2006). The no child left behind act, adequate yearly progress, and students with disabilities. Teaching Exceptional Children, 38(4), 32-39.

Zigmond, N., \& Baker, J. (1996). Full inclusion for students with learning disabilities: Too much of a good thing? Theory into Practice, 35(1), 26-34. 
Principal's Role in Shaping School Culture 167

Appendix A

Letter from School System Superintendent 


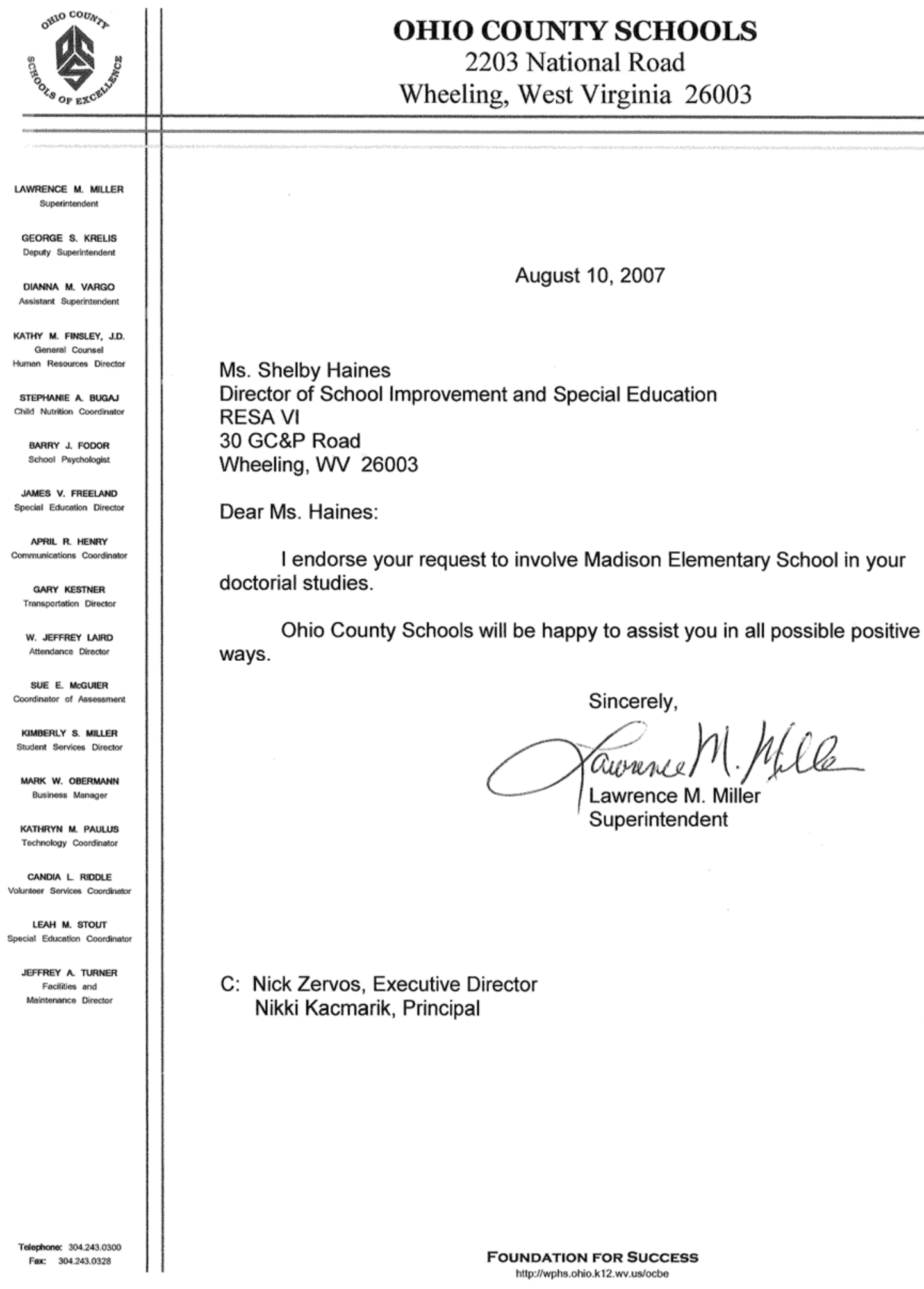


Principal's Role in Shaping School Culture 169

Appendix B

Institutional Review Board Exception Letter 
From: <wvuecomp@wvu.edu>

Date: March 27, 2009 9:51:10 AM EDT

To: <bludlow@mail.wvu.edu>, <shaines3@mix.wvu.edu>

Subject: BRAAN2: IRB Protocol Marked as Exempt

The following IRB Protocol has been marked as Exempt.

Tracking \#: H-21613

PI: Ludlow, Barbara

Title: How One Principal Influences a Culture that Fosters Higher Achievement of Students with High Incidence Disabilities: A Case Study

The BRAAN2 website can be accessed by clicking the following link: BRAAN2 Login 
Principal's Role in Shaping School Culture 171

\section{Appendix C}

Cover Letter for Research Participants 


\section{Department of Special Education WestVirginiaUniversity:}

College of Human Resources and Education

Dear Participant,

This letter is a request for you to take part in a research study to review how one principal influences a culture that fosters higher achievement of students with disabilities. This project is being conducted by Shelby Haines in the Department of Special Education at WVU with supervision of Dr. Barbara Ludlow, a professor in the College of Human Resources and Special Education, for a Doctoral Degree in Special Education.

Your participation in this project is greatly appreciated and will take approximately 30 minutes to complete an interview. Your involvement in this project will be kept as confidential as legally possible. Interviews will be recorded using a digital recording device. The audio files of these interviews will be kept on the researcher's secure computer and, following transcription, will be deleted from the computer. All transcribed interview data and back-up copies of the interviews will be shredded five years following the study. All data will be reported in the aggregate. You must be 18 years of age or older to participate. I will not ask any information that should lead back to your identity as a participant. Your participation is completely voluntary and there will be no penalty if you choose not to participate. You may skip any question that you do not wish to answer and you may discontinue at any time. West Virginia's University's Institutional Review Board acknowledgement of this project is on file.

I hope that you will participate in this research project, as it could be beneficial in understanding the impact that the principal has on shaping the culture of one school. Thank you very much for your time. Should you have any questions about this letter or the research project, please feel free to contact Shelby Haines at (304) 639-3949 or by e-mail at shaines@access.k12.wv.us or Dr. Barbara Ludlow at (304) 293-3835 or by e-mail at bludlow@mail.wvu.edu.

Thank you for your time and help with this project.

Sincerely,

Shelby Haines 


\section{Department of Special Education WestVirginiaUniversity.}

College of Human Resources and Education

Dear Participant,

This letter is a request for you to take part in a research study to review how one principal influences a culture that fosters higher achievement of students with disabilities. This project is being conducted by Shelby Haines in the Department of Special Education at WVU with supervision of Dr. Barbara Ludlow, a professor in the College of Human Resources and Special Education, for a Doctoral Degree in Special Education.

Your participation in this project is greatly appreciated and will take approximately 45 minutes to participate in a parent focus group. Your involvement in this project will be kept as confidential as legally possible. Interviews will be recorded using a digital recording device. The audio files of these interviews will be kept on the researcher's secure computer and, following transcription, will be deleted from the computer. All transcribed interview data and back-up copies of the interviews will be shredded five years following the study. All data will be reported in the aggregate. You must be 18 years of age or older to participate. I will not ask any information that should lead back to your identity as a participant. Your participation is completely voluntary and there will be no penalty if you choose not to participate. You may skip any question that you do not wish to answer and you may discontinue at any time. West Virginia's University's Institutional Review Board acknowledgement of this project is on file.

I hope that you will participate in this research project, as it could be beneficial in understanding the impact that the principal has on shaping the culture of one school. Thank you very much for your time. Should you have any questions about this letter or the research project, please feel free to contact Shelby Haines at (304) 639-3949 or by e-mail at shaines@access.k12.wv.us or Dr. Barbara Ludlow at (304) 293-3835 or by e-mail at bludlow@mail.wvu.edu.

Thank you for your time and help with this project.

Sincerely,

Shelby Haines

509 Allen Hall PO Box 6122 Morgantown, WV 26506-6122 SPED@mail.wvuedu

Phone: 304-293-3450 Fax: 304-293-6834

Equal Opportunity / Affirmative Action Institution 
Principal's Role in Shaping School Culture 174

\section{Appendix D}

Interview Protocols 


\section{Structured Interview with Teachers and Principal}

School Culture - "Culture is the underground stream of norms, values, beliefs, traditions, and rituals that builds up over time as people work together, solve problems, and confront challenges. This set of information expectations and values shapes how people think, feel, and act in schools“(Deal and Peterson, 1998, p.28).

1. How long have you been a part of the faculty at Valley?

2. Describe the school culture of Valley Elementary School.

3. How has the school culture changed over that time period?

4. What happened that influenced this shift in the culture?

5. What are the strengths of the culture of Valley Elementary?

6. How could the school culture of Valley Elementary be improved?

7. What role do you feel the principal has in shaping the culture of a school?

8. What role do you feel teachers have in shaping the culture of a school?

9. How are parents involved at Valley Elementary?

10. Is there anything I have not asked about that you think I should know? 


\section{Parent Focus Group Topics}

1. Do you think Valley Elementary is a good school? Why or why not?

2. What do your children like and dislike about Valley Elementary School?

3. Tell me about some of the times you have interacted with the principal of Valley Elementary.

4. Is there anything I have not asked about that you think I should know? 
Principal’s Role in Shaping School Culture 177

\section{Appendix E}

Data Collection Summary Sheet 


\section{Summary Sheet}

\section{Type of contact:}

Person

Location

Date

Referenced from (pagination code here)

PAGE

KEY POINTS

CODE 
Principal's Role in Shaping School Culture 179

\section{Appendix F}

Code Manual 


\begin{tabular}{|l|l|}
\hline \multicolumn{1}{|c|}{ Code } & \multicolumn{1}{c|}{ Definition } \\
\hline Principal Role & \\
\hline PR -ADMIN & $\begin{array}{l}\text { (Principal's Role as an Administrator) The principal creates the school } \\
\text { schedule, enforces policy, enlists personnel and assigns roles and other } \\
\text { administrative jobs. }\end{array}$ \\
\hline PR-INST & $\begin{array}{l}\text { (Principal's Role as an Instructional Leader) The principal provides } \\
\text { professional development, models expected behavior and monitors } \\
\text { instructional practices and academic and behavior progress of students. }\end{array}$ \\
\hline PR-COMM & $\begin{array}{l}\text { (Principal's Role as a Community Liaison) The principal supports a } \\
\text { community of learning and collaboration between parents, teachers and } \\
\text { children. }\end{array}$ \\
\hline PR-CHAD & $\begin{array}{l}\text { (Principal's Role as a Child Advocate) The principal reflects upon what is } \\
\text { best for children and acts accordingly. }\end{array}$ \\
\hline School Culture & $\begin{array}{l}\text { (School Culture Rituals, Ceremonies) The procedures within the school } \\
\text { including celebrations and rites of passage. }\end{array}$ \\
\hline SC-RIT & $\begin{array}{l}\text { (School Culture Collaboration to meet student needs) All team members } \\
\text { including students and parents but most specifically teachers working } \\
\text { together to plan and deliver instruction based on student need. }\end{array}$ \\
\hline SC-COLL & $\begin{array}{l}\text { (School Culture Individualized Instructional Focus) Individualized instruction } \\
\text { based on specific needs of the student in the areas of behavior and academics. } \\
\text { This includes data based decision making. }\end{array}$ \\
\hline SC-INSTR & $\begin{array}{l}\text { (School Culture Social Emotional Physical Well Being) Being aware of what } \\
\text { students are going through in their home lives (drugs, murder, molestation } \\
\text { etc.), an overall concern for student welfare and offering available services } \\
\text { (counseling, clothing etc.) }\end{array}$ \\
\hline SC-COM & $\begin{array}{l}\text { (School Culture Community) - Parents, students, teachers and community } \\
\text { members take pride in working together to support the school as it serves as a } \\
\text { pillar of the broader community; a display of commitment to the school. }\end{array}$ \\
\hline
\end{tabular}

What role does the principal of one elementary school play in shaping a school culture that fosters academic achievement of students with high incidence disabilities? 
Principal's Role in Shaping School Culture 181

Appendix G

Research Question Matrix 


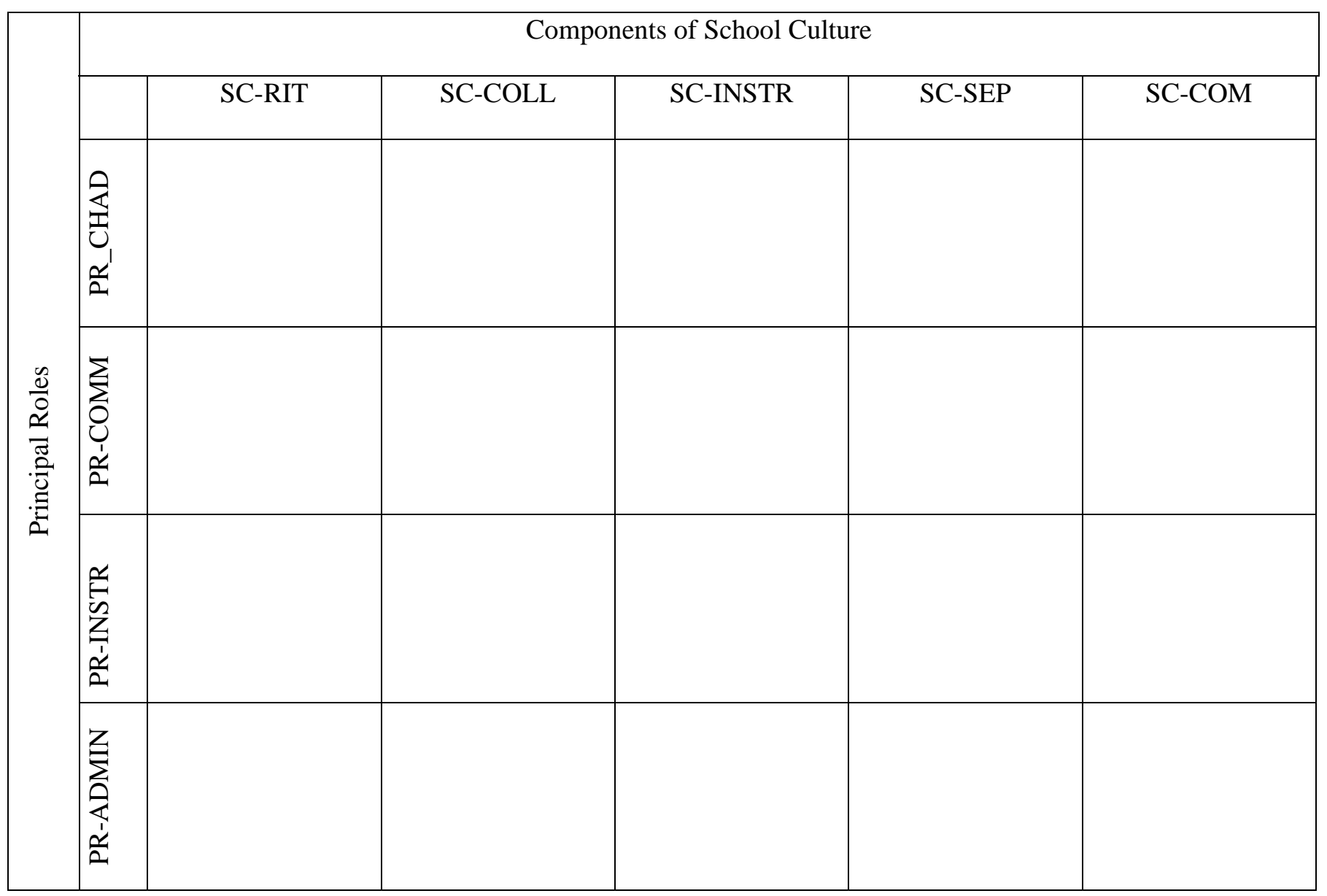

What role does the principal of one elementary school play in shaping a school culture that fosters academic achievement of students with high incidence disabilities? 
Principal's Role in Shaping School Culture 183

\section{Curriculum Vitae}




\section{Ms. Shelby B. Haines \\ 30 GC \& P Rd., Wheeling, WV 26041 \\ 304.231.3818shaines@access.k12.wv.us}

EDUCATI ON

- 2004 - Present Ed.D. Special Education, Educational Leadership,

West Virginia University, all coursework and exams complete

- 2004 Ed.S. School Psychology, Marshall University Graduate College

- 2004 Educational Leadership Certification, West Virginia University

- 1999 M.A. Specific Learning Disabilities K-12, West Virginia University

- 1996 B.A. Multi-Subjects K-8, Specific Learning Disabilities K-8, Mathematics 5-8

Bethany College

\section{PROFESSI ONAL}

EXPERI ENCE Director of Special Education Regional Education Service Agency 6

Spring 2007 - Summer 2009

- Collaborated with 5 County Region Special Education Directors

- Co-planned and Delivered the WVDE Special Education Teacher Leadership Academy

- WVDE Team Autism

- Provided Professional Development in the 5 county Region

o Autism Services

o Reading Instruction

o Behavior Intervention Planning and Modification

o $21^{\text {st }}$ Century Teaching and Learning

o Using Professional Learning Communities

Assistant Professor Bethany College Department of Teaching and Social Services

Fall 2006 - Spring 2007

- Advisor of the Special Education Club

- Advisor of the Literacy Club

- Developed online components for special education courses taught

- Partnership School Liaison with Wheeling Catholic Elementary School

- WVDE $21^{\text {st }}$ Century Skills conference

- Attendee at the Carol Toleman LETRS training

- Courses taught

o Exceptionalities and Diversity

- Assessment and Methods of Special Education

o Autism II

o The Special Education Process

o Supervision of student teachers 
Instructor

West Liberty State College Department of

Education

Fall 2004 - Summer 2006

- Special education coordinator

- Assessment committee; disposition survey, teacher work sample, portfolio assessments

- Multicultural committee; campus and community wide field day

- Advisor of the WLSC Council for Exceptional Children

- Restructuring of Special Education program to meet current policy requirements

- Developed online components for special education courses taught

- Co-developer of the annual Special Olympics field day

- Co-developer of the autism endorsement program

- Professional development school liaison with Bridge Street Middle School

- Courses taught

o Assessment and methods for students with mental impairments and learning disabilities

o Assessment and methods for students with behavior disorders

o Introduction to exceptionalities

o Classroom organization and management

o A freshman experience

o Foundations of education

\section{Consultant}

Brooke, Hancock, Ohio, and Marshall County Schools, Special Education Department

Fall 2004 - Present

- Psychological assessment and interventions

- Functional behavior assessments and intervention

- English as a second language assessment and intervention

- SIMS learning strategies

- Inclusion and co-teaching development and implementation

- Implementation of applied behavior analysis and collaborative problem solving

- McNinch Special Education Summer School Supervisor of Student Teachers

- Moundsville Junior High School SRA school wide reading initiative

- Reading strategies trainer including DIBELS and Wilson Language Systems

- First year teacher classroom management trainer

\section{Adjunct Teacher \\ Wheeling Jesuit University Department of}

Education

Fall 2004

- Courses taught

o Instructional strategies for teaching students with disabilities

o Methods of assessing students with disabilities 
Graduate Assistant

2001 - $2003 \quad$ Marshall University Graduate College

- School Psychology curriculum enhancement and presentation

- Dr. Fred Jay Krieg

Teacher of Students with Learning Disabilities, grades K - 6

1997 - $2004 \quad$ Marshall County Schools, Moundsville, WV

- Central Elementary Technology Coordinator

- County Continuing Improvement Plan for WV Special Education Department

- Central Elementary SAT team Coordinator

- INSTEP program completion and implementation

- PT3 program completion and implementation

- WV Department of Ed. School Wide Positive Behavior Support Cadre Member

- 2000 Central Elementary Teacher of the Year

- Marshall County Schools Wilson Reading Systems Pilot Program

- 2003 Council For Exceptional Children with Behavior Disorders National Presenter

- 2003 Council for Exceptional Children State Meeting Presenter

- Marshall County Schools “10 Commandments of Parenting” Presenter

- Faculty Senate Treasury and Vice President

- Parent Teacher Association President

- Multicultural Sensitivity Training County Representative

- Master Teacher for Wheeling Jesuit University

- Mentor, Marshall County Schools beginning teacher mentor program

- Alternative Education School Psychologist Grades 7-12

Teacher of Students with Learning Disabilities, grade 8 1996 - $1997 \quad$ Winchester City Schools, Winchester, VA

- Self contained classroom for students with learning disabilities

- Extended school day teacher

\section{PRESENTATI ONS}

- 2006 Ohio County School Co-Teaching Training of Trainers Facilitator

- 2006 Hancock County Schools Summer Teacher Academy; "Co-Teaching and Instructional Strategies that Increase Active Engagement”

- 2006 RESA VI reading workshop; "Wilson Language and Balanced Literacy Instruction in Regular and Special Education Environments"

- 2006 West Virginia Teachers of Mathematics Council, "Interactive Middle School Math Lessons"

- 2005 Annual international conference of the Council for Children with Behavior Disabilities; "Proactive Alternative Education Programming”

- 2003 West Virginia Council for Exceptional Children regional conference: "School Wide PBS, Where the Rubber Meets the Road" 
- 2003 Annual international conference of the Council for Children with Behavior Disabilities; "School Wide Positive Behavior Supports"

- 2002 West Virginia Department of Education Leadership for Results Conference; “Everyone Can Be a Star, Proactive Behavior Interventions”

\section{PROFESSI ONAL} MEMBERSHI PS - National Association for School Psychology

- American Psychological Association

- West Virginia School Psychology Association

- Council for Exceptional Children

- West Virginia Council for Exceptional Children Executive Committee Officer

- West Virginia Council of Teachers of Mathematics 